Anxiety in people with dementia: A common, but unidentified and underestimated, condition

\author{
Alka Rani Goyal \\ Institute of Health and Society \\ Faculty of Medicine \\ University of Oslo
}

Research Centre for Age Related Functional Decline and Diseases (AFS), Innlandet Hospital Trust and Norwegian National Advisory Unit on Ageing and Health 2018 
(C) Alka Rani Goyal, 2019

Series of dissertations submitted to the Faculty of Medicine, University of Oslo

\section{ISBN 978-82-8377-427-6}

All rights reserved. No part of this publication may be

reproduced or transmitted, in any form or by any means, without permission.

Cover: Hanne Baadsgaard Utigard.

Print production: Reprosentralen, University of Oslo. 


\section{Tamaso mā jyotir gamaya}

From darkness (ignorance), lead me to light (knowledge)

(From the Bṛhadāranyaka Upanishad 1.3.28.) 



\section{Table of contents}

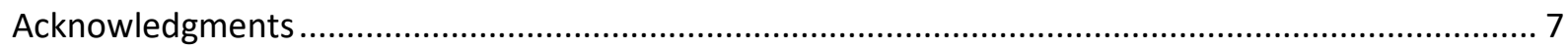

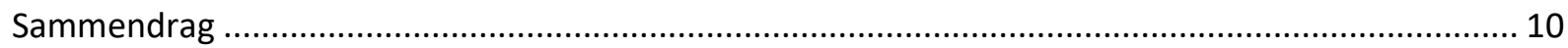

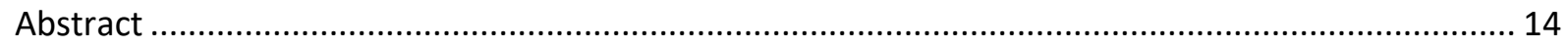

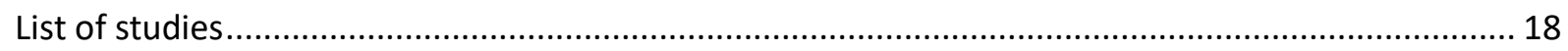

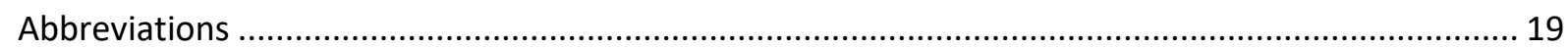

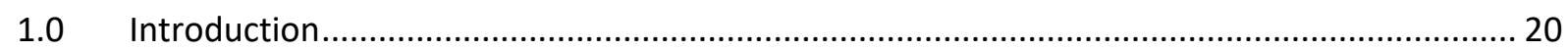

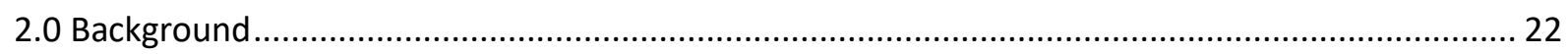

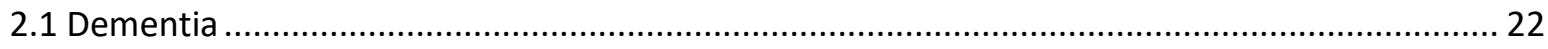

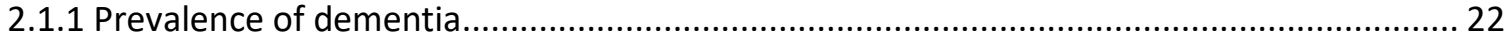

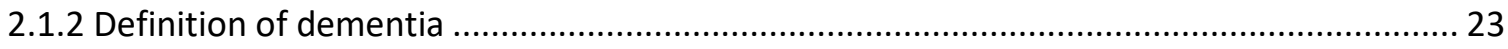

Textbox 1: Mild and major NCD according to DSM-5 criteria .................................................... 23

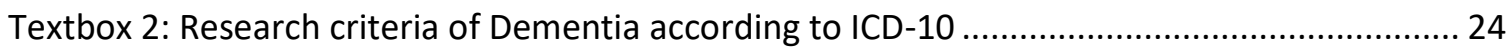

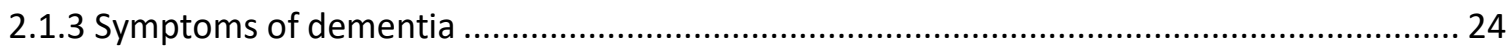

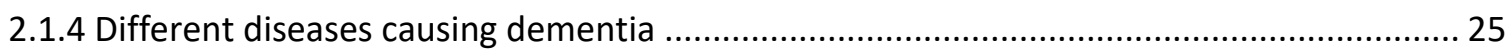

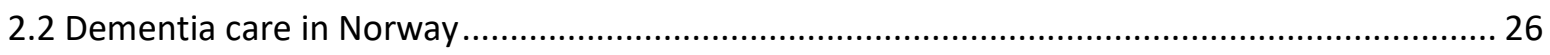

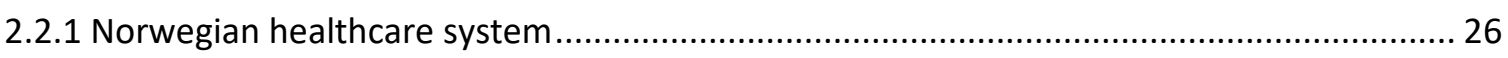

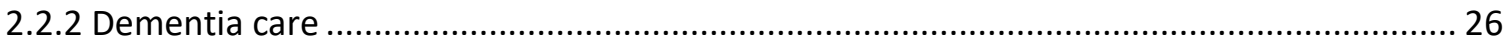

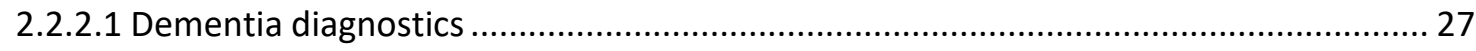

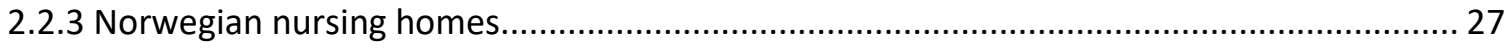

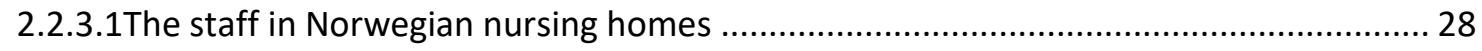

2.2.4 The prevalence of neuropsychiatric symptoms in people with dementia in nursing homes

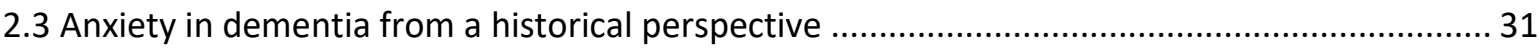

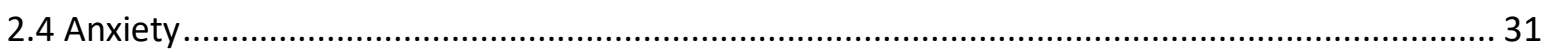

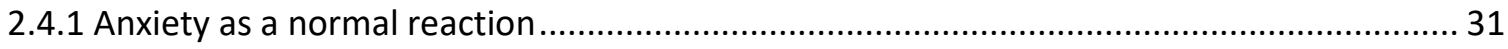

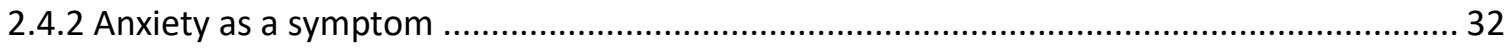

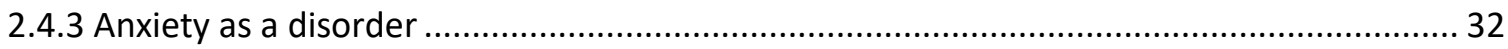

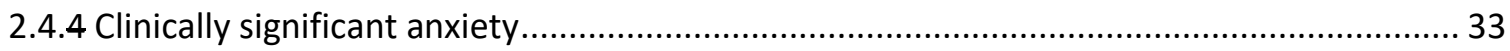

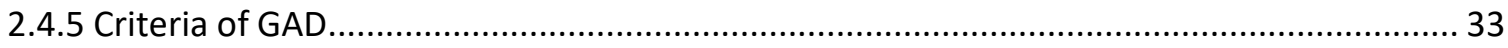

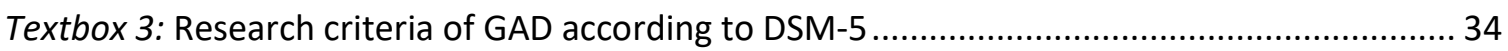

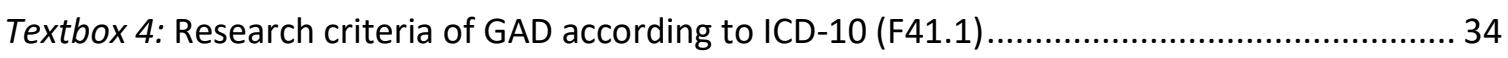

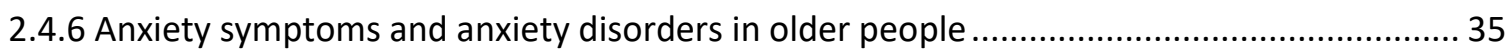

2.4.7 Comorbid anxiety and depression in older people .............................................................. 36 
2.4.8 Association between anxiety and cognitive impairment in older people.

2.5 Factors contributing to anxiety symptoms and disorder in people with dementia.................. 38

2.6 Challenges in identifying anxiety in people with dementia .............................................. 45

2.6.1 The assessment scales for anxiety in older people with cognitive impairment.................45

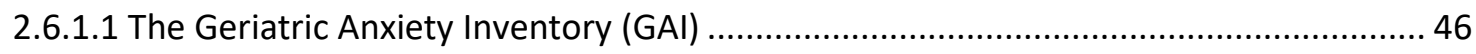

2.6.1.2 The Behavioral Pathology in Alzheimer's Disease (BEHAVE-AD) ..............................47

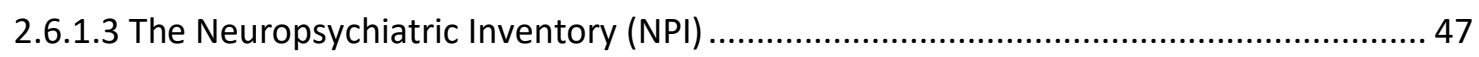

2.6.1.4 The Anxiety in Cognitive Impairment and Dementia (ACID) scale .......................... 48

2.6.1.5 The Rating Anxiety in Dementia (RAID) scale .............................................. 49

Table 1. Comparison of anxiety symptoms assessed with different anxiety scales used among people with cognitive impairment, with reference to the GAD criteria of the DSM-5 and ICD-10.

Table 2. Validity and reliability studies of the Rating Anxiety in Dementia (RAID) scale ............51

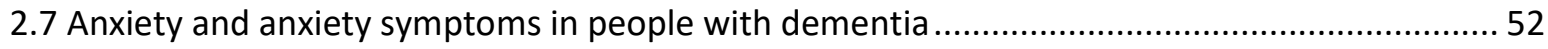

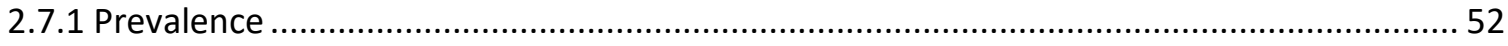

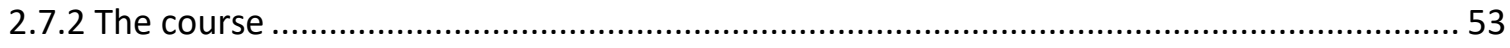

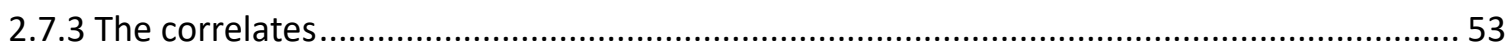

2.8 The prevalence and course of depression in people with dementia in nursing homes ............ 55

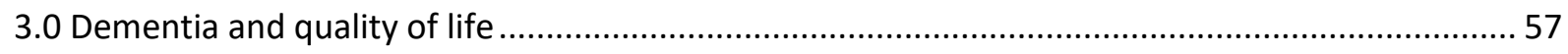

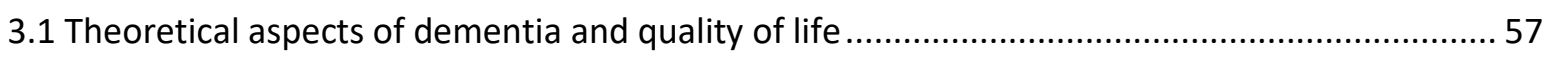

3.2 Assessing quality of life of people with dementia in nursing homes ..................................... 58

3.3 Factors affecting quality of life in people with dementia .............................................59

4.0 Caring for people with dementia, anxiety, and anxiety symptoms: a multidisciplinary approach. 61

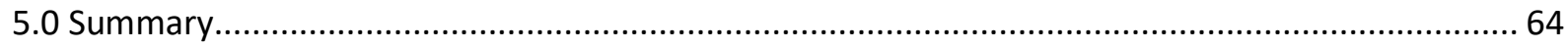

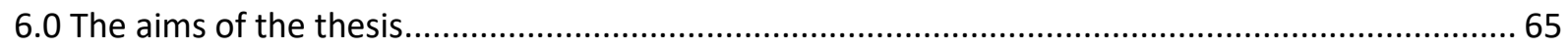

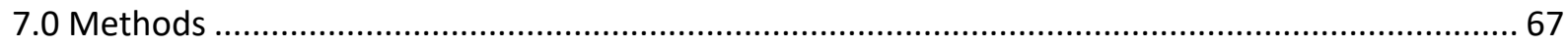

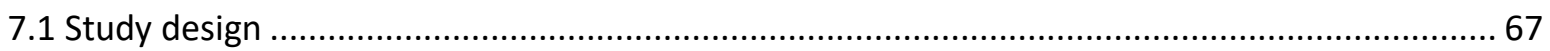

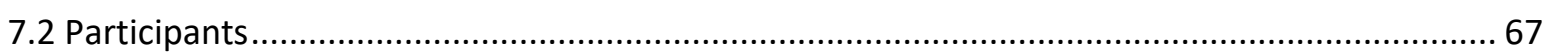

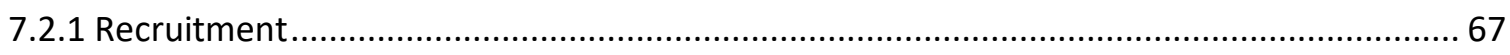

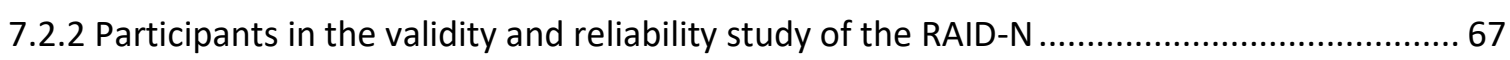

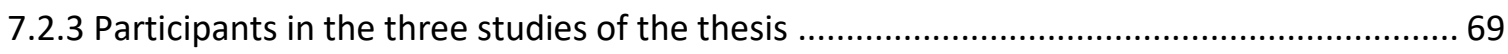

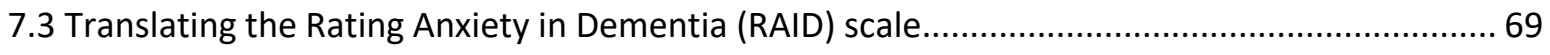

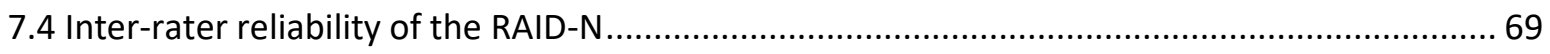

7.5 Administration of the RAID-N in the validity study ................................................ 70 
7.6 Procedure for the diagnosis of dementia, GAD, and depression in the validation of the RAID-N 70

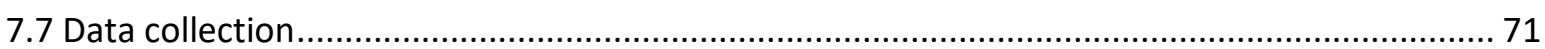

7.7.1 Other assessment scales used in data collection ............................................................. 71

The Mini-Mental State Examination-Norwegian Revised Version 2 (MMSE-NR2) ................... 71

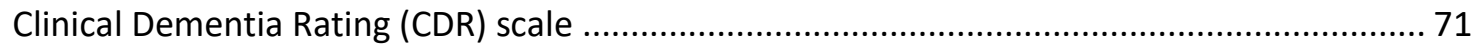

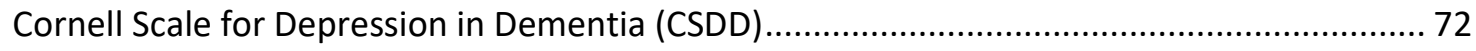

Neuropsychiatric Inventory's Brief Questionnaire (NPI-Q) ................................................. 72

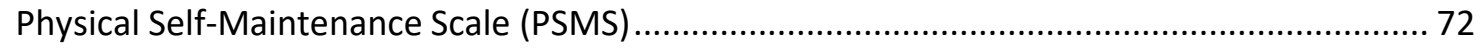

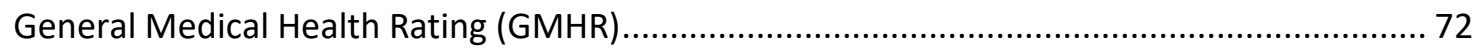

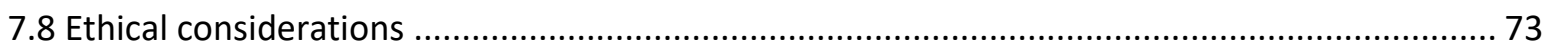

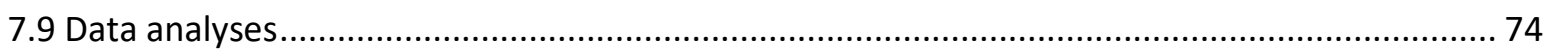

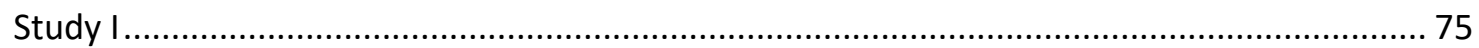

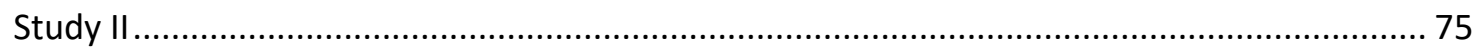

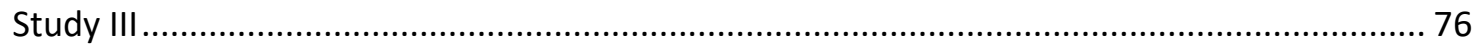

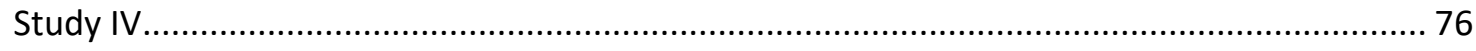

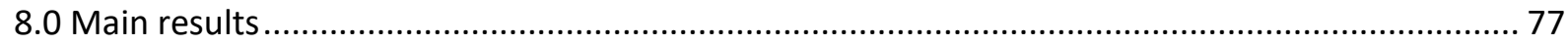

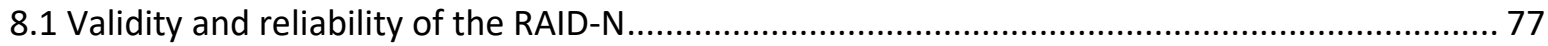

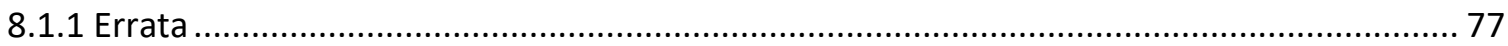

Table 3. ROC analysis showing the best RAID-N scale cut-off scores with the DSM-5 criteria of generalized anxiety disorder $(G A D)$ by comparing the two groups $(N=101)$........................... 78

8.2 Prevalence, incidence, persistence, and remission of anxiety at 12-month follow-up in people

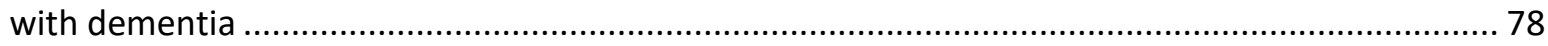

8.3 Prevalence of anxiety symptoms and changes at 12-month follow-up .................................... 78

8.4 The correlates of anxiety at baseline and at 12-month follow-up .............................................. 78

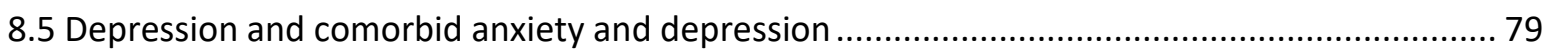

8.5.1 The prevalence, incidence, persistence, and remission of depression at 12-month follow-

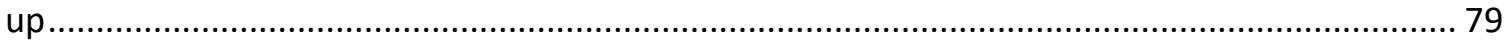

8.5.2 The prevalence of comorbid anxiety and depression ........................................................ 79

8.5.3 Severity of symptoms in people with comorbid anxiety and depression ........................... 79

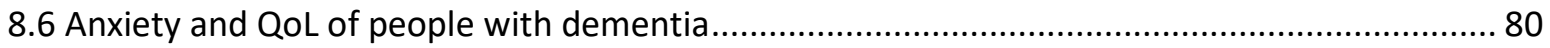

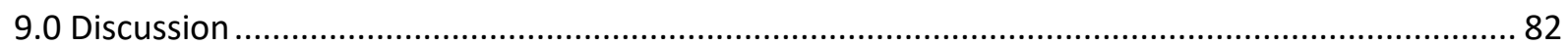

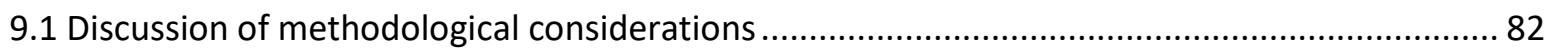

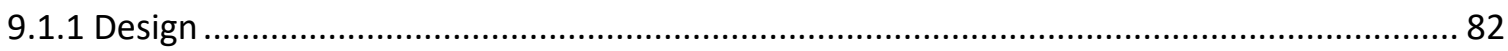

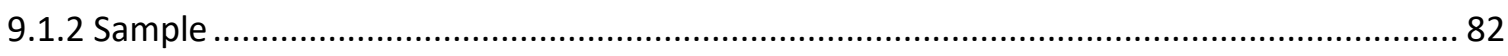


9.1.3 Selection of the RAID scale

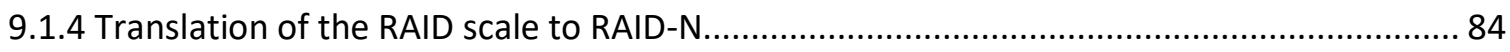

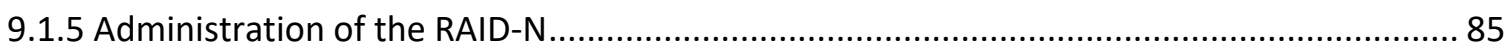

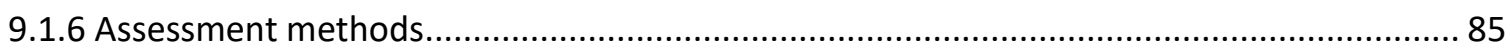

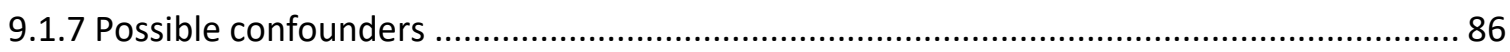

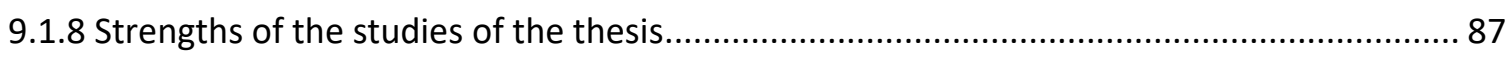

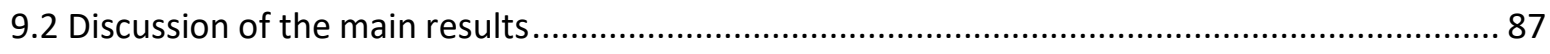

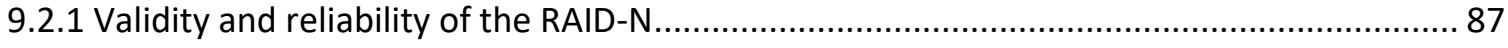

9.2.2 The prevalence and course of anxiety in people with dementia ......................................... 89

9.2.3 The prevalence and course of anxiety symptoms in people with dementia ....................... 90

9.2.4 Correlates of anxiety symptoms in people with dementia .............................................. 92

9.2.5 Depression and comorbid anxiety and depression in people with dementia...................... 94

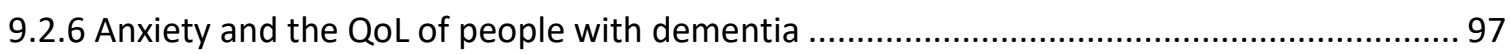

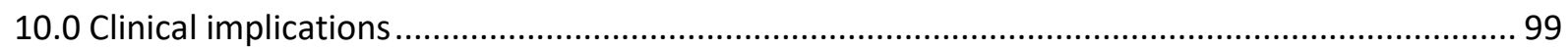

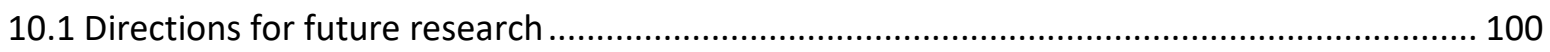

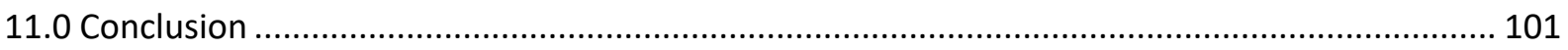

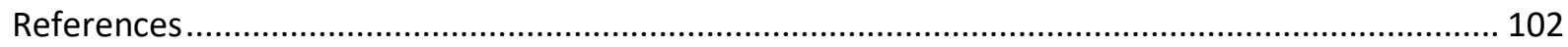

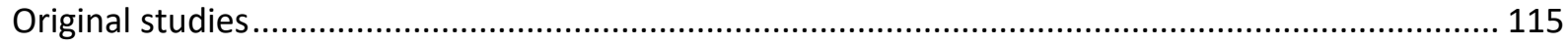

Appendices 


\section{Acknowledgments}

Conducting this thesis project has been like a journey through an unknown forest of academic and personal achievement. This thesis would have been impossible without the help and support of many people who so generously contributed to the work.

First and foremost, I would like to express my gratitude to the nursing homes' residents, their families, and the staff at the participating nursing homes for their valuable contributions.

This thesis project was funded by Innlandet Hospital Trust, and conducted at the Research Centre for Age Related Functional Decline and Diseases (AFS), Innlandet Hospital Trust. Additional support was provided by the Norwegian National Advisory Unit on Ageing and Health, Vestfold Hospital Trust. Many thanks to Innlandet Hospital Trust and Norwegian National Advisory unit on Ageing and Health for supporting this thesis project. I am thankful to the manager at AFS, Birger Lillesveen, who provided me the opportunity to join their team as a $\mathrm{PhD}$ candidate. I would like to extend my thanks to all my wonderful colleagues at AFS Innlandet Hospital and at the Norwegian National Advisory unit on Ageing and Health for their encouragement and support.

I am profoundly grateful to my co-supervisor, Professor Emeritus Knut Engedal, who developed the idea for this thesis, giving me the opportunity for this interesting and challenging project, and who believed in me. Knut Engedal has always shared his immense knowledge so generously and continues to inspire me professionally and academically. I owe my deep gratitude to my co-supervisors, Sverre Bergh and Marit Kirkevold, whose skilled guidance illuminated my path. Their constructive and thorough feedback has been invaluable, especially in academic writing.

Special gratitude goes to Øyvind Kirkevold, my main supervisor, for being so dedicated to his role. His guidance, patience, and encouragement kept me on track beneath the fog of statistical analyses and academic writing. Dear Øyvind, I deeply appreciate your ability to read between the lines of statistics and present the results in an interesting way.

Dear Knut, Øyvind, Sverre, and Marit, I have been immensely privileged to have you all as my supervisors, and I cannot thank you enough for your precious guidance and support.

My sincere thanks go to Olav Aga (retired physician-in-chief), Dr. Oskar H. Sommer, and Susan Juell (Head of the Old Age Psychiatry Department, Innlandet Hopital) for their crucial 
contributions in the translation of the RAID scale. Big thanks to the RAID-N validation study group, Kjersti Thomassen, Dr. Hege Dalsveen, and Dr. Bjørn Lichtwarck. My thanks also to Merete Andreassen for helping me with the CRF development and data scanning.

Heartfelt thanks go to Dr. Ingunn Hovland and Dr. Hilde Lobben for their keen interest in this study and their tremendous support and contributions in data collection from their nursing homes in Vestre Viken County.

I believe that librarians are special creatures with a unique characteristic to help in a kind and patient manner when their assistance is needed. Dear Linda Merete Warhuus and Gro Heidi at the Drammen Hospital Medical Library, Vigdis Knutsen and Katarina Einarsen Enne at the Norwegian National Advisory Unit on Ageing and Health Library, and Hilde Flaaten at the Rikshospital Medical Libarary: thank you so much for your incredible assistance.

I thank my fellow PhD candidates and Professor Anners Lerdal at Helsam, UIO for the constructive feedback, difficult questions, and interesting discussions throughout our seminars. I extend my thanks to Anne Marie Mork Rokstad and Tom Borza for their valuable feedback at mid-term evaluation of this thesis project.

Dear Neha, you have always been so encouraging, saying; "Stå på, mamma, dette klarer du!" Thank you, my beta!

Mummy and Papa, you are my life-coaches, and I owe it all to you. Thank you so much! I am also grateful to my brother, sisters, brothers- and sisters-in-law, other family members, and friends who have supported me along the way.

Last but not least, my dear Sunil, thank you so much for all the support, encouragement, patience, and care you have given throughout this study, and thank you for always believing in me. 
"I do not remember anything, my mind is completely out of order. [He holds his head with both the hands.] I feel so restless. What should I do?"

(Expression of a patient who is in his early 70's and in an early stage of dementia)

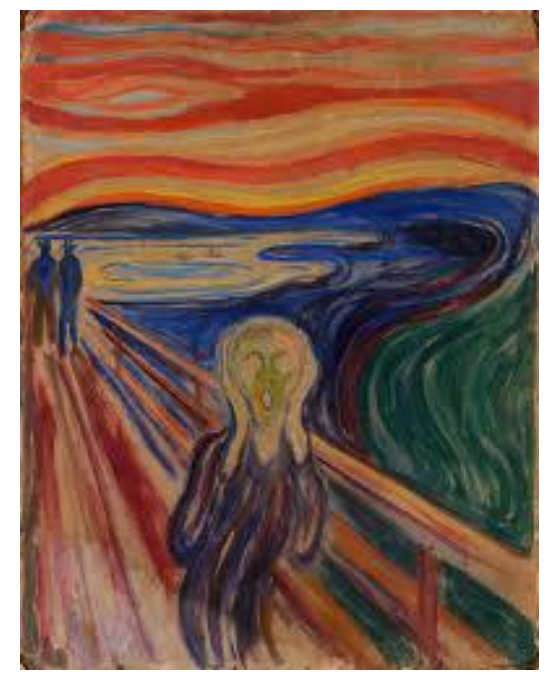

Edvard Munch: Permission from the National Museum, Oslo 



\section{Sammendrag}

\section{Bakgrunn}

Angst og angstsymptomer er hyppig forekommende hos eldre sykehjemsbeboere med demens. Til tross for at angst har mange negative konsekvenser for personer med demens, har angst og angstsymptomer ved demens fått liten oppmerksomhet i forskningen både nasjonalt og internasjonalt. Angst hos personer med demens er underrapportert og underdiagnostisert. En av årsakene kan være at det er vanskelig å skille angst og angstsymptomer fra symptomer ved demens og depresjon: Symptomene kan ligne på hverandre. Dette kan føre til at intervensjoner som forebygger og behandler angst og angstsymptomer hos personer med demens ikke utføres eller er utilstrekkelige. Mangel på validerte demensspesifikke angstskalaer på norsk kan være en medvirkende årsak til at angst forblir uoppdaget hos personer med demens.

\section{Mål}

Det overordnede målet for denne avhandlingen var å få økt kunnskap om angst og angstsymptomer hos norske sykehjemsbeboere med demens, samt å kartlegge angstsymptomer med en validert norsk versjon av en demensspesifikk angstskala. De spesifikke målene var: 1) å oversette skalaen Rating Anxiety in Dementia (RAID) til norsk og undersøke validitet og inter-rater reliabilitet av den norske versjonen av RAID (RAID-N) i en sykehjemspopulasjon av eldre personer med demens; 2) å studere prevalens av angst og angstsymptomer kartlagt med RAID-N og undersøke assosiasjoner mellom angst og depresjon, demografiske og andre kliniske variabler inkludert bruk av psykofarmaka blant sykehjemsbeboere med demens; 3) å undersøke forløpet av angst og angstsymptomer og assosiasjoner med depresjon, demografiske og andre kliniske variabler fra baseline til 12 måneders oppfølging; og 4) å utforske hvordan angst, demografiske og andre kliniske variabler er assosiert med livskvalitet fra baseline til 12 måneders oppfølging blant sykehjemsbeboere med demens. 
Metoder

Avhandlingen inneholder fire studier. I studie I, ble RAID først oversatt til norsk (RAID-N) og deretter validert mot generalisert angstlidelse (GAD) i en validitetsstudie som inkluderte 101 sykehjemsbeboere med demens fra sju sykehjem. Deltakerne i studien var 65 år eller eldre, og ble unders $\varnothing \mathrm{kt}$ av legen for diagnosen GAD uten at legen hadde kjennskap til RAID$\mathrm{N}$ vurderinger. Legens diagnose ble benyttet som "gullstandard" for validitetstesting av RAID-N. Inter-rater reliabilitet av RAID-N ble unders $\varnothing \mathrm{kt}$ i en undergruppe med 53 deltakere. Forekomsten av angst og angstsymptomer og assosiasjoner med demografiske og kliniske variabler ble unders $\varnothing \mathrm{kt}$ i et tverrsnittsstudie (baseline) ved å inkludere 298 sykehjemsbeboere med demens (inklusiv 101 deltakere fra studie I) fra 17 norske sykehjem (studie II). Forløpet av angst og angstsymptomer, og assosiasjoner fra baseline til 12 måneders oppfølging ble unders $\varnothing \mathrm{kt}$ i studie III ( $\mathrm{N}=205)$. Et frafall av 93 deltakere fra baseline til oppfølging skyldes død. I studie IV ble dataene fra studiene II og III benyttet. Her ble assosiasjoner mellom angst, demografiske og kliniske variabler og livskvalitet hos personer med demens fra baseline til 12 måneders oppfølging unders $\varnothing \mathrm{kt}$.

Resultater

I studie I, i en Receiver Operating Characteristic (ROC) analyse med DSM-5 kriteria for GAD som "gullstandard", var arealet under kurven (AUC) 0,80 (95\% konfidensintervall 0,710,89). En grenseverdi på skåre 12 og mer på RAID-N identifiserte best deltakere med klinisk signifikant GAD med sensitivitet på 82,1\%, spesifisitet på 70,0\%, og korrekt klassifikasjon på 73,3\%. Resultatene fra validitet- og reliabilitetstudien av RAID-N viste at RAID-N hadde god intern konsistens (Cronbach's alpha 0,81), var reliabel (Intraklassekorrelasjon 0,82) og var brukervennlig.

I studie II, var forekomsten av angst, definert som en skåre på 12 og mer på RAID-N, 34,2 \%. Irritabilitet $(59,7 \%)$ og rastløshet $(53,0 \%)$ var blant de hyppigste forekommende angstsymptomene. Dårlig generell fysisk helse, grad av nevropsykiatriske symptomer og bruk av angstdempende medisiner var signifikant assosiert med en høy RAID-N skåre.

Ved 12 måneders oppfølging i studie III, var antallet personer med angst ikke signifikant forskjellig fra antallet med angst ved baseline (33,7\% ved baseline og 31,2\% ved 12 måneders oppfølging). Ved å bruke samme grenseverdi på RAID-N skåre, var insidens av 
angst ved oppfølging 19,1\%, persistens angst var 55,1\%, og remisjon fra angst var 44,9\%. Muskulære spenningstilstander, lettskremt og engstelig, og irritabilitet var de hyppigste forekommende angstsymptomene blant deltakerne med angst. Høyere skåre på Neuropsychiatry Inventory - Questionnaire (NPI-Q) sub-syndrom oppstemthet og høyere bruk av antipsykotika ved baseline var assosiert med $\emptyset$ kning eller mindre reduksjon i RAID-N skåre ved 12 måneders oppfølging. Høyere skåre på NPI-Q sub-syndrom affektiv og høyere bruk av angstdempende medisiner ved baseline var assosiert med reduksjon eller mindre $\emptyset$ kning i RAID-N skåre ved oppfølgingen.

Det var en ikke-signifikant $\varnothing \mathrm{kning}$ av forekomsten av komorbid angst og depresjon (skåre 10 eller mer på Cornell Scale for Depression in Dementia) fra 17,6 \% ved baseline til 19,5 \% ved oppfølging. Deltakerne med komorbid angst og depresjon hadde dårligere generell fysisk helse, høyere gjennomsnittskåre på symptomene angst og depresjon, og flere nevropsykiatriske symptomer enn deltakerne som kun hadde angst ved baseline. Deltakerne med komorbid angst og depresjon hadde høyest persistens ved oppfølging, sammenlignet med de med kun angst $(72,2 \%$ vs. $36,4 \% \mathrm{p}=0,004)$

Deltakernes livskvalitet ble vurdert av deres primærsykepleiere med Quality of Life in LateStage Dementia (QUALID). To distinkte forløpsbaner av QUALID skåre fra baseline til 12 måneders oppfølging ble påvist og er grunnlag for studie IV i avhandlingen. Forløpsbane 1 med 206 deltakere viste en relativt stabil og lavere gjennomsnittlig QUALID skåre (bedre livskvalitet) og hadde en lavere andel av deltakere med angst sammenlignet med forløpsbane 2, med 92 deltakere (mer angstsymptomer), som hadde dårlig livskvalitet ved både baseline og oppfølging. Resultatene i studie IV viste at angst justert for depresjon, demografiske og andre kliniske variabler hos sykehjemsbeboere med demens var assosiert med å tilhøre forløpsbane 2 med dårlig livskvalitet ved både baseline og 12 måneders oppfølging. Deltakerne med komorbid angst og depresjon hadde dårligere livskvalitet enn deltakerne uten angst eller depresjon, eller de med kun angst eller kun depresjon.

\section{Konklusjon}

Angst og angstsymptomer er utbredt hos sykehjemsbeboere med demens. Symptomene muskulære spenningstilstander, lettskremt og engstelig, irritabilitet, og rastløshet kan indikere angst hos personer med demens. Høyere skåre på variablene NPI-Q sub-syndrom affektiv og bruk av angstdempende medisiner ved baseline var assosiert med redusert angstsymptomer 
ved oppfølging, mens høyere skåre på variablene NPI-Q sub-syndrom oppstemthet og bruk av antipsykotika ved baseline var assosiert med økt angstsymptomer ved oppfølging. Alvorlig grad av angst og komorbid depresjon bør gi grunn til bekymring, fordi komorbid angst og depresjon reduserer sannsynligheten for remisjon av angst eller depresjon hos personer med demens, som er et viktig funn i avhandlingen. Høy grad av angst var assosiert med dårlig livskvalitet over 12 måneder hos personer med demens. Personer med demens og komorbid angst og depresjon hadde enda dårligere livskvalitet enn personer med demens og kun angst eller kun depresjon, et annet viktig funn i avhandlingen som ikke er blitt unders $\varnothing \mathrm{kt}$ i tidligere studier av personer med demens.

Denne avhandlingen tilfører kunnskap om forekomsten av angst hos personer med demens, og gir ny kunnskap om forløpet av angst og angstsymptomer, dens assosiasjon med depresjon og livskvalitet over 12 måneder hos sykehjemsbeboere med demens. RAID-N kan være en nyttig skala for å oppdage klinisk signifikant angst som trenger behandling og oppfølging hos personer med demens i norske sykehjem. 


\begin{abstract}
Background

Anxiety and anxiety symptoms are common in older people with dementia living in nursing homes. Although anxiety is associated with many negative outcomes, anxiety and anxiety symptoms are sparsely studied in people with dementia, both nationally and internationally. Anxiety among people with dementia often goes unidentified by health care personnel due to overlapping symptoms with dementia and depression. Thereby, interventions that may prevent and treat anxiety and anxiety symptoms among people with dementia remain absent or inadequate. A lack of validated, dementia-specific anxiety assessment scales in Norwegian could be contributing to the limited knowledge about and attention on anxiety and anxiety symptoms in people with dementia in Norway.
\end{abstract}

\title{
Aims
}

The overall aim of this thesis was to gain more knowledge about anxiety and anxiety symptoms among people with dementia living in Norwegian nursing homes being assessed with a validated Norwegian version of a dementia-specific anxiety scale. The specific aims were: 1) to translate the Rating Anxiety in Dementia scale (RAID) into Norwegian and to investigate the validity and inter-rater reliability of the Norwegian version of the RAID scale (RAID-N) among older people with dementia living in nursing homes; 2) to study the prevalence of anxiety and anxiety symptoms assessed with the validated RAID-N, and their associations with depression, demographic, and other clinical variables, including use of psychotropic medications among people with dementia; 3) to investigate the course of anxiety and anxiety symptoms, and their associations with depression, demographic, and other clinical variables from baseline to 12-month follow-up; and 4) to explore how anxiety, demographic, and other clinical variables are associated with quality of life (QoL) from baseline to 12-month follow-up among people with dementia living in Norwegian nursing homes. 
Methods

This thesis included four studies. In study I, the RAID scale was first translated into Norwegian (RAID-N) and validated against the generalized anxiety disorder (GAD) in a study including 101 people with dementia aged 65 years and older from seven Norwegian nursing homes. The diagnosis of anxiety was made by the doctor who was blind to the RAID$\mathrm{N}$ scores. The inter-rater reliability of the RAID-N was examined in a sub-group of 53 participants. The prevalence of anxiety, anxiety symptoms, and their correlates among people with dementia were investigated in a cross-sectional study (baseline) that included 298 participants with dementia (including the 101 participants of study I) from 17 Norwegian nursing homes (study II). Study III was a longitudinal study that included 205 participants (attrition of 93 participants from baseline to follow-up was due to death) and investigated the course of anxiety, anxiety symptoms, and their correlates among people with dementia from baseline to 12-month follow-up. Using the data from studies II and III, the association between anxiety, demographic, other clinical variables, and QoL of people with dementia was explored in a 12-month longitudinal study, study IV of this thesis.

Results

In study I, the discriminating power of the RAID-N was examined using the DSM-5 criteria for GAD as a "gold standard." In a Receiver Operating Characteristic (ROC) analysis, the area under the curve (AUC) was 0.80 (95\% confidence interval 0.71-0.89). The best cut-off value to identify clinically significant GAD among people with dementia was 12 and above on the RAID-N score, with a sensitivity of $82.1 \%$, a specificity of $70.0 \%$, and an accuracy of 73.3\%. The RAID-N indicated satisfactory internal consistency (Cronbach's alpha 0.81) and good inter-rater reliability (Intraclass correlation 0.82 ) on overall RAID-N items, and it was reported to be user-friendly.

In study II, anxiety, as defined by a cut-off score of 12 and above on the RAID-N, was present in $34.2 \%$ of the participants. Irritability $(59.7 \%)$ and restlessness $(53.0 \%)$ were the most prevalent anxiety symptoms. The participants' poor general physical health, presence of neuropsychiatric symptoms, and use of anxiolytics were significant correlates of higher RAID-N scores. 
At 12-month follow-up (study III), no significant change in the proportion of participants with anxiety was found from baseline (33.7\%) to follow-up (31.2\%) using RAID-N cut-off $\geq 12$. Using the same cut-off on the RAID-N, the incidence of anxiety at follow-up was $19.1 \%$, persistence was $55.1 \%$, and the remission rate at 12-month follow-up was $44.9 \%$. Motor tension, feeling frightened and anxious, and irritability were the most frequent anxiety symptoms among the participants with anxiety. A higher Neuropsychiatry InventoryQuestionnaire (NPI-Q), sub-syndrome: aroused, and more use of antipsychotics at baseline were associated with increased or less reduced RAID-N scores at 12- month follow-up, whereas reduced or less increased RAID-N scores at 12-month follow-up was associated with higher score of NPI-Q, sub-syndrome: affective, and more use of anxiolytics at baseline.

The occurrence of comorbid anxiety and depression (score of 10 and above on the Cornell Scale for Depression in Dementia) showed a non-significant increase from $17.6 \%$ at baseline to $19.5 \%$ at follow-up. At baseline, the participants with comorbid anxiety and depression had poorer general physical health, higher mean scores of anxiety and depressive symptoms, and a wider range of neuropsychiatric symptoms than the participants with only anxiety. At $12-$ month follow-up, the participants with comorbid anxiety and depression had the highest persistence rate compared with the participants with only anxiety $(72.2 \%$ vs. $36.4 \%, p=$ $0.004)$

In study IV, assessing the proxy-rated QoL by the Quality of Life in Late-Stage Dementia (QUALID) scale, two distinct trajectories of QUALID scores were observed from baseline to 12-month follow-up. Trajectory group 1 (206 participants) had a rather stable and low QUALID mean score (better QoL) and included a lower proportion of participants with anxiety, compared to trajectory group 2 (92 participants), which had poor QoL both at baseline and follow-up. Anxiety, controlled for depression and other demographic and clinical variables, was associated with belonging to trajectory group 2 with poorer QoL at baseline and at 12-month follow-up. Participants with comorbid anxiety and depression had poorer QoL than the participants without anxiety or depression or with only anxiety or only depression. 


\section{Conclusion}

Anxiety and anxiety symptoms are highly prevalent among people with dementia living in nursing homes. Motor tension, frightened and anxiousness, irritability, and restlessness are the symptoms that may indicate anxiety and a need for further assessments in people with dementia. High NPI-Q, sub-syndrome: affective scores and prescription of anxiolytics at baseline were associated with reduced anxiety symptoms at follow-up, whereas a high NPI-Q, sub-syndrome: aroused score and prescription of antipsychotics at baseline were associated with increased anxiety symptoms at follow-up. Severe anxiety is highly comorbid with depression, which is a cause of concern. Comorbidity of anxiety and depression reduces the probability of remission of anxiety or depression in people with dementia, which is an important finding of this thesis. Anxiety is associated with poor QoL over a 12-month period among people with dementia. Furthermore, people with dementia and comorbid anxiety and depression have poorer QoL than people with dementia and only anxiety or only depression, another important novel finding that has not been investigated in previous studies of people with dementia.

This thesis adds to the knowledge about the prevalence of anxiety in people with dementia, and it provides important knowledge about the course of anxiety and anxiety symptoms, their association with depression, and their impact on QoL for people with dementia living in nursing homes. RAID-N could be a useful scale in the assessment of clinically significant anxiety that needs adequate attention and management among people with dementia in Norwegian nursing homes. 


\section{List of studies}

Study I: Goyal, A. R., Bergh, S., Engedal, K., Kirkevold, M., \& Kirkevold, Ø. (2016).

Norwegian version of the rating anxiety in dementia scale (RAID-N): a validity and reliability study. Aging \& Mental Health, 21(12), 1256-1261.

doi:10.1080/13607863.2016.1220921

Study II: Goyal, A. R., Bergh, S., Engedal, K., Kirkevold, M., \& Kirkevold, Ø. (2017).

Anxiety, anxiety symptoms, and their correlates in persons with dementia in Norwegian nursing homes: a cause for concern. Dementia and Geriatric Cognitive Disorders, 43(5-6), 294-305. doi: 10.1159/000471796

Study III: Goyal, A. R., Bergh, S., Engedal, K., Kirkevold, M., \& Kirkevold, O. (2018). The course of anxiety in persons with dementia in Norwegian nursing homes: a 12-month follow-up study. Journal of Affective Disorders, 235, 117-123.

doi:10.1016/j.jad.2018.04.015

Study IV: Goyal AR, Bergh S, Engedal K, Kirkevold M, Kirkevold Ø (2018) Trajectories of quality of life and their association with anxiety in people with dementia in nursing homes: a 12-month follow-up study. PLoS ONE, 13(9), 1-14: e0203773.

doi: 10.1371 /journal.pone. 0203773 


\section{Abbreviations}

ACID- Anxiety in Cognitive Impairment and Dementia

ACID-PR- Anxiety in Cognitive Impairment and Dementia-Proxy Report

ACID-SR- Anxiety in Cognitive Impairment and Dementia-Self Report

AD- Alzheimer's Disease

ADL- Activities of Daily Living

AUC- Area Under the Curve

BEHAVE-AD- The Behavior Pathology in Alzheimer's Disease

CDR-Sob- Clinical Dementia Rating-Sum of Boxes

CSDD- Cornell Scale for Depression in Dementia

DSM- Diagnostic and Statistical Manual of Mental Disorders

FTD- Frontotemporal Dementia

GAD- Generalized Anxiety Disorder

GAI- Geriatric Anxiety Inventory

GAI-SF- Geriatric Anxiety Inventory-Short Form

GMHR- General Medical Health Rating

GP- General Practitioner

ICC- Intraclass Correlation Coefficient

ICD-10-International Classification of Diseases $10^{\text {th }}$ edition

ICPC- International Classification of Primary Care

LBD- Lewy Body Dementia

LR- Likelihood Ratio

MDD- Major Depressive Disorder

MMSE-NR2- Mini Mental State Examination- Norwegian Revised Version 2

NCD- Neurocognitive Disorders

NPI- Neuropsychiatry Inventory

NPI-Q- Neuropsychiatry Inventory-Questionnaire

NPS- Neuropsychiatric Symptoms

PLST- Progressively Lowered Stress Threshold

PSMS- Physical Self-Maintenance Scale

QoL- Quality of Life

QUALID- Quality of Life in Late-Stage Dementia

RAID- Rating Anxiety in Dementia

RAID-N- Norwegian version of Rating Anxiety in Dementia

ROC- Receiver Operating Characteristics

SD- Standard Deviation

VaD- Vascular Dementia

WHO- World Health Organization 


\subsection{Introduction}

One of my acquaintances told me that her mother has been an excellent mother, a good wife, a good cook, and had a part-time job in addition to being a full-time housewife. She had good health, without any signs of illness, and enjoyed being home alone whenever circumstances required it. She developed diabetes after the age of 50. In her mid-seventies, she suffered a stroke, from which she recovered quite well. A couple of years before she had the stroke, she started complaining that the oven in the kitchen was not good anymore, and she had experienced troubles cooking good food. A few months after the stroke, she was admitted to hospital in an almost unconscious state with high blood sugar levels and dehydration; she had forgotten to take her insulin. After this incident, she received in-home nursing care to take care of her insulin and to check her blood sugar. She was reluctant to receive help from outside, but accepted when her children persuaded her. She lived at home with her husband. Her memory deteriorated gradually, but she managed as she lived with her husband and received both in-home nursing care and house help from the municipality.

A few months later, her husband was admitted to the hospital due to physical ailments. She was now afraid of being alone at home and asked her children to stay with her. She expressed her worries about being alone and asked repeatedly why her husband was not at home. She now seemed very unlike herself, appearing to be very insecure, dependent, fearful, and clingy. The changes in her behavior and lifestyle were apparent. The family realized that her quality of life was not as good as it had been. With increased difficulty being at home alone, my acquaintance's mother was admitted to a nursing home for respite care, thereafter on longterm stay. In the nursing home, she often wandered in the corridor, asking the staff repeatedly “where should I go?”, “where should I sit?”, and "what should we do now?” My acquaintance often described her mother as restless after her visits to the nursing home.

Many relatives and caregivers might identify themselves in the above description. During my many years of clinical work as a nurse in a psychogeriatric unit, I experienced that the described symptoms, such as wandering/restlessness, repetitive behavior, and sleep disturbances among the patients with dementia did not receive adequate attention from the nursing staff. These symptoms were often considered an inevitable part of dementia due to a decline in the patient's memory and orientation, which could be the case, but these symptoms could also be an expression of anxiety. Due to the unavailability of a dementia-specific anxiety assessment scale, these symptoms were not always seen as the phenotype of anxiety 
among people with dementia, and were therefore not treated as anxiety. Healthcare personnel's understanding of the patients' symptoms or behaviors is the foundation of their choice of intervention. Compared to the existing knowledge about depression in people with dementia, knowledge about anxiety in people with dementia is sparse among healthcare personnel (Seignourel, Kunik, Snow, Wilson, \& Stanley, 2008). The unavailability of a dementia-specific anxiety assessment scale in Norwegian could be one reason for anxiety symptoms in people with dementia not being as routinely and systematically assessed or as managed as the depression symptoms among this population in Norwegian psychogeriatric units and in primary care settings.

Having this case report in mind, the aim of the present thesis was 1) to translate a dementiaspecific anxiety scale into Norwegian and to validate the Norwegian version of the scale; 2 and 3) to investigate the prevalence and the course of anxiety assessed with the validated dementia-specific anxiety scale; and 4) to gain knowledge about factors associated with anxiety. The further purpose was to explore the association between anxiety and other variables, including quality of life (QoL), for people with dementia living in Norwegian nursing homes. 


\subsection{Background}

This section is divided into four main parts: dementia, anxiety, dementia and quality of life, and caring for people with dementia and anxiety. In the first part, the prevalence, definition, and causes of dementia will be described, followed by a brief description of the care for dementia in primary healthcare and a description of Norwegian nursing homes. The second part of the background is about anxiety, which is the main topic. Anxiety as a normal response, as a symptom and disorder, definitions, various aspects of anxiety in older people, contributing factors for anxiety in people with dementia, challenges in identification, and anxiety assessment scales will be described. Finally, a brief description of dementia and quality of life and caring for people with dementia and anxiety will follow.

\subsection{Dementia}

\subsubsection{Prevalence of dementia}

Dementia is an emerging global health concern. Among the general population, the prevalence of dementia increases exponentially with age. For example, the rate of dementia is about $0.9 \%$ for people aged $65-69$ years, about $2 \%$ for people $70-74$ years, and about $35-40 \%$ for people above the age of 90 years (Prince et al., 2013). A decrease in age-specific dementia prevalence has been reported in some western countries, mainly due to better education, better health, and lifestyle factors such as physical exercise, reducing or stopping smoking, factors that have changed drastically compared to two or three decades ago (Livingston et al., 2017; Prince et al., 2013). However, due to increased longevity, the number of people with dementia globally is expected to increase in the near future. Worldwide, the number of people with dementia is estimated to be $35-40$ million, and the number of older people with dementia is expected to be 115 million in 2050 (Prince et al., 2013). According to Statistics Norway, the proportion of people 70 years and above with dementia will increase from $12 \%$ at present to $21 \%$ in 2060 , and the population of people 80 years and above with dementia will be triple in the same period (Statistics Norway, 2018). In 2018, there are about 80,000 people with dementia in Norway, which is $1.5 \%$ of the total population (Statistics Norway, 2018). Using the same prevalence rates as Prince et al. (2013), the number of people with dementia in Norway would be about 130,000 in 2050. 


\subsubsection{Definition of dementia}

According to the Diagnostic and Statistical Manual of Mental Disorders - Fifth Edition (DSM-5), published by the American Psychiatric Association, dementia is defined as a mild or major neurocognitive disorder (NCD) characterized by a person's cognitive decline from a previous level of performance in one or more cognitive domains. Textbox 1 displays the criteria of mild and major NCD according to the DSM-5 (American Psychiatric Association, 2013). Textbox 2 shows the criteria of dementia diagnosis according to the International Classification of Diseases, Version 10 (ICD-10), published by the World Health Organization (WHO) in 1993 (WHO \& Helsedirektoratet, 2011).

Textbox 1: Mild and major NCD according to DSM-5 criteria

A Evidence of significant cognitive decline from a previous level of performance in one or more cognitive domains (complex attention, executive function, learning and memory, language, perceptual-motor, or social cognition) based on:

1. Concern of the individual, a caregiver or the clinician that there has been a significant decline in cognitive function; and

2. A documented modest (mild NCD) or substantial (major NCD) impairment in cognitive performance.

B The cognitive deficits interfere with independence in everyday activities.

C The cognitive deficits do not occur exclusively in the context of a delirium.

D The cognitive deficits are not better explained by another mental disorder. 
Textbox 2: Research criteria of Dementia according to ICD-10

Dementia is a syndrome occurring due to various brain diseases which are usually chronic or progressive, disturbing many higher cortical functions, such as:

I. Decline in memory, especially of the recent information, objectively verified.

Decline in other cognitive abilities, such as thinking, orientation, learning capabilities, language, judgment, and abstract thinking.

Mild: The cognitive declines influence the management of the activities of daily living.

Moderate: The cognitive declines make the individual unable to function in daily living without help.

Severe: The cognitive declines result in a need for continuous help.

II. Preserved awareness of the environment.

III. A decline in emotional control or motivation, or a change in social behavior, manifesting as at least one of the following:

a. Emotional lability;

b. Irritability;

c. Apathy;

d. Coarsening of social behavior.

IV. The condition should have been present for at least six months.

(Adapted from research criteria of dementia according to ICD-10)

The criteria of dementia according to the ICD-11 were released in June 2018 with small but important changes. Dementia in the ICD-11 is defined as a decline in two or more cognitive domains. In contrast to the ICD-10 criteria, impairment of memory is not a criterion of dementia in the ICD-11. The cognitive impairment should interfere with ADL functions, as in the ICD-10, but the criterion of the minimum six months of cognitive decline has been removed (WHO, 2018).

\subsubsection{Symptoms of dementia}

Dementia is a clinical syndrome characterized by, in most cases, an inevitable progressive deterioration in cognitive ability and capacity for independent living. The symptoms of dementia may include: reduction or loss of memory and capacity to be oriented in time and place; difficulty finding the right words or understanding what people are saying; difficulty performing previous routine tasks; decline in motor functions such as gait and balance 
impairment and rigidity; and changes in behavior and personality (Engedal, Haugen, \& Brækhus, 2018; Kueper, Speechley, Lingum, \& Montero-Odasso, 2017).

Neuropsychiatric symptoms (NPS), also known as the behavioral and psychological symptoms of dementia (BPSD), are commonly observed during the clinical course of dementia and include delusions, hallucinations, depression, anxiety, agitation, irritability, wandering, elation, and sleep problems (Finkel, e Silva, Cohen, Miller, \& Sartorius, 1997). These non-cognitive symptoms of dementia cause many negative impacts such as increased distress and discomfort both for the person and his/her caregiver, reduced the quality of life (QoL) for people with dementia and their family, and early institutionalization (Beerens, Zwakhalen, Verbeek, Ruwaard, \& Hamers, 2013; Finkel et al., 1997).

\subsubsection{Different diseases causing dementia}

Several diseases may cause dementia. The most common cause of degenerative dementia is Alzheimer's disease (AD), accounting for about 60-70\% of the cases (Alzheimer's Association, 2018; Grossberg, 2003), characterized by senile plaques and neurofibrillary degeneration in the cortex and other parts of the gray matter, resulting in global cognitive deterioration with memory problems as a main symptom in the early stage of the disease, and changes in behavior with the progression of the disease (Gale, Acar, \& Daffner, 2018). In some people, the onset of $\mathrm{AD}$ may be observed in the form of language difficulties, such as difficulty finding words and lack of speech flow, lack of orientation in space and direction, and, eventually, difficulties performing everyday tasks (Engedal et al., 2018). Little is known about the cause of $\mathrm{AD}$, but in rare cases various mutations are found. Some dementia risk factors such as genetics, cardiovascular and cerebrovascular diseases, and metabolic and psychiatric factors do exist (Livingston et al., 2017).

Cerebrovascular diseases are the main causes of non-degenerative dementia, known as vascular dementia $(\mathrm{VaD})$. Approximately $20 \%$ of those with dementia have $\mathrm{VaD}$, in which subcortical parts of the brain are injured by multiple small strokes or by a single stroke (cortical damage), often reflected in focal neurological symptoms and changes in mood, besides progressive cognitive deterioration (Román, 2003). Many of the older people with dementia have mixed dementia, such as when AD and vascular disease cause mixed dementia (American Psychiatric Association, 2013). Other common forms of degenerative dementias are, Lewy body dementia (LBD), which causes approximately $10 \%$ of dementia cases and is 
characterized by fluctuations in consciousness and visual hallucinations besides other symptoms of progressive cognitive decline (Mak, Su, Williams, \& O'Brien, 2014); and frontotemporal dementia (FTD), which accounts for about $5 \%$ of dementia cases and is caused by degeneration of the frontal and temporal lobes of the brain. Changes in behavior and language difficulties are common initial symptoms of FTD, such as disinhibition, apathy, loss of sympathy or empathy, and lack of spontaneous speech flow (Gale et al., 2018). There are several other diseases and causes leading to dementia, such as Parkinson's disease with dementia (PD), Huntington's disease, Creutzfeldt-Jacob disease, alcohol-related dementia, HIV-related dementia, and several other neurodegenerative diseases leading to dementia (Engedal et al., 2018).

\subsection{Dementia care in Norway}

This section of the thesis provides a brief description of the Norwegian healthcare system and the dementia care provided by the primary healthcare, focusing on Norwegian nursing homes.

\subsubsection{Norwegian healthcare system}

In Norway, healthcare is provided at two levels: primary care, and specialist services. Norwegian municipalities have the responsibility of providing primary and emergency healthcare to all their inhabitants, including home care and institutional care such as nursing homes when needed. All inhabitants have a general practitioner (GP), which is the base of the healthcare system. The hospitals and other specialist services such as memory clinics and clinics for old age psychiatry are run by health trusts which are owned by the government. To receive specialist healthcare services, referrals from the GP are required (Ministry of Health and Care Services, 2007).

\subsubsection{Dementia care}

In Norway, the municipalities provide dementia care, including diagnosis; follow-ups; inhome care and home help services; day activity services; respite care; and institutional longterm care. In-home care is provided by district nurses and home help employees who are employed by the municipalities or by companies contracted by municipalities. In recent years, the municipalities have been encouraged to enhance day activity services to people with dementia with two main aims: promoting attendance of people with dementia to the day activity centre, which helps in improving their circadian rhythm; and providing respite to caretakers of people with dementia, which may postpone their admission to nursing homes 
(Ministry of Health and Care Services, 2011). To meet the needs of the growing number of people with dementia and their families, the Norwegian Ministry of Health and Care Services (HOD) launched the second Norwegian Dementia Plan 2020 (extending from 2015 to 2020) in August of 2016. The purpose of Dementia Plan 2020 is to promote and develop flexible and tailored primary health and care services so that people with dementia may live at home as long as possible (Ministry of Health and Care Services, 2015). As shown in textbox 2, most people with severe dementia will require 24-hour health and care services in their homes or in institutions, and, accordingly, their families will need support and respite care (Ministry of Health and Care Services, 2015).

\subsubsection{Dementia diagnostics}

Most municipalities have a dementia coordinator or an interdisciplinary memory team that can assist the GPs in dementia assessments. The dementia diagnosis is often made by the patient's GP and defined as P70 (senile dementia) using the International Classification of Primary Care, Version 2 (ICPC-2). ICPC-2 is the official classification system used in research and computer based patient records in primary healthcare in Norway (Bentsen, 1986; Hofmans-Okkes \& Lamberts, 1996). Based on the ICD, ICPC-2 is formally recognized by the World Health Organization's Family of International Classifications (WHO-FIC) system for primary care. The ICPC-2 provides the level of specificity that is necessary for appropriate patient care, and it allows for the exchange of patient data with specialists and hospitals. P70 (senile dementia) is the only code for dementia diagnosis within the ICPC-2 and does not specify the subtypes of dementia (Hofmans-Okkes \& Lamberts, 1996). For advanced assessments of dementia, GPs can refer patients to specialists such as a memory clinic or a clinic for old age psychiatry, if needed. In specialist healthcare, the ICD-10 criteria of dementia diagnoses, which do specify dementia subtypes, are used. The ICD-10 criteria will soon be replaced by the ICD-11 criteria (WHO, 2018).

\subsubsection{Norwegian nursing homes}

All the Norwegian municipalities have nursing homes. As many as $40 \%$ of the people with dementia in Norway live in institutions (Engedal et al., 2018), mainly nursing homes. Higher age, impairment in activities of daily living (ADL) functions, dementia, and NPS such as delusions and hallucinations are associated with nursing home admission (Wergeland, Selbæk, Bergh, Soederhamn, \& Kirkevold, 2015). Norwegian nursing homes are operated and financed by the municipalities and provide a room with full board, a common living room, assistance with ADL, medication management, supervision, and access to medical care and 
other health services around the clock (Helse- og omsorgsdepartementet, 2013). In recent years, the percentage of single-bed rooms in the nursing homes has increased to $97.5 \%$ (Statistics Norway, 2017), which has increased the opportunity for privacy for nursing homes residents. Within nursing homes there are regular long-term care units, respite care units, and rehabilitation units for short-term care. In addition, about $25 \%$ of nursing home beds are in special care units for people with dementia. These units have usually $8-12$ beds and are designed for people with dementia, with nurses trained in dementia care providing some or all of the care and social activities (Gjøra, Eek, \& Kirkevold, 2015). The number of nursing homes beds in special care units has increased from $13 \%$ to $25 \%$ from 1997 to 2014, indicating improvement in the care of people with dementia with severe disruptive behavior (Gjøra et al., 2015).

Roughly $70 \%$ of the residents in nursing homes are women, and the mean age of the residents is approximately 85 years (Mjørud, Kirkevold, Røsvik, Selbæk, \& Engedal, 2014; Roen et al., 2017; Rokstad et al., 2013; Selbæk, Kirkevold, \& Engedal, 2007). About 80\% of the nursing home residents in long-term care in Norway seem to have dementia, but only $56 \%$ of those with dementia in long-term care have a dementia diagnosis registered in their medical record (Roen et al., 2017).

Many of the people with dementia in nursing homes have other chronic disorders in addition to dementia, and inappropriately prescribed medications have been a challenge in Norwegian nursing home residents (Halvorsen, Selbæk, \& Ruths, 2017). A recent study described that a Norwegian nursing home resident on average used 6.8 different drugs on daily basis, and about $83 \%$ of the nursing home residents have, on average three drug-related problems (Fog, Kvalvaag, Engedal, \& Straand, 2017). The authors found that use of inappropriate drugs, high dosages, and lack of drug use monitoring were some of the most frequent drug-related problems. Use of psychotropic drugs and opioids were involved in most of the drug-related problems among nursing home residents (Fog et al., 2017). Another Norwegian study reported that $69 \%$ of nursing home residents receive one or more psychotropic medications; however, the use of antipsychotics was significantly reduced from $24 \%$ in $2004-05$ to $17 \%$ in 2010-11 (Selbæk et al., 2017).

\subsubsection{The staff in Norwegian nursing homes}

Registered nurses and auxiliary nurses are the main healthcare personnel involved in the care and support of people with dementia in nursing homes. In 2010, 28\% of registered nurse positions were in special care units while $22 \%$ were in regular units (Kirkevold, Eek, \& 
Engedal, 2012). Special care units have a higher staff-resident ratio, with an average of 3 residents per staff member on a weekday, compared to 3.5 for regular units (Kirkevold et al., 2012). One of the more difficult tasks for nursing home staff is the management of NPS among nursing homes residents with dementia. The training of healthcare personnel is covered in national policies, supplemented by various dementia-specific training programs hosted by the municipalities. Nursing homes may receive grants for training programs in basic dementia knowledge and NPS (The ABC's of Dementia Care) (Garden \& Toft, 2013). A Norwegian randomized control study reported that nursing home staff's training and implementation of person-centered dementia care (intervention group) was more effective than receiving video lectures (control group) in reducing the severity of NPS and enhancing the QoL of nursing home residents (Rokstad et al., 2013). Person-centered dementia care approach focuses on the preferences and comfort of the person with dementia and is recommended in the management of NPS and improvement of QoL of nursing home residents (Ballard et al., 2018; Chenoweth et al., 2009; Edvardsson, Winblad, \& Sandman, 2008).

\subsubsection{The prevalence of neuropsychiatric symptoms in people with dementia in nursing homes}

Defining clinically significant NPS as a score of four and above on any single item of the neuropsychiatry inventory (NPI) (Cummings, Mega, Gray, Rosenberg-Thompson, \& et al., 1994; Selbæk, Kirkevold, Sommer, \& Engedal, 2008b), previous Norwegian nursing home studies have reported that $63 \%$ of people with dementia exhibited at least one clinically significant NPS, and anxiety and depression were the most prevalent (Roen et al., 2017). Selbæk et al. (2007) reported that $72 \%$ of people with dementia had clinically significant NPS and that the frequency of NPS increased with the severity of the dementia. The prevalence of NPS was 55\% in mild, $70 \%$ in moderate, and $84 \%$ in severe dementia (Selbæk et al., 2007). Assessing NPS at five points, Bergh et al. reported that $92 \%$ of people with dementia in Norwegian nursing homes had at least one clinically significant NPS at one or more assessments during 16 months of follow-up. Irritability, agitation, and disinhibition were the most prevalent NPS in nursing homes (Bergh, Engedal, Røen, \& Selbæk, 2011).

A study by Ballard et al. (2001) reported an insignificant change in the overall prevalence of NPS over the course of a year (76\% at baseline vs. $82 \%$ at one year) among people with dementia in long-term care. The authors report that the participants with subclinical NPS (total NPI score of 1-3) at baseline were more likely to develop clinically significant NPS 
(NPI score of three and above) at follow-up than the participants who were symptom free $($ NPI score $=0)$ at baseline. Persistence of aggression was $76 \%$, depressive symptoms $68 \%$, and aberrant motor behavior $43 \%$ at one-year follow-up. Unfortunately, this study did not report anxiety symptoms (Ballard et al., 2001). However, a systematic review including 18 longitudinal prospective studies of people with dementia in long-term care reported that the symptoms of aberrant motor behavior, depression, anxiety, and euphoria declined and apathy, agitation, irritability, and disinhibition increased, whereas psychotic symptoms remained constant over time (Wetzels, Zuidema, Jansen, Verhey, \& Koopmans, 2010). These studies indicate that NPS are widely prevalent in nursing homes residents with dementia.

NPS has also been categorized into clusters or sub-syndromes, and different studies have reported varying NPS sub-syndromes depending on the study sample (Aalten et al., 2003; Lyketsos et al., 2001; Selbæk \& Engedal, 2012; Wergeland et al., 2015). For example, anxiety was considered as a separate symptom in the study by Aalten et al. (2003), whereas apathy was not included in any of the three NPS sub-syndromes, but was instead regarded as a separate symptom in the study by Selbæk et al. (2012). The study by Aalten et al. included people with dementia living in a community, and $71 \%$ of the study sample had mild dementia. By performing separate analyses for people with mild and severe dementia, the authors found that anxiety loaded on different factors and was considered a separate symptom (Aalten et al., 2003). Selbæk et al.'s (2012) sample, however, was a cohort of nursing home residents with dementia assessed at three points from baseline to 31-month follow-up, and 77\% of the participants had moderate to severe dementia with severe NPS at baseline. The authors found that the factor structure of NPI was stable across all three assessments except for apathy and appetite, which were found to have a minor correlation with one another (Selbæk et al., 2012). There have been controversies over whether NPS should be studied and treated individually or in sub-syndrome clusters, and some argue that reducing the number of NPS into subsyndromes leads to a greater possibility of finding associations with other characteristics (Aalten et al., 2003) (see section 7.9 of this thesis).

NPS may differ among people with different types of dementia. For example, visual hallucinations are more common in people with LBD (Engedal et al., 2018; McKeith, 2007), while disinhibition is more common in FTD (McKhann et al., 2001), and anxiety and depression are highly prevalent in $\mathrm{VaD}$ (Ballard et al., 2001). Thereby, studying individual NPS in people with dementia would be reasonable while studying the severity of and 
evaluating the effects of non-pharmacological and pharmacological interventions on individual NPS such as agitation, depression, or anxiety.

\subsection{Anxiety in dementia from a historical perspective}

The knowledge about the subjective experiences of people with dementia was sparse in the beginning of the previous century, as researchers were engaged in studying the histopathology of Alzheimer's disease. Documentation of anxiety in the medical records of patients with dementia was rare, with the exception of "anxiety" due to paranoid delusions (Shorter, 1991). Anxiety was considered a part of depression rather than a separate symptom, which may have contributed to the lack of attention anxiety in people with dementia received both in clinical settings and in research in the early part of the twentieth century (Shorter, 1991).

In the 1930s, Johannes Schottky at the Institute of Psychiatric Research in Munich (as cited in Shorter, 1991, p. 38) reported anxiety among some of his patients with AD. In the literature from the 1970s and onwards, a gradual increase in documentation of anxiety was reported in the medical records of patients with AD, often in association with agitation (Liston, 1979). Thereafter, the subjective experiences of anxiety in people with early stages of dementia were reported, and, that anxiety was considered a product of the perceived stress and demands of daily life that the person with dementia could no longer successfully fulfill (Reisberg, 1996a; Shorter, 1991).

\subsection{Anxiety}

\subsubsection{Anxiety as a normal reaction}

When anxiety has an object, it is often called fear and is considered a natural reaction (Barlow, 2002). Barlow describes anxiety as the body's "alarm system" responsible for its survival, protecting against potentially life-threatening situations with the reflexive urge to escape (flight) or to stand and encounter the threat (fight) (Barlow, 2002). During this defensive mechanism, the peripheral blood vessels constrict and raise arterial pressure, decreasing the blood flow to the extremities to reduce blood loss and redirecting it to the skeletal muscles and other vital organs to allow a person to defend oneself. The skin often becomes pale or white from fear due to reduced blood flow to the skin. A sweat breaks out; a person may feel hot and cold sensations, and body hair can stand erect to conserve heat. Breathing becomes more rapid to provide sufficient oxygen to the rapidly circulating blood 
and to the brain, where cognitive and sensory functions are stimulated. Digestive activity is suspended, reducing the flow of saliva and resulting in dry mouth (Barlow, 2002). There is a third response-fainting/tonic immobility or "playing dead" (freezing), caused by a marked decrease in heart rate and blood pressure to minimize blood loss and increase the chances of survival (Barlow, 2002).

\subsubsection{Anxiety as a symptom}

Unlike objective evidence of a disease, such as a fever or skin rash, symptoms are the subjective experiences of an individual, such as fatigue or headache (Stedman, 2012). Anxiety is a subjective state of inner distress, an unpleasant and vague feeling of apprehension that seems to anticipate some imminent danger, the source of which is unknown or unrecognized, and is accompanied by a range of behavioral symptoms across one's lifetime (Eugene \& Joshua, 2010). The symptoms of anxiety include cognitive (worry, difficulty concentrating), physical (fatigue, muscle tension, and sleep disturbances) and emotional (restlessness, irritability) components (Lindesay, Stewart, \& Bisla, 2012; Nordhus, 2008). Anxiety as a symptom can frequently be found in a number of medical and psychiatric diseases.

Anxiety symptoms as operationalized in the anxiety assessment scales may indicate the severity and clinical significance of anxiety, both of which may factor into the choice of intervention in each individual case. A number of anxiety assessment scales have been developed and validated for a specific population, such as the Geriatric Anxiety Inventory (GAI), which is intended to assess anxiety symptoms in older people (Pachana et al., 2007), and the Rating Anxiety in Dementia (RAID) scale, which is intended for the assessment of anxiety symptoms in people with dementia (Shankar, Walker, Frost, \& Orrell, 1999). The presence of anxiety symptoms is not an automatic diagnosis of anxiety disorder (Porter et al., 2003). One of the challenges is to distinguish between anxiety as a symptom and anxiety as a disorder or condition.

\subsubsection{Anxiety as a disorder}

A disorder (dis-order) or lack of order is a disturbance of function (dysfunction), structure, or both, or a departure from normal, healthy function (Porta, 2014). A disorder usually has a characteristic clinical course and etiology that can be assigned to a diagnostic category, and the presence of many symptoms collectively can indicate the presence of a disorder, reflecting underlying pathological processes (Porta, 2014; Salzman \& Lebowitz, 1991). 
Anxiety symptoms may reach pathological levels that cause significant distress and impairment in functioning and constitute a specific diagnosis of anxiety disorder, the primary symptoms of which are unrealistic and excessive anxiety and/or worry, as in the generalized anxiety disorder (GAD) outlined in the DSM-5 (American Psychiatric Association, 2013; Bryant et al., 2013). The GAD is the most frequently observed anxiety disorder in older people both with and without dementia (Lindesay et al., 2012; Nordhus, 2008).

\subsubsection{Clinically significant anxiety}

When anxiety is clinically significant, the anxiety symptoms are impairing or causing distress to the individual and/or to his/her caregivers to such an extent that they need to be taken care of by healthcare personnel and require treatment even in the absence of a clinical diagnosis (Beaudreau \& O'Hara, 2008). Clinically significant anxiety is often defined by a cut-off score of an anxiety assessment scale validated psychometrically for that particular population, or in some cases based on clinical experiences. For example, a cut-off score of seven or higher on the Hospital Anxiety and Depression Scale, Anxiety subscale, (HADS-A) was considered to be clinically significant in the study by Bierman et al. (Bierman, Comijs, Jonker, \& Beekman, 2007; Zigmond \& Snaith, 1983).

However, it can be difficult to determine the degree of impairment or distress due to anxiety in people with dementia. For example, is it the distress of the patient or the caregiver that needs to be taken into consideration? There is also a question of when anxiety is considered a normal response to dementia, and when it becomes a pathological condition. Another challenge in studying anxiety in people with dementia is that, in the literature, the term anxiety is used interchangeably for anxiety symptoms, anxiety disorders, and/or clinically significant anxiety.

\subsubsection{Criteria of GAD}

Diagnostic criteria provide a common language among healthcare professionals and are essential for clinicians and researchers. The DSM-5 (American Psychiatric Association, 2013) and ICD-10 (WHO, 2011) are the two leading diagnostic tools in mental and behavioral disorders currently in use. See textboxes 3 and 4. 
Textbox 3: Research criteria of GAD according to DSM-5

A. Excessive anxiety and worry, occurring more days than not for at least 6 months, about a number of events or activities.

B. The individual finds it difficult to control the worry.

C. The anxiety and worry are associated with three (or more) of the following six symptoms:

1. Restlessness or feeling keyed up or on edge.

2. Being easily fatigued.

3. Difficulty concentrating or mind going blank.

4. Irritability.

5. Muscle tension.

6. Sleep disturbance (difficulty falling or staying asleep, or restless, unsatisfying sleep).

D. The anxiety, worry, or physical symptoms cause clinically significant distress or impairment in day-to-day life.

E. The disturbance is not attributable to other physiological or medical conditions.

F. The disturbance is not better explained by another mental disorder.

DSM anxiety disorders are based on descriptive symptoms and do not address the issue of etiology or the specific characteristic of old age.

Textbox 4: Research criteria of GAD according to ICD-10 (F41.1)

A. Free-floating anxiety that is generalized and persistent, not limited to defined situations or any particular environmental circumstances.

B. The dominant symptoms are variable, but include complaints of persistent nervousness, trembling, muscular tensions, sweating, light-headedness, palpitations, dizziness, and epigastric discomfort.

C. The individual often expresses fear that he or she himself/herself or a relative will shortly become ill or have an accident.

There is no distinct criterion of GAD in people with dementia. Using the DSM-IV and ICD10 criteria of GAD as the "gold standard," Starkstein and colleagues validated a set of GAD diagnostic criteria for patients with $\mathrm{AD}$ and suggested the following revised criteria: "Excessive anxiety and worry as the key criterion and at least three of a list, including restlessness, irritability, muscle tension, excessive fears, and respiratory symptoms of anxiety as additional criteria” (Starkstein, Jorge, Petracca, \& Robinson, 2007, p. 47). 


\subsubsection{Anxiety symptoms and anxiety disorders in older people}

Anxiety symptoms and disorders are more likely to go unnoticed and untreated in older people than in younger populations (Balsamo, Cataldi, Carlucci, \& Fairfield, 2018). Anxiety, both as a symptom and disorder, is under-recognized in older people and is related to many challenges: 1) older people are less willing to report their emotions due to stigmatization related to psychological health issues; 2) it is a common belief (even among professionals) that anxiety is a normal condition of aging (Nordhus, 2008); 3) expression of fears and worries among older people are often related to being a burden on their families, financial problems, and fear of dying, which are often not included in existing anxiety assessment scales (Lindesay et al., 2006); 4) older people often attribute their anxiety symptoms to their physical health (Balsamo et al., 2018); 5) a higher rate of medical comorbidities in older people and corresponding use of multiple medications often complicate the assessment of anxiety symptoms and anxiety disorder (Bryant et al., 2013); and 6) anxiety is often a hidden comorbidity with other psychiatric illnesses (Bendixen \& Engedal, 2015; Jeste, Blazer, \& First, 2005).

Approximately $30-40 \%$ of older people with anxiety report an onset of anxiety after the age of 50 years, suggesting that late-onset anxiety is common (Le Roux, Gatz, \& Wetherell, 2005; Nordhus, 2008). In a review, the prevalence of anxiety symptoms in older people was reported to be up to $52 \%$ in community-based samples and up to $56 \%$ in clinical samples from geriatric and general hospitals and nursing homes (Bryant, Jackson, \& Ames, 2008), whereas the prevalence of anxiety disorders was reported to be up to $15 \%$ in community-based samples and up to $28 \%$ in clinical samples (Bryant et al., 2008; Wolitzky-Taylor, Castriotta, Lenze, Stanley, \& Craske, 2010). Among geriatric inpatients, significant anxiety symptoms were reported for up to $41 \%$ of female and $47 \%$ of males (Kvaal, Macijauskiene, Engedal, \& Laake, 2001), and these symptoms remained higher at 3- and 12-month follow-ups after discharge, indicating that anxiety symptoms tend to be persistent in physically ill older people (Kvaal \& Laake, 2003).

Regarding the occurrence of different anxiety disorders in older population, after GAD, panic disorder, social anxiety disorder, post-traumatic stress disorder (PTSD), acute stress disorder (ASD), and anxiety disorder due to a general medical condition (ADGMC) are the most common (American Psychiatric Association, 2013; Nordhus, 2008). In older people, social anxiety disorder may develop due to a medical condition making the person feel uncomfortable getting involved in social situations. Contrary to PTSD, ASD symptoms are 
experienced immediately after a traumatic event (Nordhus, 2008). For example, some older people find it difficult dealing with a sudden death in the family and may develop stress and anxiety. Obsessive-compulsive disorder is relatively less prevalent in older people as compared to younger adults (American Psychiatric Association, 2013). ADGMC becomes apparent as a panic attack, commonly caused by cardiovascular or respiratory conditions (American Psychiatric Association, 2013). About 30\% of the patients suffering from chronic obstructive pulmonary disease also had an anxiety disorder (Hynninen, Breitve, Wiborg, Pallesen, \& Nordhus, 2005).

Another issue is the presence of sub-threshold anxiety in the older population, which means that anxiety symptoms are severe enough to be clinically significant, having impact on day-today life, without fulfilling the diagnostic criteria of any anxiety disorder (Grenier et al., 2011). A study by Grenier et al. (2011) reported that the 12-month prevalence of sub-threshold anxiety was much higher (26\%) than any anxiety disorder diagnosed by DSM-IV criteria $(6 \%)$ in community-dwelling older people. Much like anxiety disorder, sub-threshold anxiety imposed significant social impairment on the participants (Grenier et al., 2011). The challenges for the health professionals are to identify clinically significant anxiety in older people needing interventions.

\subsubsection{Comorbid anxiety and depression in older people}

Like in the general adult population, anxiety and depression often coexist in the older population, and comorbidity of anxiety and depression increases with the age (Beekman et al., 2000). Individuals with early-onset depression are more vulnerable to comorbid anxiety in old age than individuals with late-onset depression, and vice versa (Nordhus, 2008). Different studies report different prevalence rates of comorbidity of anxiety and depression, but there is a consensus about their high co-occurrence. A large community-based Dutch study reported that $60 \%$ of the older people with GAD were also diagnosed with depression, and the comorbidity of anxiety and depression increased with the severity of anxiety or depression (Schoevers, Beekman, Deeg, Jonker, \& Tilburg, 2003), and the finding was supported by a nursing home study (Smalbrugge, Jongenelis, Pot, Beekman, \& Eefsting, 2005). In the follow-up study of Schoevers et al. (2005) the participants with comorbid anxiety and depression indicated a significantly poorer prognosis with lower remission rates compared to the participants with only anxiety or only depression at 3-year follow-up. Participants with comorbid anxiety and depression had more chronic illness and functional disability than the participants with only anxiety or only depression (Schoevers et al., 2005). Another large 
community-based Australian longitudinal study of the older people reported that about 57\% of participants with depression showed evidence of comorbid anxiety, while only $28 \%$ of those with clinically significant anxiety had comorbid depression. At two-year follow-up, the persistence of anxiety, depression, and comorbid anxiety and depression was $31 \%, 23 \%$, and 35\%, respectively (Almeida et al., 2012). The studies of Schoevers et al. and Almeida et al. indicate that the long-term prognosis is poor among older people with both disorders (Almeida et al., 2012; Schoevers et al., 2005). Besides, a recent study found that the severity of anxiety symptoms in older people with depression is associated with suicidality (Bendixen, Engedal, Selbæk, \& Hartberg, 2018).

Both GAD and major depressive disorder (MDD) have unique characteristics, but they also share some common symptoms. Excessive worry, frightened and anxiousness are unique to GAD, and marked loss of pleasure and increased pessimism are unique to MDD. Characteristics that overlap in GAD and MDD according to DSM-5 criteria are: sleep disturbances, restlessness, fatigue, and difficulty in concentration (American Psychiatric Association, 2013; Zbozinek et al., 2012). Although anxiety and depression share some common vulnerabilities, including genetic risks and personality traits, they have distinct environmental risk factors and should be considered different diagnostic entities (Beaudreau \& O'Hara, 2008; Beekman et al., 2000; Smalbrugge et al., 2005). Adequate assessment of both anxiety and depression in the context of the individual background history, resources, and vulnerability is also important for older people, and should be better addressed to achieve better prognosis. The prevalence and the course of comorbid anxiety and depression among people with dementia are yet to be explored. There is a lack of studies investigating the impact of comorbid anxiety and depression among people with dementia.

\subsubsection{Association between anxiety and cognitive impairment in older people}

The association between anxiety and cognitive impairment is complex, non-linear, and ambiguous (Bierman et al., 2007). A population-based 17-year prospective study of men aged 48 to 67 years at baseline reported that anxiety was associated with cognitive impairment and dementia (Gallacher et al., 2009). These findings were not supported by another study reporting that anxiety at baseline was not associated with conversion from mild cognitive impairment to AD (Devier et al., 2009). A review on late-life anxiety and cognitive impairment indicated that cognitively impaired older people exhibit more anxiety symptoms compared to cognitively intact older people, and the risk of dementia nearly doubles when 
anxiety symptoms are present in older people with cognitive impairment (Beaudreau \& O'Hara, 2008). A recent systematic review and meta-analysis reported that anxiety increased the risk of progression to dementia in people with mild cognitive impairment as compared to those with mild cognitive impairment without anxiety ( $\mathrm{Li} \& \mathrm{Li}, 2018$ ). In another systematic review, an association between anxiety and cognitive impairment was reported to be ambiguous, and a meta-analysis of anxiety studies was not possible due to their limited number $(\mathrm{n}=5)$ included in the review (John, Patel, Rusted, Richards, \& Gaysina, 2018). Teri et al. (1999) found that anxiety symptoms were associated with increased cognitive impairment in community-dwelling people with dementia. People with severe cognitive impairment were more likely to be anxious than people with mild to moderate cognitive impairment due to dementia (Teri et al., 1999). Other studies have not found an association between anxiety and level of cognitive impairment in people with dementia (Shankar et al., 1999; Twelftree \& Qazi, 2006). Other researchers found that anxiety symptoms peak at the mild to moderate stages of dementia when insight is preserved, and anxiety decreases when cognition is severely impaired (Bierman et al., 2007; Orrell \& Bebbington, 1996). In a Norwegian study, anxiety was associated with dementia-related cognitive impairment as assessed by the Cognitive Dementia Rating (CDR), but not with cognitive test performance (Hynninen, Breitve, Rongve, Aarsland, \& Nordhus, 2012).

There is no consensus on whether or how anxiety and cognitive impairment are related. Do they have a unilateral relationship? In that case, in which direction? Or do they have a bilateral relationship, and if so, is poor cognition a risk factor for anxiety, or does anxiety lead to poorer cognition? More prospective longitudinal studies may cast light on their association. Anxiety can be a normal reaction to cognitive impairment, especially in the context of dementia. In some cases, anxiety about the cognitive decline may be very distressing for the individual him/herself and/or for his/her caregivers. Many potential factors may play an important role in illuminating the phenomenon of anxiety in cognitive impairment due to dementia.

\subsection{Factors contributing to anxiety symptoms and disorder in people with dementia}

Anxiety in people with dementia may be a consequence of multiple underlying biological and psychosocial factors in a dynamic interplay. The understanding of a disease or disorder from a biological, psychological, and social model as pioneered by Engel (Engel, 1977) is accepted by the WHO (WHO, 2001). The aspects of dementia and anxiety that are beyond the control 
of individual and their environment and cannot be changed are called fixed factors, and other aspects that can either be risks or protective factors and can be influenced through interventions are called tractable factors (Spector \& Orrell, 2010). An interaction between fixed and tractable factors from biological and psychosocial perspectives could be the cause of anxiety in people with dementia, as illustrated in figure1.

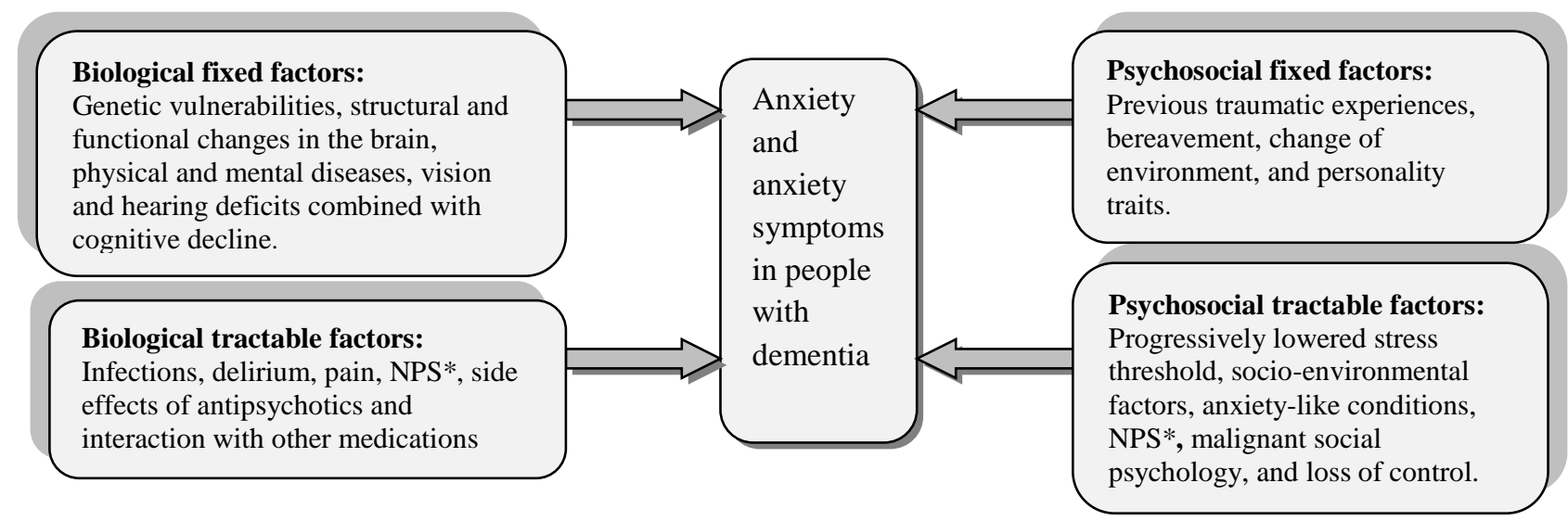

Figure 1. Biological and psychosocial factors contributing to anxiety and anxiety symptoms in people with dementia, inspired by Spector and Orrell, 2010. *Overlapping factors

\section{Fixed factors}

Neurodegeneration is considered an underlying cause of changes in cognition, communicative ability, and behavior in dementia. Higher age is a risk factor of getting dementia as the prevalence of dementia increases exponentially with age throughout the world (Prince et al., 2013). Genetic vulnerabilities could be a common fixed factor for developing dementia and anxiety. Apolipoprotein E (ApoE4) is a well-known genetic marker that increases the probability that one will develop $\mathrm{AD}$, but carriage of one or more ApoE4 marker and lower executive function in women may also be associated with increased anxiety symptoms and impairment in abstract problem-solving (Beaudreau \& O'Hara, 2008; Caselli, Reiman, Hentz, Osborne, \& Alexander, 2004; Holmes et al., 2018).

There is evidence indicating an association between anxiety and structural and functional changes in the brain that tend to go along with $\mathrm{AD}$ and other dementias. Imaging studies of patients with AD have reported functional and structural abnormalities in the amygdala, hippocampus, prefrontal cortex, and anterior cingulated cortex (ACC), which are significant components in the processing of emotions, fear, and stress (Beaudreau \& O'Hara, 2008; Shin 
\& Liberzon, 2010; Tagai et al., 2014). Research has also found anxiety to be associated with metabolic reduction in the medial temporal lobe, a component of the fear neurocircuitry, in patients with AD (Hashimoto et al., 2006; Tagai et al., 2014). These findings suggest that anxiety in AD patients might be associated with degeneration in specific brain areas associated with AD, and not only a change in the fear circuitry (Tagai et al., 2014). Other brain changes are seen in dementia patients, such as changes in the availability of neurotransmitter or receptor site functioning, especially of serotonin and acetylcholine. These changes may influence cognition and anxiety, though an association between anxiety symptoms and these neurotransmitters is not well documented (Beaudreau \& O'Hara, 2008).

Certain mental health and physical conditions such as depression, schizophrenia, and cardiovascular, respiratory, and endocrine diseases are associated with anxiety and anxiety symptoms among people with dementia (Badrakalimuthu \& Tarbuck, 2012; Johansson \& Gustafson, 1996). Poorly defined stimuli such as shadows and noises combined with vision and hearing deficits in older people with dementia may be misinterpreted and cause anxiety. One anxiety symptom, sleep disturbance, has been linked to greater autonomic arousal, suggesting that sympathetic tonus heightens in the evening hours (Gurian \& Miner, 1991), but sleep disturbance may also be related to psychological factors and changes in routine and environment. Major life events like previous traumatic experiences, bereavement, and loss could also be related to anxiety in people with dementia (Spector \& Orrell, 2010). Sometimes a person's personality traits become exaggerated over the course of dementia. Depression and anxiety disorders and other behavior disturbances such as delusions, hallucinations, and aggression were associated with neurotic personalities among nursing home residents with dementia (Low, Brodaty, \& Draper, 2002), and could be a fixed factor of developing anxiety.

\section{Tractable factors}

Interventions can help to control certain biological, psychological, and social factors, thereby reducing or preventing anxiety in people with dementia. Some of the common medical conditions of older nursing home residents with dementia, such as urinary tract and lung infections, delirium, pain, delusions, hallucinations, side effects of antipsychotics and interaction with other medications (Fog et al., 2017; Gulla et al., 2016), may cause additional stress and anxiety-like symptoms. These conditions among nursing home residents may be prevented (to a certain extent) by vigilant nursing care and managed by regular health checkups and critical review of medication prescriptions. 
Based on the Progressively Lowered Stress Threshold (PLST) model (Hall \& Buckwalter, 1987), the stress threshold among older people with dementia is reduced due to their diminished ability to receive and process stimuli and information as dementia progresses, and they are therefore more vulnerable to stress, which may result in anxiety and dysfunctional behavior (Hall \& Buckwalter, 1987; Smith, Gerdner, Hall, \& Buckwalter, 2004). Without an effective intervention to reduce or eliminate stress, it may accumulate and exceed the threshold, leading to anxiety and agitated behavior (Hall \& Buckwalter, 1987; Skovdahl, Sörlie, \& Kihlgren, 2007).

According to the PLST model (Hall \& Buckwalter, 1987), an older person with dementia exhibits three main types of behavior throughout the trajectory of dementia: baseline or normative, anxious, and dysfunctional. The proportion of each behavior varies as the dementia progresses. Baseline or normative behavior is a calm state where a person is socially (able to communicate needs and interact with others) and cognitively (oriented to the environment) accessible. Baseline behaviors are reduced with the progression of dementia and are replaced by anxious and dysfunctional behavior. Anxious behavior occurs when the person with progressive dementia is disoriented, insecure, and stressed, and the person stops making eye contact and attempts to avoid offensive stimuli. At this state, caregivers are still able to maintain contact with the person. If the stress level continues or increases, a dysfunctional behavior in the form of wandering, fearfulness, night wakening, panic and/or agitation results, which is a drastic change from the normative behavior and similar to a delirium. These behaviors apparently come on suddenly, last for a short duration, and are described as a PLST symptom cluster. Dysfunctional behavior comes from anxiety resulting from an overwhelming input of internal or external stimuli creating a state of physiological stress (Hall \& Buckwalter, 1987; Smith, Hall, Gerdner, \& Buckwalter, 2006). Based on Hall's PLST model, anxiety symptoms among people with dementia can be reduced by providing optimal environmental support, such as care in the special care unit, being empathetic, providing one-on-one contact, tactile stimulation, and adequate management of acute illness, infections, and pain. These interventions would be helpful in reducing both external and internal stressors, helping the person relax, and minimizing anxiety symptoms (Skovdahl et al., 2007; Smith et al., 2006).

The Adaptation-Coping model by Dröes suggests that people constantly strive for equilibrium (Dröes, Van Der Roest, Van Mierlo, \& Meiland, 2011). When experiencing a decline in 
memory and cognition due to dementia, the person may have to develop new coping strategies to deal with the situation. These strategies can be denial, de-emphasizing the situation, use of humor, overcompensation, avoiding social contact, and confabulations (Clare, 2003; Dröes et al., 2011). Nursing staff may interpret these strategies as repetitive behavior, worry over trifles, false belief or perceptions, and/or complaints of pain and fatigue to avoid social contact. The degree to which these adaptive strategies are stressful to the person and/or his/her caregivers depends upon the person's internal resources, such as cognitive status, general physical health, communicative abilities, and external factors, such as physical and social environment (Dröes et al., 2011). Certain behavioral expressions of anxiety may therefore be coping strategies for people with dementia.

Certain socio-environmental situations may create anxiety-like conditions in people with moderate to severe dementia (Cohen, 1998). According to Cohen, demanding or challenging situations, such as an inability to complete a task or answer a question, may sometimes trigger anxiety-like reactions in people with dementia. The reaction reflects a sense of frustration or fear over losing control of the situation. In extreme cases, the caregivers may observe behavioral and somatic symptoms, such as verbal and physical agitation, restlessness, sweating, and palpitations, and Cohen describes this situation as the "challenge anxiety of Alzheimer's disease" (Cohen, 1998). Cohen also described the "unfamiliarity anxiety of Alzheimer's disease," or when a person with dementia exhibits anxiety-like symptoms in response to unfamiliar surroundings, such as change in environment, moving to a nursing home, and unfamiliar caregivers. According to Cohen, anxiety may also occur when a person with severe dementia experiences a lack of engagement with people or the environment, described as the "isolation anxiety of Alzheimer's disease" (Cohen, 1998). Studies have reported that unmet psychological and social needs of people with dementia in residential care, such as lack of social company, poor patient-caregiver relationship, and lack of daytime activity, are associated with anxiety symptoms (Creighton, Davison, \& Kissane, 2017; Hancock, Woods, Challis, \& Orrell, 2006). These situations can be prevented or minimized by nursing interventions, such as being with the patient, listening to music, going for a walk or outdoor activity, and engagement in social activities in small groups or one-on-one according to the person's preferences.

In addition to the practical consequences, people with dementia may also experience adverse reactions from others in response to their memory loss. Kitwood emphasized the dementia process as a dialectical interplay between neurological and social-psychological factors. $\mathrm{He}$ 
introduced the term malignant social psychology, explaining that a neurologically impaired individual's well-being or personhood is undermined in various ways by his/her caregivers. Adverse reactions from caregivers may lead to a loss of identity and self-esteem, insecurity, anxiousness, protest, withdrawal from activities, and depression (Kitwood, 1990).

Based on the model of self-psychology from Daniel Stern's object relations theory (Stern, 1985), an individual is able to sustain a sense of self under stress through a prolonged process of identification with important others, memories that are internalized as comforting images. The individual's capacity to retain a stable image of a comforting other is maintained by object constancy. Object constancy allows the individual to tolerate a temporary separation without undue levels of anxiety. The capacity to be alone is a basic characteristic of the mature individual (Stern, 1985). With a decline in coping capacities in many areas as the dementia progresses, the ability to maintain object constancy may decline. Each time the important relative or next-of-kin for the person with dementia is out of the visual contact, the person with dementia may become anxious and fear being abandoned, leading to desperate phone calls and asking for help (Sadavoy, 1991). This may be illuminated by the example of my acquaintance's mother.

The core element in the maintenance of self and self-identity is memory, which serves many psychological functions apart from day-to-day functioning (Sadavoy, 1991). Metaphorically, the memory serves as a hook or "knagg" (in Norwegian) to help a person "hold on" to his or her identity by recalling past experiences, connecting the past with the future, and experiencing life moment by moment (Sadavoy, 1991). A person with diminished short-andlong-term memory may feel lost in time and space, being with others without being related to them and having difficulties handling a sense of identity in relation to him/herself (Zingmark, Norberg, \& Sandman, 1993). The situation may lead to a sense of insecurity. As long as patients' personal past experiences remain available, they are able to recognize themselves and maintain their identities and self-esteem despite their gradually declining cognitive function. Without an intact memory, the present is chaotic, as expressed by the man in the example presented in the beginning of this thesis.

According to Sadavoy, an intact memory from long ago combined with missing recent memory may confuse a person with moderate or severe dementia, as the past memory is not the current reality. The person with dementia may anxiously and desperately insist on seeing a dead or absent relative or next-of-kin. A cognitive disability coupled with a complex 
environment and interpersonal disharmony may lead to this sense of loss, abandonment, insecurity, and chaos. Sometimes pleasant images from the past seem to become the reality of people with severe dementia, leading to a comforting source of "self" (Sadavoy, 1991).

Severe cognitive impairment reduces the person's capacity to distinguish between realitybased stimuli and imaginary stimuli (hallucinations) and between relevant and irrelevant stimuli (Sadavoy, 1991). A trivial noise may be perceived as a dangerous attack from an unseen object or person. The environmental stimuli frequently experienced in nursing homes, such as door alarms, shouting patients, meal trolleys, loud conversations between the staff during mealtimes, inconsiderate use of television, etc., may be chaotic and a source of anxiety for a person with severe dementia. From my own experiences as a nurse, anxiety in people with severe dementia is related to the here-and-now situations and nursing staff should strive to create as many good moments as possible.

From the clinicians' perspectives, anxiety in people with dementia is a consequence of biological, psychological, and social causes and is related to new situations and worries about managing everyday life (Goyal, Engedal, \& Eriksen, 2016a). According to the clinicians, due to the development of dementia, most patients experience several losses related to everyday life, including a loss of control over their situation and a loss of meaning. The person with dementia feels insecure, worried, concerned, and restless. The experience of insecurity, loss, and uncertainty triggers anxiety reactions, which the clinicians described as existential anxiety. The transition from being an independent individual to being dependent on others may trigger an existential crisis (Goyal et al., 2016a). Anxiety as experienced by people with dementia was related to loss of functional ability, increased dependency on others, loss of self-esteem, and negative thoughts (Qazi, Spector, \& Orrell, 2010). However, the phenomenon of existential anxiety has been poorly investigated from the perspectives of people with dementia.

In summary, the biological and psychosocial approach enables a richer understanding of anxiety in the context of dementia by integrating pathophysiological and psychosocial processes within the brain associated with dementia and anxiety, and by looking within the person struggling with dementia. Certain factors associated with the development of dementia and anxiety are fixed, or generally not modifiable, whereas other factors are tractable, or potentially modifiable. Tractable factors could therefore be used in intervention strategies to prevent and manage anxiety in people along with dementia. 


\subsection{Challenges in identifying anxiety in people with dementia}

Identification of anxiety in older people with dementia, especially in cases of moderate to severe dementia, is complicated due the degree of memory impairment, inability to report subjective experiences accurately, physical comorbidities, and overlapping symptoms of dementia and depression, such as difficulty concentrating and tiredness.

Physical illness can mask psychological problems, but psychological problems may also mask physical illness in older people with dementia (Nordhus, 2008). Further, autonomic symptoms of anxiety such as palpitations, hyperventilation, dizziness, and stomach troubles may be misinterpreted as physical morbidities in older people with dementia. Without adequate knowledge of the psychological processes occurring, behavioral symptoms such as restlessness, seeking attention, repetitive behavior, and difficulty sleeping could be identified as symptoms of impaired memory instead of anxiety. As dementia progresses and cognitive functions decline, anxiety may be expressed as behavioral manifestations such as body aches, irritability, restlessness, and agitation (Ferretti, McCurry, Logsdon, Gibbons, \& Teri, 2001; Mega, Cummings, Fiorello, \& Gornbein, 1996; Ownby, Harwood, Barker, \& Duara, 2000; Porter et al., 2003). The impaired cognitive function in severe dementia may limit the patient's ability to express worries as one of the main symptoms of anxiety, as conceptualized in the GAD diagnosis in the DSM-5 and ICD-10.

Nursing home personnel's awareness and understanding of the expression of anxiety symptoms in people with dementia is important to prevent and better manage anxiety in residents with dementia. For dementia patients, subjective affective symptoms may not cluster together as they do in the cognitively intact population (Yesavage \& Taylor, 1991). Therefore, care should be taken in how anxiety symptoms in older people with cognitive impairment are expressed, as they may represent a distinct clinical manifestation of anxiety. It is often difficult to diagnose anxiety disorders in people with dementia (Yesavage \& Taylor, 1991), and the lack of appropriate anxiety assessment scales for this population may further complicate the problem.

\subsubsection{The assessment scales for anxiety in older people with cognitive impairment} Various assessment scales for anxiety have been used to assess anxiety in people with cognitive impairment, with varying sensitivity and specificity according to dementia severity. One assessment scale, the Geriatric Anxiety Inventory (GAI), has been developed to assess anxiety in older people in long-term care (Pachana et al., 2007). Two of the scales developed to assess NPS in dementia, the Behavioral Pathology in Alzheimer's Disease scale 
(BEHAVE-AD) (Reisberg, Auer, \& Monteiro, 1996b), and the Neuropsychiatry Inventory (NPI) (Cummings et al., 1994), also include an anxiety subscale. Both scales assess anxiety based on caregivers' observations. Two assessment scales were specifically designed to assess the severity of anxiety symptoms in people with dementia: the Anxiety in Cognitive Impairment and Dementia (ACID) scale (Gerolimatos et al., 2015), and the Rating Anxiety in Dementia (RAID) scale (Shankar et al., 1999).

Since assessment scales measure different constructs, using different assessment scales in the same population may lead to different results. If the overlap of symptoms in two assessment scales is high, the interchangeable use of the scales may not cause any serious problems (Fried, 2017). On the other hand, use of multiple assessment scales with low overlap or routine use of one particular scale may lead to biased results in research and clinical work-up. An anxiety assessment scale should be able to distinguish anxiety from depression, as both conditions co-exist frequently. The following section of the thesis describes anxiety assessment scales that are widely used in older people with cognitive impairment. Table 1 presents how these scales differ or overlap with each other regarding anxiety symptoms, compared to the GAD criteria of DSM-5 and ICD-10 as reference.

\subsubsection{The Geriatric Anxiety Inventory (GAI)}

The GAI is a self-report assessment scale consisting of 20 dichotomous items (agree/disagree). Its items originated from a variety of anxiety instruments to reflect the primary domains of anxiety, such as worry, anxiety sensitivity, and cognition about anxiety, in older people. The GAI is easy to administer to cognitively intact as well as mildly cognitively impaired older people in a variety of settings, including nursing home and psychogeriatric settings (Pachana et al., 2007). The short form of GAI, the GAI-SF, is composed of five items (items 1, 6, 8, 10 and 11 of the long version) for quicker administration (Byrne \& Pachana, 2011). For both versions, the total score is calculated by summing the scores of each item ( 0 or 1$)$. The score ranges between 0 and 20 for the GAI and 0 and 5 for the GAI-SF, with higher scores indicating more severe anxiety. A clinical cutoff score of above 8 (for the GAI) with a sensitivity of $73 \%$ and specificity of $80 \%$ determines the presence of an anxiety disorder in psychogeriatric units and community-dwelling older populations (Pachana et al., 2007). In a community-dwelling older population, the GAI demonstrated lower psychometric properties when used by participants experiencing cognitive decline compared to when used by participants with intact cognition (Balsamo et al., 2018; Gould, Ponsford, \& Spitz, 2014). Including participants with Mini Mental State 
Examination (MMSE) scores above 18 from residential care facilities, a cut-off score of 9 on the GAI scale indicated a sensitivity of $90 \%$ and specificity of $81 \%$ (Creighton, Davison, \& Kissane, 2018b).

\subsubsection{The Behavioral Pathology in Alzheimer's Disease (BEHAVE-AD)}

The BEHAVE-AD scale is widely used to assess behavioral disturbances in seven major categories, one of which is anxieties and phobias (see Table 1). The caregiver is asked to determine the presence and severity of anxieties and fears from the previous two weeks without knowing specifically what behavioral or emotional symptoms anxieties include. The items are rated on a 4-point scale; 0 (not present), 1 (present), 2 (present, generally with an emotional component), and 3 (present, generally with an emotional and physical component). The scale also assesses a 4-point global severity of behavioral symptoms in terms of disturbance to the caregiver and/or danger to the patient. The reliability of the scale has been found acceptable (Reisberg et al., 1996b).

\subsubsection{The Neuropsychiatric Inventory (NPI)}

The NPI is one of the most common scales used to assess NPS, including anxiety, in people with dementia (Lai, 2014). The symptoms assessment is based on the caregivers' direct observations during the last four weeks. Each symptom is assessed as present or not present, and, if present, the frequency is scored on a four-point scale from 1 (occasionally) to 4 (very frequently), and thereafter the severity is assessed from 1 (mild) to 3 (severe). The score of each symptom is attained by multiplying the frequency and severity scores. The maximum score for each symptom is 12 , and the total score on the NPI scale is obtained by adding the scores of all 12 items, giving a total score between zero and 144. Additionally, the caregiver's perceived distress pertaining to each item of the NPI is scored ranging from 0 (not at all) to 5 (very severe or extreme) (Cummings et al., 1994). The NPI-Questionnaire (NPI-Q) is the short form of the NPI, assessing the same 12 NPS as the original NPI, again based on the caregivers' observations over the previous four weeks (Kaufer et al., 2000). In the NPI-Q, the presence of NPS is scored as "yes" or "no," if yes, the severity of the symptoms is assessed on a three-point scale; 1 (mild), 2 (moderate), and 3 (severe). The total score ranges between zero and 36, where a higher score represents more severe NPS. The NPI-Q is a validated and reliable assessment of NPS and is useful in a busy clinical schedule (Kaufer et al., 2000). The NPI includes a broad spectrum of NPS, which makes interpreting the total score difficult. To study specific NPS item or their association with other variables, several studies have performed factor analyses of the NPI to identify NPI sub-scales (Aalten et al., 2003; Cheng, 
Kwok, \& Lam, 2012; Selbæk \& Engedal, 2012; Van Der Linde, Dening, Matthews, \& Brayne, 2014; Wergeland et al., 2015).

\subsubsection{The Anxiety in Cognitive Impairment and Dementia (ACID) scale}

The ACID scale was developed to assess anxiety in persons over 60 years of age with mild cognitive impairment or dementia and includes both a proxy (ACID-PR) and a self-report (ACID-SR) version (Gerolimatos et al., 2015). The assessment scale includes cognitive, behavioral, and physical symptoms of anxiety in 13 items. The presence of anxiety symptoms is assessed over the previous 24-hour timeframe in a yes/no format. In the presence of a symptom, the distress and interference it caused are also assessed. Items are scored as 0 (symptoms were absent), 1 (symptom present), or 2 (symptom present and associated with distress or interference). The total score ranges from 0 to 26 , and higher scores indicate a higher level of anxiety. ACID-SR is based on the participant's self-report, and is administered as an interview, while the ACID-PR is based on anxiety symptoms observed by proxies. The psychometric properties of ACID were examined in a small sample of older people living in long-term care ( $\mathrm{N}=44$ for ACID-SR and $\mathrm{N}=45$ for ACID-PR). In addition, 38 professional caregivers were included for the proxy information (Gerolimatos et al., 2015).

Compared with the GAI and the NPI-Anxiety, both versions of the ACID demonstrated satisfactory reliability and validity in measuring anxiety among older individuals with cognitive impairment. The ACID-SR scores were more strongly correlated with the GAI scores and with self-reported depression symptoms on the Cornell Scale of Depression in Dementia (CSDD) (Alexopoulos, Abrams, Young, \& Shamoian, 1988), but weaker correlations existed with the NPI-Anxiety scores. The ACID-PR scores were strongly correlated with the NPI-Anxiety scores but weakly correlated with the GAI scores. The scores for both versions of the ACID indicated an insignificant correlation with the cognitive and physical disability assessment scores, representing good discriminant validity. The ACID assesses anxiety independent of cognitive and physical impairment in older people. The ACID-SR and the ACID-PR are weakly correlated with each other, perhaps due to different assessment methods. The authors suggest that self-reported anxiety symptoms are preferable when possible (Gerolimatos et al., 2015). 


\subsubsection{The Rating Anxiety in Dementia (RAID) scale}

Shankar and colleagues (Shankar et al., 1999) developed the RAID scale to assess anxiety symptoms in people with all stages of dementia. The RAID scale includes 20 items, 18 of which can be scored from zero (absent) to three (severe) or U (unable to measure). The total score ranges between zero and 54, with higher scores indicating more severe anxiety. Five items assess worry (worry about physical health, cognitive performance, finances, false beliefs or perceptions, and worry over trifles), and five items assess physical symptoms (palpitations, dry mouth, hyperventilating, dizziness or light-headedness, and sweating). Four items assess apprehension and vigilance (frightened and anxious, sensitive to noise, sleep disturbances, and irritability), and four items assess motor tension (trembling, muscle tension, restlessness, and fatigue). Two items (phobias and panic attacks) are not included in the total score.

Information about the patient's symptoms over the past two weeks is collected from the caregiver, clinical observations, medical records, and the patient himself/herself. For each item, the clinician determines a single score based on this information. A cut-off score of 11 and above provides a sensitivity of $90 \%$ and specificity of $79 \%$ for identifying clinically significant anxiety (Shankar et al., 1999). By using multiple sources of information including the person's own experience, the RAID scale is considered to be one of the most adequate instruments for assessing anxiety in people with dementia (Seignourel et al., 2008).

A comparison of anxiety symptoms at different scales listed in Table 1 indicates that the RAID scale captures the majority of anxiety symptoms with reference to the GAD criteria in the DSM-5 and ICD-10; thus, it has the most research and clinical relevance (for details, see section 9.1.3 of this thesis). 
Table 1. Comparison of anxiety symptoms assessed with different anxiety scales used among people with cognitive impairment, with reference to the GAD criteria of the DSM-5 and ICD-10.

\begin{tabular}{|c|c|c|c|c|c|}
\hline & GAI & $\begin{array}{c}\text { Behave-AD } \\
\text { Anxieties } \\
\text { and phobias } \\
\end{array}$ & $\begin{array}{c}\text { NPI/NPI-Q } \\
\text { anxiety screening } \\
\text { questions } \\
\end{array}$ & $\begin{array}{l}\text { ACID-SR, } \\
\text { ACID-PR }\end{array}$ & $\begin{array}{l}\text { RAID } \\
\text { scale }\end{array}$ \\
\hline \multicolumn{6}{|l|}{ Criteria of GAD by DSM-5 } \\
\hline $\begin{array}{l}\text { *Excessive anxiety and worry / } \\
\text { worries difficult to control }\end{array}$ & $\mathrm{X}$ & $\mathrm{X}$ & $\mathrm{X}$ & $\mathrm{X}$ & $\mathrm{X}$ \\
\hline \multicolumn{6}{|l|}{$\begin{array}{l}\text { Worry and anxiety associated with } \\
\text { at least three: }\end{array}$} \\
\hline $\begin{array}{l}\text { Restlessness or feeling keyed up or on } \\
\text { edge }\end{array}$ & $\mathrm{X}$ & & $\mathrm{X}$ & $\mathrm{X}$ & $\mathrm{X}$ \\
\hline Being easily fatigued & & & & $\mathrm{X}$ & $\mathrm{X}$ \\
\hline \multicolumn{6}{|l|}{$\begin{array}{l}\text { Difficulty concentrating or mind going } \\
\text { blank }\end{array}$} \\
\hline Irritability & & & & $\mathrm{X}$ & $\mathrm{X}$ \\
\hline *Muscle tension & & & & $\mathrm{X}$ & $\mathrm{X}$ \\
\hline Sleep disturbances & & & & $\mathrm{X}$ & $\mathrm{X}$ \\
\hline \multicolumn{6}{|l|}{ Criteria of GAD by ICD-10 } \\
\hline$*$ General and persistent anxiety & $\mathrm{X}$ & & & $\mathrm{X}$ & $\mathrm{X}$ \\
\hline $\begin{array}{l}* * \text { Not associated to any situation, free- } \\
\text { floating }\end{array}$ & $\mathrm{X}$ & & $\mathrm{X}$ & $\mathrm{X}$ & $\mathrm{X}$ \\
\hline Complaints of persistent nervousness & $\mathrm{X}$ & & $\mathrm{X}$ & & $\mathrm{X}$ \\
\hline Shivering/trembling & & & $\mathrm{X}$ & & $\mathrm{X}$ \\
\hline *Muscle tension & & & & $\mathrm{X}$ & $\mathrm{X}$ \\
\hline Sweating & & & & & $\mathrm{X}$ \\
\hline Light-headedness & & & & & $\mathrm{X}$ \\
\hline Palpitations & & & $\mathrm{X}$ & $\mathrm{X}$ & $\mathrm{X}$ \\
\hline Dizziness & & & & & $\mathrm{X}$ \\
\hline Discomfort in epigastrium & $X$ & & $X$ & $X$ & $X$ \\
\hline $\begin{array}{l}\text { *Worries of one's own or family } \\
\text { members' wellbeing }\end{array}$ & $X$ & $X$ & $X$ & $X$ & $X$ \\
\hline
\end{tabular}

*Common criteria of DSM-5 and ICD-10.

**None of the scales have specific items about free-floating anxiety. However, the scales marked as covering this item have questions about anxiety symptoms that are not associated with any specific situation.

\section{Studies of the validity and reliability of the RAID scale}

Few studies to date have tested the validity and reliability of the RAID scale in different populations of dementia patients, instead using different reference standards for a diagnosis of anxiety. The optimal cut-off value is nearly consistent in two of the studies (Shankar et al., 1999; Snow et al., 2012), whereas the reported optimal cut-off value was higher with lower sensitivity in the study by Creighton et al. (Table 2) the authors of which suggest that their cut-off score may not be suitable for screening purposes (Creighton et al., 2018b). One study has translated the RAID scale into Chinese. To our knowledge, the validity and reliability study of Chinese version of the RAID scale is not published. The studies of validity and reliability of the RAID scale are shown in Table 2. 
Table 2. Validity and reliability studies of the Rating Anxiety in Dementia (RAID) scale

\begin{tabular}{|c|c|c|c|c|c|}
\hline Author & Study sample & $\mathbf{N}$ & Reference standard & Validity & Reliability \\
\hline $\begin{array}{l}\text { Shankar et } \\
\text { al. (1999) }\end{array}$ & $\begin{array}{l}\text { Dementia patients } \\
\text { from in- and out- } \\
\text { patient settings, age } \\
62+\end{array}$ & 83 & $\begin{array}{l}\text { GAD by M-DSM-IV and } \\
\text { visual analog scale for the } \\
\text { presence of anxiety } \\
\text { symptoms }\end{array}$ & $\begin{array}{l}\text { Internal consistency, } \\
\text { Cronbach's alpha = } \\
\text { 0.83. Optimal cut-off } \\
\text { value } \geq 11 \text {, sensitivity } \\
90 \% \text {, specificity } 78.5 \% .\end{array}$ & $\begin{array}{l}\text { Inter-rater agreement } \\
\text { (n = 33): from 82\% to } \\
100 \% \text {, kappa for } \\
\text { individual item from } \\
0.51 \text { to1. Test-retest } \\
\text { reliability: from } 84 \% \text { to } \\
100 \% \text {, kappa from } 0.53 \\
\text { to1. }\end{array}$ \\
\hline $\begin{array}{l}\text { Twelftree } \\
\text { \& Qazi, } \\
\text { (2006) }\end{array}$ & $\begin{array}{l}\text { Patients with mild } \\
\text { and moderate CI } \\
\text { attending day hospital } \\
\text { and community } \\
\text { mental health team, } \\
\text { age 64+ }\end{array}$ & 40 & STAI-S & $\begin{array}{l}\text { Internal consistency, } \\
\text { Cronbach's alpha = } 0.79\end{array}$ & Not examined \\
\hline $\begin{array}{l}\text { Cooke et al. } \\
\text { (2010) }\end{array}$ & $\begin{array}{l}\text { Dementia patients } \\
\text { from two aged care } \\
\text { facilities, age } 75+\end{array}$ & 47 & $\begin{array}{l}\text { Self-rated RAID item } \\
\text { scores }\end{array}$ & $\begin{array}{l}\text { Internal consistency, } \\
\text { Cronbach's alpha = } 0.91 \\
\text { (baseline), } 0.85 \text { (mid- } \\
\text { point), } 0.90 \text { (post- } \\
\text { intervention) }\end{array}$ & Not examined \\
\hline $\begin{array}{l}\text { Sung et al. } \\
(2010)\end{array}$ & $\begin{array}{l}\text { Dementia patients } \\
\text { from a nursing home, } \\
\text { age } 65+\end{array}$ & 52 & $\begin{array}{l}\text { Chinese-Taiwanese RAID } \\
\text { item scores }\end{array}$ & $\begin{array}{l}\text { Internal consistency, } \\
\text { Cronbach's alpha }=0.73\end{array}$ & $\begin{array}{l}\text { Inter-rater agreement (n } \\
=5 \text { ) }=90 \% \text {.Translation } \\
\text { of RAID into Chinese } \\
\text { (Chinese version of } \\
\text { RAID not published) }\end{array}$ \\
\hline $\begin{array}{l}\text { Snow et al. } \\
(2012)\end{array}$ & $\begin{array}{l}\text { Mild and moderate } \\
\text { dementia patients } \\
\text { attending primary or } \\
\text { specialized care } \\
\text { clinics, age } 50+\text {, NPI- } \\
\text { A } \geq 4 \text { (completed by } \\
\text { collateral) }\end{array}$ & 32 & GAD by MINI, RAID-SI & $\begin{array}{l}\text { Internal consistency, } \\
\text { Cronbach's alpha = } \\
0.75 . \text { Optimal cut-off } \\
\text { score } \geq 10, \text { sensitivity } \\
90 \%, \text { specificity } 67 \% \text {, } \\
\text { AUC }=0.80\end{array}$ & $\begin{array}{l}\text { Inter-rater }(\mathrm{n}=11) \\
\text { kappa }=0.71\end{array}$ \\
\hline $\begin{array}{l}\text { Creighton } \\
\text { et al. } \\
(2018 b)\end{array}$ & $\begin{array}{l}\text { Residents of aged care } \\
\text { facilities with MMSE } \\
\text { score } \geq 18 \text {, aged } 65+\end{array}$ & 180 & $\begin{array}{l}\text { MINI version } 6.0 \text { for } \\
\text { DSM-5 GAD }\end{array}$ & $\begin{array}{l}\text { Internal consistency, } \\
\text { Cronbach's alpha = } \\
0.85 . \text { AUC = 0.85for } \\
\text { MMSE 18-23 ( } \mathrm{n}=65) \text {; } \\
\text { AUC = 0.88 for MMSE } \\
24-30 \text { ( } \mathrm{n}=115) \text { : Overall } \\
\text { optimal cut-off score } \\
\geq 17 \text { with sensitivity } \\
75 \% \text {, specificity 83.8\%, } \\
\text { accuracy } 82.8 \%, \\
\text { AUC }=0.87\end{array}$ & $\begin{array}{l}\text { Inter-rater }(\mathrm{n}=19) \\
\text { kappa }=0.77\end{array}$ \\
\hline
\end{tabular}

M-DSM-IV = Modified DSM-IV criteria

$\mathrm{CI}=$ Cognitive Impairment

STAI-S = Modified version of the Speilberger State-Trait Anxiety Inventory with yes/no format

NPI-A $\geq 4$ = Neuropsychiatry Inventory-Anxiety subscale score 4 and above

MINI = Mini International Neuropsychiatric Interview

RAID-SI = Rating Anxiety in Dementia-Structured Interview

AUC $=$ Area Under the Curve

MMSE $=$ Mini Mental Status Examination 


\subsection{Anxiety and anxiety symptoms in people with dementia}

\subsubsection{Prevalence}

Anxiety is common among people with dementia, with prevalence rates from 5\% to $21 \%$ for anxiety disorders, mainly GAD, and $8 \%$ to $71 \%$ for anxiety symptoms in various studies from different settings (Seignourel et al., 2008). Anxiety is more common in VaD (Ballard et al., 2000; Porter et al., 2003), FTD (Porter et al., 2003), and LBD than AD (Hynninen et al., 2012). Anxiety is stable in mild and moderate dementia, but declines in severe dementia (Seignourel et al., 2008). In the context of ethnicity, prevalence of anxiety in one study was higher among Latinos and Asians than Caucasians or African Americans (Chen, Borson, \& Scanlan, 2000). Comparing the prevalence of anxiety symptoms among people with dementia from three Chinese university hospitals (two from Taiwan and one from Hong Kong) against one Caucasian sample from an Alzheimer's disease research center in Los Angeles, Chow et al. (2002) assumed that variations in anxiety prevalence were not due to ethnicity.

In a systematic review including 18 studies from nursing homes and residential care facilities with residents 50 years and above with and without dementia, Creighton et al. (2016) reported an overall prevalence of anxiety disorders varying between $3 \%$ to $20 \%$, GAD varying between $<1 \%$ to $11 \%$, and anxiety symptoms varying widely from $7 \%$ to $58 \%$. Anxiety disorders were diagnosed using different criteria or scales determined by cut-off scores, and anxiety symptoms were defined as feelings of anxiety assessed either by self-report or proxy rated scales in different studies in the review by Creighton et al. (2016) which is, to our knowledge the first review of the prevalence of anxiety in residential care facilities in English. The reported prevalence of anxiety disorders and GAD among residential care facilities is higher in Creighton et al.'s study than among community-dwelling older populations (3-14\% and $1-7 \%$, respectively) (Wolitzky-Taylor et al., 2010).

Assessing anxiety symptoms by asking a set of questions from the participants attending a memory clinic with a mean age of 73 years, Ballard et al. reported that $38 \%$ of people with dementia reported "tensions" as an anxiety symptom, 22\% experienced subjective anxiety (worry and fear), 13\% experienced situational anxiety, 11\% experienced autonomic anxiety (physical symptoms of anxiety), and 2\% had panic attacks (Ballard, Boyle, Bowler, \& Lindesay, 1996). Overall, 29\% had one or more anxiety symptoms, and the symptoms of sleep disturbance, restlessness, and irritability were not included as core symptoms of anxiety (by a factor analysis) (Ballard et al., 1996). Assessing anxiety by the RAID scale (RAID score 
$\geq 11$ ) and the Clinical Anxiety Scale (CAS) (CAS score $\geq 30$ ) (Westhuis \& Thyer, 1989), Neville and Teri (2011) reported the prevalence of anxiety to be $11 \%$ and $18 \%$, respectively. Forty-nine percent of those assessed on the RAID and $48 \%$ on the CAS reported one or more anxiety symptoms in the study, which was conducted among older people with dementia in assisted-living facilities (Neville \& Teri, 2011). Differences in the definitions of anxiety and anxiety symptoms, the use of assessment scales, and the study population (institutionalized vs. community-dwelling; ethnicity) may lead to variations in the prevalence of anxiety.

\subsubsection{The course}

Assessing anxiety symptoms by the anxiety subscale of the NPI (Cummings et al., 1994), previous studies have reported ambiguous results in the prevalence of anxiety symptoms over time in people with dementia: a decline in anxiety symptoms over time in people with dementia living in residential care (Bergh \& Selbæk, 2012; Selbæk, Engedal, Benth, \& Bergh, 2013a), an increase in anxiety symptoms over time in community-dwelling studies of people with dementia (Bergh \& Selbæk, 2012), and fluctuations in anxiety symptoms across different studies over time in people with dementia (Van Der Linde et al., 2016). Moreover, these studies do not provide information about the changes occurring in the nature of anxiety symptoms over time or associating factors of anxiety other than cognitive impairment in people with dementia. However, a review by Seignourel et al. (2008) reported that anxiety is relatively stable in mild and moderate dementia, but declines in severe dementia.

There is a scarcity of longitudinal studies investigating the course of anxiety and the changes occurring in anxiety symptoms over time in people with dementia (Creighton, Davison, \& Kissane, 2018a).

\subsubsection{The correlates}

This section of the thesis highlights the studies that have investigated an association of anxiety with demographic, clinical, and psychosocial factors of people with dementia, and in a way is an extension of Section 2.5 of this thesis. To our knowledge, the earliest review examining the correlates of anxiety among residents (aged $\geq 50$ years) of various long-term care is an Australian review that included 34 studies (Creighton et al., 2017). Thirty studies utilized cross-sectional designs, only six of which included participants with dementia. The remaining four studies had prospective/longitudinal designs including participants without dementia (Creighton et al., 2017). 
Demographic correlates: Being younger, female, and having a higher level of education were significantly associated with higher anxiety levels among residents of various long-term care with or without dementia in the review by Creighton et al. (2017), whereas anxiety was not found to be associated with age, gender, or education level in people with dementia in a review that included studies from various settings (Seignourel et al., 2008).

Health related correlates: Assessing anxiety with the NPI-anxiety subscale (NPI-A), Porter et al. (2003) reported that higher anxiety symptoms were associated with severe cognitive impairment among people with AD. In the review by Creighton et al. (2017), an association between higher cognitive functioning and higher anxiety level was the least consistent variable. A more recent study by Creighton et al. (2018a) indicated that lower cognitive functioning was associated with higher self-rated anxiety symptoms assessed on the GAI scale among residents of long-term care with MMSE score of 18 and above.

A higher level of functional impairment in ADL, more pain, more medical diagnoses, more medical specialist consultations, worse self-perceived health, stroke, impaired vision, use of medications such as anticholinergics and antipsychotics (among residents with dementia) or antidepressants, and use of more medications in general were consistently correlated with higher anxiety levels among the residents of long-term care (Creighton et al., 2017; Creighton et al., 2018a). Porter et al. (2003) did not find any association between the presence of anxiety symptoms and the use of anxiolytics, antipsychotics, antidepressants, or anti-dementia medications in their study of community-dwelling patients with dementia. Use of anxiolytics, presence of chronic obstructive pulmonary disease, and impaired hearing were not associated with anxiety among the residents of long-term care (Creighton et al., 2017), whereas both anxiety and depression were strongly associated with use of multi-psychotropic medications in a large Norwegian nursing home cohort followed up at seven years (Gulla et al., 2016).

Psychological and social correlates: Relocating to a more dependent living facility compared to an independent living facility, residing at a care facility for longer, negative life events, lacking social support, memory and communication problems, poor patient-caregiver relationships, fear of falling, lacking daytime activity, increased number of behavioral problems including sleep disturbance and wandering, and low self-perceived QoL have all been associated with higher levels of anxiety in people with dementia (Creighton et al., 2017; Gibbons et al., 2002; Hoe et al., 2009; Orrell \& Bebbington, 1996; Selwood, Thorgrimsen, \& Orrell, 2005; Teri et al., 1999). 
Correlation with depression symptoms: Symptoms of depression could be due to psychological and/or biological causes and are highly correlated both with self- and proxyrated anxiety symptoms in older people with dementia, a consistent finding across the studies (Creighton et al., 2017; Creighton et al., 2018a; Hynninen et al., 2012; Seignourel et al., 2008).

Studies investigating an association between anxiety and other variables vary from each other, and with variations in the results. The most consistent correlate of anxiety is depression across the research.

\subsection{The prevalence and course of depression in people with dementia in nursing homes}

Since anxiety is highly associated with depression across populations, studying the prevalence and the course of depression in people with dementia living in nursing homes is relevant in context of this thesis. Depression both as symptoms and clinically significant is more common among people with dementia than those without (Forsell \& Winblad, 1998; O'Brien, 2005), including across various settings of people with dementia (Van Der Linde et al., 2016). A study by Ballard et al. reported the prevalence of clinically significant depression (NPIDepression score > 3) to be $18 \%$, incidence $11 \%$, and the persistence and remission both by $32 \%$ at one-year follow-up among residents with dementia from long-term care (Ballard et al., 2001). Assessing clinically significant depression (CSDD score > 12) among people with dementia in a long-term care facility, Payne et al. (2002) reported the prevalence of depression to be $20 \%$ on admission, $6 \%$ at six months, and $5 \%$ at 12 months, with an incidence of $2 \%$ at six months and $6 \%$ at 12 months. The authors report that only $8 \%$ of the participants who were depressed on admission were still depressed at 12 months, and most of the participants with new depression at 6 months were no longer depressed at 12 months. Assessing depressive symptoms by CSDD, a Norwegian nursing home study including residents with and without dementia ( $77 \%$ and $23 \%$, respectively) reported the prevalence of clinically significant depression (CSDD score $\geq 8$ ) to be $21 \%$ at baseline and at 12 -month follow-up, with incidence of $15 \%$ and persistence of $45 \%$ at 12-month follow-up (Barca, Engedal, Laks, \& Selbæk, 2010a).

Considering only the studies from long-term care, the prevalence of depression symptoms among people with dementia was reported to be between $8 \%$ and $22 \%$ in two reviews (Bergh 
\& Selbæk, 2012; Van Der Linde et al., 2016). Including 25 cross-sectional and seven longitudinal studies in a systematic review by Selbæk at al. (2013b), the prevalence of depression symptoms were reported to be $28 \%$ (studies that used scales other than the NPI scale) and 20\% (for studies that used NPI to assess symptoms of depression) among nursing home patients with dementia. The incidence rate of depression symptoms varied from 3-14\%, and the persistence of depression symptoms ranged widely from $0-85 \%$ in the systematic review by Selbæk et al. (2013b). 


\subsection{Dementia and quality of life}

Dementia disorders have a negative impact on many aspects of peoples' lives and their families. Future treatment may reduce the burden dementia has on the person and his/her family. With longer life expectancy and an increase in the number of people with dementia, one of the Norwegian government's goals in dementia care is to facilitate a more dementiafriendly society (Ministry of Health and Care Services, 2015) so that people with dementia and their families are able to maintain optimal quality of life (QoL) throughout the dementia trajectory. Research on QoL for people with dementia was built on the assumptions that people with dementia will not be able to report their QoL reliably, but during recent years, QoL has become an important outcome in dementia care and treatment in all settings (Beerens et al., 2013).

\subsection{Theoretical aspects of dementia and quality of life}

There is no widely accepted or supported theory of QoL, but there is consensus that a person's QoL has multidimensional aspects including physical and mental health, social relationships, and the environment (WHOQOL Group, 1998). According to the definition by the WHO, an individual's QoL is based on the person's subjective experience of life, objective criteria in the context of culture, and the values of the society in which the person lives (WHO, 1995). However, QoL aspects may vary with the population under study, such as people with chronic diseases, and the purpose of the research being conducted (Ettema et al., 2005; Jonker, Gerritsen, Bosboom, \& Van der Steen, 2004; Missotten, Dupuis, \& Adam, 2016).

As for the general population, QoL in the context of dementia also has multidimensional aspects, as it is evaluated by the person itself and by social normative criteria (Lawton, 1994). Lawton's concept of QoL, which is widely used in dementia research, distinguishes four sectors of QoL that overlap with each other to some extent (Abel, 2017; Jonker et al., 2004; Lawton, 1994). Lawton's sector behavioral competence includes physical health, activities of daily living (evaluated by an observer using normative criteria), cognitive functioning (evaluated by neurological testing), and social behavior (evaluated by different scales or with social interaction). However, these variables are not considered central components of QoL in dementia, as these aspects of functioning are strongly influenced by the dementia (Jonker et al., 2004; Rabins \& Kasper, 1997). Another sector is objective environment - including material possessions, social support, network, and the physical environment in which the person lives. According to Lawton, both sectors - behavioral competence and objective environment - generate objective data about a person's QoL that can be provided by the 
caregivers or family (Lawton, 1994). The last two sectors, domain-specific perceived QoL and psychological wellbeing, concern the subjective perception of the individual's QoL. Domainspecific perceived $Q o L$ relates to the degree of satisfaction and happiness with all important life domains, such as social functioning, recreational activities, housing and income (Ettema et al., 2005; Lawton, 1994). Psychological wellbeing is the subjective evaluation of the overall quality of the person's inner experience (Lawton, 1994).

Lawton and other authors of dementia-specific literature consider that psychological wellbeing, or a general feeling of wellness, to be a central indicator of QoL, as the various sectors will have their individual contribution to the psychological wellbeing of each individual with dementia (Abel, 2017; Brod, Stewart, Sands, \& Walton, 1999a; Jonker et al., 2004; Lawton, 1994, 1997). Brod et al. (1999a) have described five aspects of psychological wellbeing: a sense of aesthetics (ability to enjoy sensory stimuli, such as touch and listening to music), positive and negative affects, self-esteem, and feelings of belonging. Based on focus group interviews with professional caregivers, Rabins et al. (Rabins, Kasper, Kleinman, Black, \& Patrick, 1999) further modified the aspects of psychological wellbeing to assess the QoL of patients with $\mathrm{AD}$, adding enjoying recreational activities, response to surroundings, social interaction, awareness of self, and emotions. The authors considered two of the aspects of psychological wellbeing, enjoying recreational activities and response to surroundings, to be more dementia-specific, especially in patients with severe dementia, than the three others, namely social interaction, awareness of self, and emotions (Jonker et al., 2004; Rabins et al., 1999).

\subsection{Assessing quality of life of people with dementia in nursing homes}

One of the important aspects of QoL is the subjectivity. There is evidence that people in the early stages of dementia often can express their QoL (Brod, Stewart, \& Sands, 1999b; Jonker et al., 2004; Mozley et al., 1999; Selwood et al., 2005; Trigg, Jones, \& Skevington, 2007). For people in the later stages of dementia, communicating subjective experiences is challenging due to increased impairment in cognition and difficulty communicating. Most nursing home residents with dementia have moderate to severe dementia. Therefore, observation of the behavior of a person with moderate to severe dementia could be a window into their QoL (Abel, 2017; Lawton, 1994). For example, behavior such as smiling, enjoying participating in 
activities, or sadness/crying is observable by caregivers. A proxy-rated assessment scale of QoL based on direct observations of the person's behavior and emotions such as the Quality of Life in Late-Stage Dementia (QUALID) is considered appropriate to assessing QoL in persons with later stages of dementia, especially those residing in nursing homes (Weiner et al., 2000). Development of the QUALID items was based upon consensus between experienced clinicians in the field of late-stage dementia, and signs of psychological wellbeing such as smiling, crying, enjoying being touched, facial expressions, and social interactions were included (Weiner et al., 2000).

In paper IV of the present thesis, QoL was assessed with the Norwegian version of QUALID, which indicated acceptable psychometric properties in assessing the QoL of people with dementia living in Norwegian nursing homes (Røen et al., 2015). QUALID has 11 items that assess both positive and negative dimensions of behaviors considered to be indicative of QoL. Each item is rated from 1 to 5; the minimum score is 11 and indicates best QoL, and the maximum score is 55 and indicates the poorest QoL. QUALID is administered as a structured interview of the caregiver based on his/her direct observations of the person over the previous seven days (Weiner et al., 2000). QUALID is sensitive to changes in QoL over a time period, yielding valid longitudinal measures of proxy-rated QoL (Martin-Cook, Hynan, Rice-Koch, Svetlik, \& Weiner, 2005; Mjørud, Røsvik, Rokstad, Kirkevold, \& Engedal, 2014).

\subsection{Factors affecting quality of life in people with dementia}

Memory problems are often the first symptoms of most dementia disorders that negatively affect one's daily life, thereby affecting his/her QoL. One systematic review and one metaanalysis of QoL indicate that more than 300 studies have investigated various factors affecting the QoL of people with dementia, and the majority of these studies are cross-sectional with a scarcity of longitudinal studies (Beerens et al., 2013; Martyr et al., 2018). These studies have reported that poor physical and mental health, including depression and other NPS such as agitation, are associated with poor QoL in people with dementia, a consistent finding across studies (Beerens et al., 2013; Martyr et al., 2018). From the perspectives of people with dementia, mood factors, wellbeing versus illness, and happiness versus sadness were reported as important variables related to their QoL (O'Rourke, Duggleby, Fraser, \& Jerke, 2015). The evidence of association between anxiety and QoL in people with dementia is limited (Banerjee et al., 2006; Hoe, Hancock, Livingston, \& Orrell, 2006; Hoe et al., 2009; Selwood et al., 2005). To our knowledge, only two longitudinal studies have reported an association 
between anxiety and QoL over time in people with dementia, and their findings are ambiguous (Hoe et al., 2009; Selwood et al., 2005). Anxiety was not controlled for depression or other variables of interest in the study by Selwood et al. (2005), while anxiety was associated with self-rated poor QoL but not with proxy-rated poor QoL at 20-week follow-up in the study by Hoe et al. (2009). Since anxiety represents many negative outcomes in people with dementia, it is crucial to gain more knowledge about how anxiety is associated with QoL over time in nursing home residents with dementia. 


\subsection{Caring for people with dementia, anxiety, and anxiety symptoms: a multidisciplinary approach}

Since anxiety and anxiety symptoms are highly prevalent among nursing home residents with dementia and are difficult to identify among older people in severe stages of dementia, healthcare personnel's awareness and skills in identifying anxiety symptoms in this population are crucial in preventing and intervening in anxiety. The interplay of biological and psychosocial factors as illustrated in Figure 2 should be taken into consideration with a multidisciplinary approach in the management of anxiety in each individual person. Since anxiety and depression often co-occur in people with dementia, assessment of both anxiety and depression symptoms by dementia-specific scales is suggested at the indication of disruptive behavior.

Biological interventions:

- Knowledge of resident's medical history and management of anxiety risk factors

- $\quad$ Adequate management of infections and pain

- Critical review of medications use

- Appraisal of cholinesterase inhibitors, antidepressants, and anxiolytics, if needed

- $\quad$ Provision of sensory aids: glasses and hearing aid

- Physical activity*

- Multi-sensory stimulation*
Psychosocial interventions:

- Knowledge of resident's likes and dislikes, social history, and prevention of anxiety risk factors

- Adjustment of environment, care in special unit (PLST model)

- Dementia-sensitive attitude of the staff and person-centered approach

- Assessment of anxiety and depression symptoms by dementia-specific scales

- $\quad$ Social support and engagement in social and physical* activities.

- $\quad$ Cognitive stimulation therapy, music therapy, reminiscence, validation, and multi-sensory stimulation*

Figure 2. Biopsychosocial approach for the management of anxiety and anxiety symptoms in people with dementia.

*Overlapping of interventions

A person-centered approach proposed by Kitwood (1997) should be the base of interventions to improve the well-being and QoL of people with dementia, and non-pharmacological approaches should be used first (Douglas, James, \& Ballard, 2004; Edvardsson et al., 2008; Rokstad et al., 2013; Rosvik, Kirkevold, Engedal, Brooker, \& Kirkevold, 2011). Knowledge of the person's medical and social history and identification of risk factors such as misuse of alcohols and benzodiazepine could be of importance to initiate appropriate interventions to manage anxiety symptoms (Johannessen, Helvik, Engedal, \& Sørlie, 2016). Biomedical interventions such as a thorough medical examination of the older person to exclude any 
underlying cause of anxiety and treatment of infections, physical and mental diseases, and pain in people with dementia may prevent and reduce anxiety symptoms. A regular critical review of resident's medication use in general and use of antipsychotics in particular is important to ensure that he/she does not receive unnecessary medications, as they may cause delirium, restlessness, and other side effects among people with dementia (Douglas et al., 2004; Fog et al., 2017; Halvorsen et al., 2017). A large Australian prospective longitudinal study conducted a multidisciplinary intervention program comprised of case review, medication review, and staff education and reported a $13 \%$ decline in antipsychotic prescriptions and a $21 \%$ decrease in benzodiazepine prescriptions at 6-month follow-up among the residents of aged care facilities (Westbury et al., 2018). Use of cholinesterase inhibitors, anxiolytics, and antidepressants combined with psychosocial interventions may be evaluated, especially for severe anxiety symptoms and comorbidity with depression (Badrakalimuthu \& Tarbuck, 2012; Gustafson, 1995; Shankar \& Orrell, 2000).

Dementia care in small, well-structured units, preferably with the same caregivers, may compensate for deficits in the person's reality and object constancy due to dementia, thus reducing insecurity and anxious behavior (PLST model). Caregivers must reduce the number of situations in which the patient's deficits are challenged unnecessarily, accepting impairments without unnecessary corrections (Smith et al., 2006). Improvement of visual and hearing impairments by use of glasses, hearing aids, and adequate light may be helpful in reducing misinterpretations of visual and auditory stimuli, thereby reducing anxiety symptoms. Meeting the patient's needs therapeutically and reacting appropriately can be complex and challenging at times, but this perspective may help caregivers establish approaches to reduce anxiety and anxiety symptoms in people with dementia. Otherwise, there is a risk that patient's anxious reactions are deemphasized or treated with medicine without understanding other therapeutic approaches (Ballard et al., 2009). The Targeted Interdisciplinary Model for Evaluation and Treatment of Neuropsychiatric symptoms (TIME), person-centered care, social interaction, and staff education approaches are found to be effective in the reduction of agitation, affective symptoms, and improving QoL among nursing home residents with dementia (Ballard et al., 2018; Lichtwarck et al., 2018; Rokstad et al., 2013).

From the perspectives of self-psychology, memories can remind a person with dementia of a time when he/she felt more competent, vital, and significant. Reminiscence therapy has been 
shown to positively affect mood, communication, cognition, well-being, and QoL among people with dementia (Woods, O'Philbin, Farrell, Spector, \& Orrell, 2018). Validation therapy is about attempting to communicate with the person with dementia by empathizing with the feelings hidden behind his/her confused behavior rather than the person's orientation to the present (Miesen \& Jones, 2006). Reflecting on the resident's desire to see long deceased parents may be more comforting than confronting the resident with the reality of loss. Implementing a group music intervention and individualized music preference interventions for residents with dementia in long-term care, two studies reported a significant reduction in the residents' anxiety symptoms compared to the residents who received standard care (Sung et al., 2010; Sung, Lee, Li, \& Watson, 2012). Information on the resident's life history is important in validation and music therapy and may help to reduce anxiety-like symptoms of unfamiliarity and isolation anxiety such as repetitive behavior, wandering and attention seeking (Cohen, 1998).

The anxiety and depression caused by dramatic life events in an older person's life may be relieved to some extent by providing psychosocial interventions such as adequate social support (Orrell \& Bebbington, 1996), cognitive stimulation therapy, psychomotor therapy, and other personalized activities that may help people with dementia in improving and maintaining their well-being (McClive-Reed \& Gellis, 2011; Orgeta, Qazi, Spector, \& Orrell, 2015). Multi-sensory approaches including bright light therapy, tactile stimulation, aroma therapy, and garden therapy have been shown to have positive effects on anxiety symptoms such as sleep disturbances, restlessness, and irritability/agitation, improving the QoL of people with dementia (Douglas et al., 2004; Kirkevold \& Gonzalez, 2012; Skovdahl et al., 2007). Encouragement to participate in physical activities such as going for a walk may improve residents' general physical health, QoL, and well-being (Edwards, Gardiner, Ritchie, Baldwin, \& Sands, 2008; Telenius, Engedal, \& Bergland, 2013). This list of psychosocial interventions is not exhaustive.

A caregiver's ability to sense how much activity and stimuli an individual can tolerate and promote engagement in meaningful, person-oriented activities to increase the residents' control over their environment may prevent and reduce anxiety and anxiety symptoms (Creighton et al., 2017; Hancock et al., 2006). A nurse with knowledge about the residents and sensitivity towards the changes occurring in their lives may better determine the presence of anxiety symptoms, as anxiety in older people with dementia was associated with the staff's skills and competence in providing care (Neville \& Teri, 2011). 


\subsection{Summary}

Anxiety is common in people with dementia as a symptom and as a disorder. NPS is highly prevalent among nursing home residents with dementia, and the use of antipsychotics is widespread, although decreasing. The interplay of biopsychosocial factors may be the cause of anxiety and anxiety symptoms among people with dementia. Person-centered care and nonpharmacological approaches should be the first interventions in the management of anxiety in people with dementia. There is a scarcity of studies examining the clinical course of anxiety, anxiety symptoms, and their correlates in elderly people in general and in people with dementia in particular. There is also a knowledge gap of the course of anxiety symptoms and their association with other factors, especially the association of anxiety and depression over time in people with dementia in nursing homes. Knowledge is also scarce about how anxiety is associated with QoL over time in people with dementia. 


\subsection{The aims of the thesis}

To address the above-mentioned knowledge gap, the overall aims of this thesis were to validate the Norwegian version of the RAID scale (RAID-N) in people with dementia living in Norwegian nursing homes, and to study the occurrence and course of anxiety, anxiety symptoms, and their correlates by using the RAID-N in this population. Further, we wanted to study how anxiety is associated with QoL over time in people with dementia in nursing homes. We hypothesized that anxiety is more prevalent in people with dementia of mild and moderate degree compared to dementia of severe degree, and that anxiety is associated with reduced ADL functions, general physical health, and increased NPS of dementia.

In the present thesis, clinically significant anxiety is defined as a score of $\geq 12$ on the RAID$\mathrm{N}$, and is in accordance with the cut-off score reported in the validation study, study I of this thesis (Goyal, Bergh, Engedal, Kirkevold, \& Kirkevold, 2016b). The presence of one or more items on the RAID-N is defined as anxiety symptoms. Depression is defined as a cut-off score of $\geq 10$ on the CSDD, and is in accordance with the cut-off score reported by Barca et al. (2010).

The specific aims of this thesis, which resulted in four papers, were:

1. To translate the Rating Anxiety in Dementia (RAID) scale into Norwegian and to investigate the validity and inter-rater reliability of the Norwegian version of the RAID scale (RAID-N) among people with dementia living in nursing homes (study I).

2. To examine the prevalence of (clinically significant) anxiety and anxiety symptoms assessed with the RAID-N. Further, to explore the association of anxiety with comorbid depression and demographic and other clinical variables, including NPS and use of psychotropic medications, among people with dementia living in Norwegian nursing homes (study II).

3. To investigate the course of anxiety and anxiety symptoms assessed with the RAID-N at a 12-month follow-up in people with dementia in Norwegian nursing homes, and to explore the association with comorbid depression and demographic and other clinical variables by studying changes in the RAID-N scores from baseline to 12-month follow-up in people with dementia in Norwegian nursing homes (study III).

4. To identify possible groups of people with dementia in nursing homes with different trajectories of proxy-rated quality of life (QoL), and to explore how anxiety and other 
characteristics were associated with these trajectories of QoL. In addition, we wanted to investigate the association between participants' baseline and follow-up characteristics with QUALID scores at a 12-month period in people with dementia in nursing homes (study IV). 


\subsection{Methods}

\subsection{Study design}

A quantitative, observational design was used in the four studies of this thesis. A crosssectional design was used to study the validity and reliability of the RAID-N (study I), the prevalence of anxiety and anxiety symptoms, and their associations with other variables (study II). A prospective longitudinal design with a second assessment at 12 months was used: to study the course of anxiety, anxiety symptoms, and their associations with other variables (study III); to identify the trajectories of QoL; and to study an association between participants' baseline and follow-up characteristics with QUALID scores (study IV).

\subsection{Participants}

The inclusion criteria for all four studies in the present thesis were men and women 65 years and above living in nursing homes on a long-term basis and having a dementia diagnosis documented in their medical records. Residents who were terminally ill, had schizophrenia, or did not speak or understand Norwegian well (linguistic background) were excluded from the study.

\subsubsection{Recruitment}

Twenty-one nursing homes from two counties in southeastern Norway were approached to recruit participants for the studies of this thesis. Four of the nursing homes were unable to recruit participants: two were under reorganization, and two were lacking resources. Of 483 potential participants from 17 nursing homes ( 6 with $<25$ beds, 6 with $25-50$ beds, and 5 with $>50$ beds), 298 residents were recruited for the studies of this thesis (see Figure 3).

Participants were recruited by the nursing homes' lead nurses or doctors.

\subsubsection{Participants in the validity and reliability study of the RAID-N}

Of 298 residents, 101 residents from seven of the 17 nursing homes participated in the validity and reliability study of the RAID-N. A subgroup of 53 residents, 50 from the validity study and three from the study on the prevalence of anxiety (study II), participated in the inter-rater reliability study of the RAID-N (study I). 


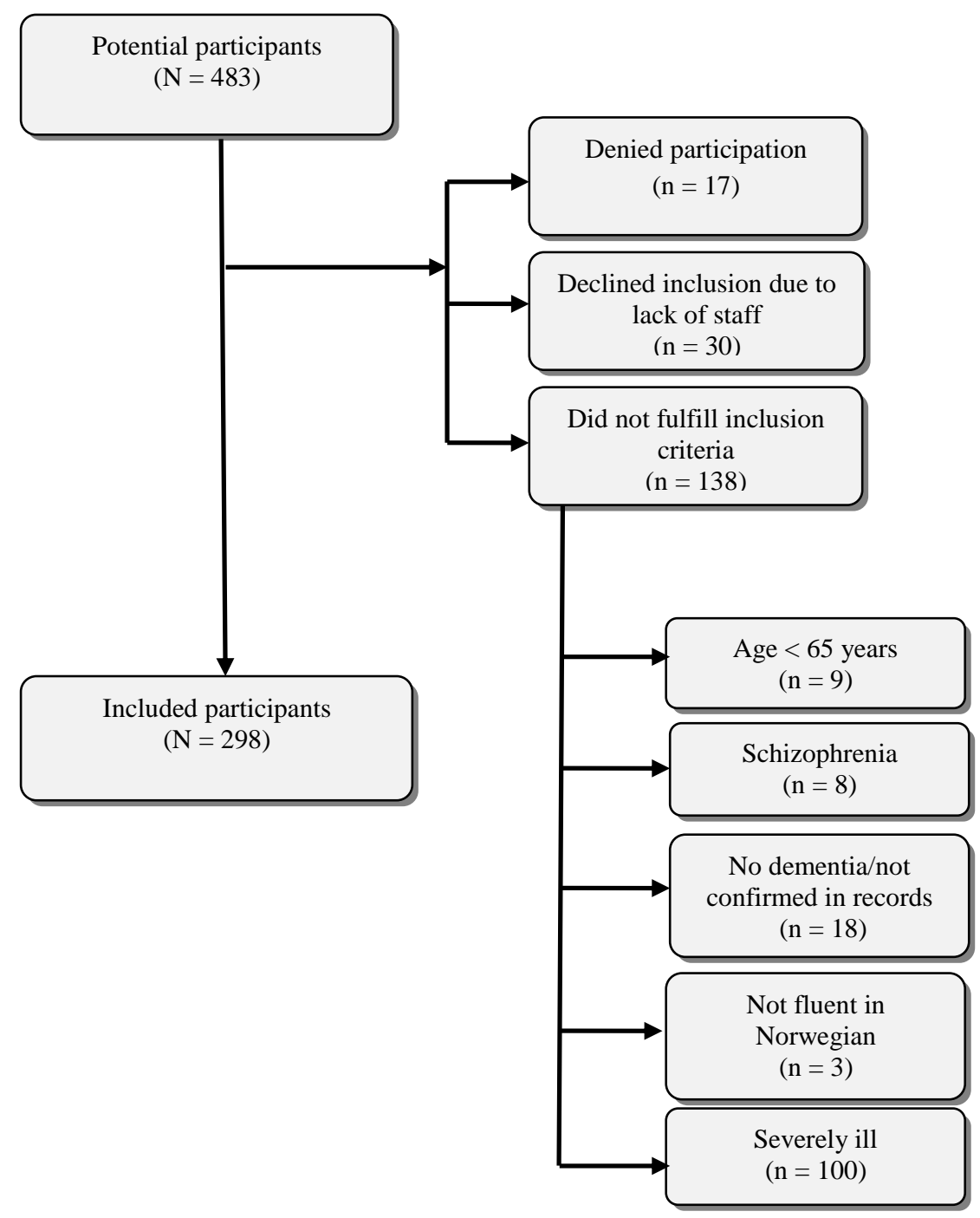

Figure 3. Flowchart of the participants 


\subsubsection{Participants in the three studies of the thesis}

In total, 298 residents, including the 101 residents from the validity study, participated in the cross-sectional study (study II). Of these, 205 participants were followed-up after 12 months, with a mean follow-up period of 350 days (SD 12.3) (study III). The attrition of 93 participants (31.2\%) from baseline to follow-up was due to death. Participants in the crosssectional and follow-up studies were included in the QoL study (study IV).

\subsection{Translating the Rating Anxiety in Dementia (RAID) scale}

The RAID scale was first translated into Norwegian by a native experienced geriatrician, and translated back into English by a specialized and experienced nurse in psychogeriatric medicine who is a native English speaker and did not have exposure to the original RAID scale. The back translation was sent to the author of the RAID scale for feedback. A slight alteration was made to the Norwegian version of the RAID (RAID-N) to achieve a conceptual equivalence between the original RAID scale and the RAID-N. By assessing eight Norwegian patients with and without dementia from a psychogeriatric unit, the RAID-N was pilot tested for language clarity by three raters (a psychologist, a psychiatric nurse and the $\mathrm{PhD}$ student of the present thesis). The patients received verbal information about the purpose of testing the scale and about their anonymity. The patients provided their oral consent for pilot testing the RAID-N. This translation process corresponds with the guidelines suggested by Maneesriwongul and Dixon (2004). The RAID-N was found to be easy to understand, and thus, no further alterations were made to the scale, which was used in all four studies of the present thesis. As described in study I, the raters' comments were taken into consideration in developing the guidelines for administering the RAID-N before conducting the validity and reliability study.

\subsection{Inter-rater reliability of the RAID-N}

The $\mathrm{PhD}$ student of the present thesis (rater A) and a nurse at one of the participating nursing homes who had many years of clinical experience of working with people with dementia (rater B) conducted the inter-rater assessments of the RAID-N. To obtain a mutual understanding of the RAID-N items between raters A and B, pilot interviews with two residents were conducted before the onset of the reliability study. The raters interviewed the participants and their caregivers separately. In case the staff had a shortage of time, the interview with the caregiver was conducted in the presence of both raters $(n=8)$. The second 
rater asked questions for clarification. Any relevant information related to the RAID-N items was collected from the participant's record over the past two weeks. Participants' information was taken into account, including symptoms of palpitations, dry mouth, dizziness or lightheadedness, or if the caregiver was uncertain about the information. The two raters made their final assessments of the RAID-N items independently.

\subsection{Administration of the RAID- $\mathrm{N}$ in the validity study}

After receiving training from the $\mathrm{PhD}$ student of the present thesis in administering the RAID$\mathrm{N}$, and using the standardized guidelines for the administration of the RAID-N, the primary nurses of 51 participants administered the RAID-N. Assessments for the remaining 50 participants were taken from the inter-rater assessments conducted by rater A.

\subsection{Procedure for the diagnosis of dementia, GAD, and depression in the validation of the RAID-N}

DSM-5 criteria were used as the "gold standard" for the diagnoses of dementia, GAD, and depression in the validity study of the RAID-N. The diagnoses were made either by the psychogeriatrician $(n=50)$ or by one experienced general practitioner with special interest in treating old people $(n=51)$, using the criteria of the diagnoses of a major or mild NCD due to $\mathrm{AD}$ or other subtypes of dementia, MDD, and persistent depressive disorder (dysthymia). To achieve a mutual understanding of the diagnostic procedure of GAD, the general practitioner consulted the psychogeriatrician before the onset of the assessments. Diagnosis of GAD was made by summarizing the relevant information from three sources:

1. Interview with the participant.

2. The participant's medical records.

3. Interview with the participant's primary nurse.

The diagnoses were made within a week of the RAID-N scale assessments, and the doctors were blind to the scores on the RAID-N scale. If a participant had a previous anxiety diagnosis documented, but no anxiety symptoms during the last six months, a diagnosis of GAD was not made. Whether the participant required treatment or not was decided based on the severity of the GAD. 


\subsection{Data collection}

Before data collection, the primary and auxiliary nurses of the participating nursing homes received 2-3 hours of training in administering the assessment scales to ensure a common application. The assessment scales were administered by the participants' primary nurses (in total, 57 nurses) or by the $\mathrm{PhD}$ student of the present thesis. The primary nurses scored the assessment scales based on their direct observations of the residents, and a short interview with the resident for the assessments of RAID-N and CSDD scales. The PhD student interviewed the participants' primary caregiver and the participants for the assessments of the RAID-N and CSDD scales. Participants' data, including age, gender, marital status, education, length of stay in nursing homes, dementia, other diagnoses, and regular use of medications, were collected from the participants' records.

Data was collected: between September 2014 and April 2015 for the validity and reliability study of the RAID-N; between August 2014 and November 2015 for the cross-sectional study; and between September 2015 and September 2016 for the follow-up study. The mean interval for the follow-up was 350 days (SD 12.3).

\subsubsection{Other assessment scales used in data collection}

The Mini-Mental State Examination-Norwegian Revised Version 2 (MMSE-NR2)

The MMSE-NR2 is a screening test to assess cognitive function and to detect impairment (Folstein, Folstein, \& McHugh, 1975; Strobel \& Engedal, 2014). The minimum score on the MMSE-NR2 is 0 and the maximum score is 30. A higher score indicates better cognitive function (Folstein et al., 1975; Strobel \& Engedal, 2014). Due to missing data on MMSE-NR2 (6.9\% of the participants in the validity study; $9.4 \%$ in the cross-sectional study; and $17.1 \%$ in the follow-up study), the MMSE-NR2 scores were analyzed only in the validity and reliability study of the RAID-N (paper I). Missing data was due to progressive dementia or significantly impaired vision and hearing of the participants.

\section{Clinical Dementia Rating (CDR) scale}

The CDR is used to determine the severity of dementia based on proxy information (Hughes, Berg, Danziger, Coben, \& Martin, 1982). The CDR assesses six items individually: memory; orientation (time, place, and person); problem solving, community affairs; home and hobbies; and personal care (Hughes et al., 1982). Each of the items has five possible answers with scoring from zero to three, which means the CDR-sum of boxes (CDR-sob) scores can range 
from zero to 18.0. Scores in the 4.5-9.0 range indicate mild dementia, 9.5-15.5 show moderate dementia, and 16.0-18.0 denote severe dementia (O'Bryant et al., 2008). The scale can also be used as a categorical variable $(0=$ no dementia, $0.5=$ possible dementia, $1=$ mild dementia, 2 = moderate dementia, 3 = severe dementia) (Hughes et al., 1982). In all four studies of this thesis, the continuous variable CDR-sob has been used, which correlates highly with the categorical score of CDR (in the cross-sectional study of the present thesis $r=0.877$ ) (O'Bryant et al., 2008). The scale has been found to be valid and reliable in Norwegian nursing-home populations (Engedal \& Haugen, 1993).

\section{Cornell Scale for Depression in Dementia (CSDD)}

The CSDD is widely used to assess depressive symptoms among people with dementia (Alexopoulos et al., 1988). The Norwegian version of the CSDD was used to assess depressive symptoms (Barca et al., 2010b). The CSDD is scored using an interview with the participant and a report from the primary caregiver based on direct observations. It has 19 items assessing depressive symptoms over the past week. The total score ranges between zero and 38, where a higher score denotes more severe depression, and a score $\geq 10$ indicates clinically significant depression for nursing home residents (Barca et al., 2010b).

\section{Neuropsychiatric Inventory's Brief Questionnaire (NPI-Q)}

The NPI-Q with 12 items was used to assess the severity of NPS based on caregivers' observations over the previous month (Kaufer et al., 2000). The NPI-Q score ranges between zero and 36, where a higher score represents more severe NPS (Kaufer et al., 2000).

\section{Physical Self-Maintenance Scale (PSMS)}

Lawton and Brody's PSMS was used to assess participants' basic activities of daily living (ADL). The PSMS is scored based on the caregivers' observations over the past week (Lawton \& Brody, 1969). The total score ranges between 6 and 30, and a higher score indicates more severe functional impairment.

\section{General Medical Health Rating (GMHR)}

The participants' general physical health was assessed by the GMHR including four categories, excellent, good, fair, and poor, based on the participant's present physical health status and the prescription of regular medication (Lyketsos et al., 1999). 


\subsection{Ethical considerations}

The present study was approved by the Regional Committees for Medical and Health Research Ethics in South-East Norway (ref. 2012/1958) in July of 2014. The declaration of Helsinki (World Medical Association, 2013) principles of informed consent were followed in the present thesis. To be able to give informed consent, the participant must have the ability to understand a sufficient amount of information and the consequences of taking part in the research. They should also understand their right to withdraw at any point (Hellström, Nolan, Nordenfelt, \& Lundh, 2007). Such an approach could exclude people with dementia from the participation in research, as due to cognitive decline their understanding of the consequences of involvement in research declines.

Excluding nursing homes residents with dementia from research may deprive them of possible benefits of research. Therefore, it is morally unacceptable not to do research with people with dementia who do not have the capacity of informed consent due to progressive cognitive impairments (Slaughter, Cole, Jennings, \& Reimer, 2007). On the other hand, this is a very vulnerable group of people whose fundamental right of freedom to participate could be easily exploited for the sake of improving scientific knowledge (Agarwal, Ferran, Ost, \& Wilson, 1996).

The information provided to people with dementia should be modified to the person's cognitive ability, and he or she should be comfortable with the situation by providing adequate time, conversations and observations (Nordhus, Skjerve, \& Aasen, 2006). This will maximize the potential of real choice and is a benchmark for good practice (Hellström et al., 2007; Nordhus et al., 2006). The competence to consent depends on what the person with dementia is being asked to do. According to the Act on medical and health research (the Health Research Act) paragraph 17, competence to give consent, for persons who lack competence to give consent, the person's next-of-kin have authority to grant consent (Ministry of health and Care Services, 2008) and are most commonly family members.

Based on Health Research Act, paragraph 18, Conditions for research including people who lack competence to give their consent, the following conditions should be met; a) potential risks or disadvantages of research for the person are insignificant; b) the person would not have denied to participate if he/she had the capacity to give consent; c) there is reason to assume that results of the research are beneficial for the person involved and other people 
with the same-age-specific disorder, and similar research cannot be done on people who have the capacity to give consent (Ministry of health and Care Services, 2008). The present study has no side effects due to its observational design in a natural clinical setting and minimum potential discomfort due to participating. Most of the assessment scales are based on healthcare personnel's observations, except for the RAID-N and CSDD scales, which require a short interview with the participant if possible in addition to healthcare personnel's observations. Consent in dementia research should be considered a continuous process over time based not only on verbal language but also on non-verbal and behavioral cues (Agarwal et al., 1996).

Based on present study's inclusion and exclusion criteria and judging the potential benefits, potential residents for recruitment were identified either by the nursing homes' leading nurses or by the nursing homes' doctors. They provided information about the study to the potential residents and their authorized family members. The participants' capacity to consent to participate in the studies of the thesis was judged by the participants' primary nurses in cooperation with the participants' doctor. Two separate written explanations of the study for both the people with and without consent competence were provided to the participating nursing homes. Written informed consent was obtained from 106 participants. Of the remaining participants, the next-of-kin gave consent in writing.

\subsection{Data analyses}

Data was analyzed with the IBM-SPSS, version 21.0 (study I), IBM-SPSS, version 23.0 (study II, study III, and study IV) (Armonk, USA), and the MLwiN, version 3.01 (Bristol, UK) (the linear mixed model in study III and IV). P-values $\leq 0.05$ were considered statistically significant.

Clinically significant anxiety was dichotomized into present (RAID-N score $\geq 12$ ) or absent (RAID-N score $<12$ ) in accordance with the validity study (paper I); depression was dichotomized into present (CSDD score $\geq 10$ ) or absent (CSDD score $<10$ ) (Barca et al., 2010b); and the GMHR scale was dichotomized into excellent/good and fair/poor (studies II, III, and IV). Differences between groups were analyzed using t-tests on a continuous scale. Differences in proportions between independent groups were analyzed using Chi-square tests on categorical scales (studies II, III, and IV) and McNemar tests between the dependent proportions (study III). To investigate an association between anxiety, anxiety symptoms, and 
NPS (studies II, III, and IV) a principal component analysis (with Varimax rotation) of NPI-Q variables was conducted to identify NPI-Q sub-syndromes. The Varimax rotation tries to load a smaller number of variables that are highly loaded on each factor, thus making clusters of factors easy to interpret (Field, 2013). This factor analysis loaded all 12 NPI-Q items into four distinct components: psychosis (delusions and hallucinations), affective (dysphoria, anxiety, apathy, and appetite), agitation (agitation, irritability, disinhibition, and aberrant Motor), and aroused (euphoria and nighttime disturbances). The participants' regular prescription of psychotropic medication was grouped into anxiolytics, antidepressants, antipsychotics, hypnotics and sedatives, and cognitive enhancers according to the Anatomical Therapeutic Chemical (ATC) index (WHO Collaborating Centre for Drug Statistics Methodology \& Norwegian Institute of Public Health).

\section{Study I}

Receiver operating characteristic (ROC) analysis was used to calculate the sensitivity, specificity, positive and negative likelihood ratios (LR+ and LR-), and accuracy of the RAID$\mathrm{N}$ scores at various cut-off points. The positive likelihood ratio is the ratio of true test positives divided by false test positives (sensitivity/1-specificity). The negative likelihood ratio is the ratio of false test negatives divided by true test negatives (1-sensitivity/specificity). Accuracy is the proportion that correctly identifies positive or negative tests in the population (Zweig \& Campbell, 1993). The area under the curve (AUC) was calculated as well. To investigate the agreement between the two raters for each item of the RAID-N, the ratings of each item of the RAID-N were dichotomized into symptoms present or not present, and the agreement was assessed by Cohen's kappa ( $\kappa)$. According to Ciccethi (1976), when assessing the inter-rater reliability for a dichotomous ordinal rating scale, the minimum sample size should be approximately $2 \mathrm{x} \mathrm{k}^{2}(\mathrm{k}=$ number of ordinal points on the scale). Thereby, for the four points RAID-N ( $2 \times 4 \times 4=32)$, the number of participants $(n=53)$ in the inter-rater reliability test was considered sufficient to calculate Cohen's kappa statistics for each item of the RAID-N. The inter-rater reliability of the RAID-N total score was assessed by an intraclass correlation coefficient (ICC). The internal consistency of each item and the overall scale (except for phobias and panic attacks, which are not included in the total score of RAIDN) was tested by Cronbach's alpha.

\section{Study II}

A descriptive analysis was carried out for the participants as a whole and by comparing the groups with and without anxiety. Using the RAID-N score as dependent variable, associations 
between anxiety symptoms and the participants' demographic and clinical characteristics were analyzed with bivariate and forward stepwise multivariate linear regression analyses.

\section{Study III}

The differences between the groups - followed-up versus not followed-up and baseline versus follow-up - were described by descriptive statistics. Incidence rates were defined as the proportion of participants with anxiety, depression, or comorbid anxiety and depression at follow-up, but with none of these conditions at baseline. Persistence rates were defined as the proportion of participants with anxiety, depression, or comorbid anxiety and depression at both assessments. Remission rates were defined as the proportion of participants with anxiety, depression, or comorbid anxiety and depression at baseline, but not at follow-up. The incidence, persistence, and remission rates were analyzed with Chi-square tests. The difference between RAID-N scores at follow-up and baseline was denoted as change in RAID-N score. The cluster effect between the nursing homes was checked with the ICC, and it was 0.041 . The cluster effect was adjusted by using a multilevel restricted iterative generalized least square (RIGLS) model. The change in RAID-N score was the dependent variable, and associations between participants' demographic and clinical variables with the change in RAID-N score from baseline to follow-up were identified by univariate and multivariate regression analyses. Due to a high correlation between the baseline CSDD scores and the baseline NPI-Q sub-syndrome affective scores $(r=0.765)$, the baseline CSDD score was not included in the multilevel regression models.

\section{Study IV}

A growth mixture model was estimated to identify potential groups of participants following distinct trajectories of QUALID scores from baseline to follow-up. Baseline differences in demographic and clinical variables between the trajectory groups were analyzed. Participants' characteristics and related risk factors associated to QUALID score trajectories were analyzed by bivariate and multivariate logistic regression models. The QoL group was kept as a dependent variable $(0=$ better $\mathrm{QoL}, 1=$ poor $\mathrm{QoL})$ in the logistic regression models. To investigate an association between the participants' characteristics assessed at baseline and follow-up and a trend in QUALID scores, a linear mixed model with random effects for residents was conducted. Fixed effects for time, coded as before or after each of the characteristics of the participants, was included in the linear mixed model. The same independent variables were used in the linear mixed model as in the logistic regression. 


\subsection{Main results}

The mean age of the participants at baseline in the studies of the present thesis was 85.5 years (SD 6.8); 218 (73.2\%) participants were female, and the mean score of CDR-sob was 12.8 (SD 3.5). AD was the most common dementia disorder (57.0\%), followed by unspecified dementia $(24.8 \%)$.

\subsection{Validity and reliability of the RAID-N}

Anxiety disorders as diagnosed by the doctors in the validity study of the RAID-N (study I) were found in 32 of the 101 participants (31.7\%). Twenty-eight participants (27.7\%) met the DSM-5 diagnostic criteria of GAD, and four participants (4.0\%) had unspecified anxiety disorder. A cut-off RAID-N score of $\geq 11$ yielded the best sensitivity (85.7\%) and fairly good specificity (67.1\%), whereas a cut-off score of $\geq 12$ on the RAID-N gave a sensitivity of $82.1 \%$, a specificity of $70.0 \%$, and an accuracy of $73.3 \%$ in identifying GAD in people with dementia. The sensitivity and specificity for the RAID-N cut-off score of $\geq 12$ was higher (92.3\% and $75.8 \%$, respectively) for the subgroup with CDR-sob $<14$ than for the subgroup with CDR-sob $\geq 14$ (73.3\% and 65.0\%, respectively). The RAID-N indicated satisfactory internal consistency with a Cronbach's alpha of 0.81 . Inter-rater agreement for the cut-off scores of $\geq 11$ and $\geq 12$ on the RAID-N was $79.2 \%(\kappa=0.58)$. The RAID-N was found to be user friendly and may be a useful tool in the identification of clinically significant anxiety in nursing home residents with dementia.

\subsubsection{Errata}

The values of positive (LR+) and negative (LR-) likelihood ratios, provided for the sub-group CDR-sob $<14$ in Table 3 of the published paper (study I), were incorrect. The correct values of LR+ and LR- for the sub-group CDR-sob $<14$ are listed in the following Table 3. Values in bold have been corrected. 
Table 3. ROC analysis showing the best RAID-N scale cut-off scores with the DSM-5 criteria of generalized anxiety disorder (GAD) by comparing the two groups $(\mathrm{N}=101)$.

\begin{tabular}{llllllll}
\hline & Cut-off & SS \% & SP \% & LR+ & LR- & ACC \% & AUC (SE; CI) \\
\hline CDR-SOB $<14$ & $\geq 11$ & 100 & 72.7 & 3.7 & $\mathbf{0}$ & 80.4 & $0.87(0.05 ; 0.77-0.97)$ \\
$(\mathrm{n}=46)$ & $\geq 12$ & 92.3 & 75.8 & 3.8 & 0.1 & 80.4 &
\end{tabular}

CDR-SOB = Clinical Dementia Rating-Sum of Boxes; SS= Sensitivity; SP= Specificity; LR = Likelihood ratio; $\mathrm{ACC}=$ Accuracy; $\mathrm{AUC}=$ Area under the curve $($ Standard error; $95 \%$ confidence interval)

\subsection{Prevalence, incidence, persistence, and remission of anxiety at 12- month follow-up in people with dementia}

Anxiety as defined by a cut-off score of $\geq 12$ on the RAID-N was present in $34.2 \%(102 / 298)$ of the participants at baseline (study II). Of those who were assessed at followed-up, 33.7\% $(69 / 205)$ of the participants had anxiety at baseline, and 31.2\% (64/205) of the participants had anxiety at12-month follow-up (McNemar test, $\mathrm{p}=0.597)$. The incidence of anxiety was $19.1 \%(26 / 136)$, persistence $55.1 \%(38 / 69)$, and the remission rate at 12 -month follow-up was $44.9 \%$ (31/69) (Table 2, study III).

\subsection{Prevalence of anxiety symptoms and changes at 12-month follow-up} Anxiety symptoms defined as the presence of one or more items on the RAID-N were present in $93.6 \%$ of the participants at baseline (study II). Of those who were followed-up, $93.7 \%$ of the participants had one or more anxiety symptoms at baseline, and $95.1 \%$ of the participants had one or more anxiety symptoms at 12-month follow-up (McNemar, p = 0.629). "Motor tension," "frightened and anxious," and "irritability" were the most frequent anxiety symptoms, whereas "palpitations," "sweating or chills," and "dry mouth, sinking feeling in the stomach" were the least frequent anxiety symptoms in the participants with dementia and significant anxiety. Worry about cognitive performance was the only anxiety symptom that indicated significant reduction from baseline to 12-month follow-up (Figure 1, study III).

\subsection{The correlates of anxiety at baseline and at 12-month follow-up}

The participants' general physical health; NPI-Q sub-syndromes: psychosis, affective, agitation, and aroused; and use of anxiolytics were associated with higher RAID-N scores at baseline (Table 4, study II). A reduction in RAID-N score at follow-up was associated with higher score of NPI-Q sub-syndrome: affective and more use of anxiolytics at baseline, whereas an increase in RAID-N score at follow-up was associated with a higher score of NPIQ sub-syndrome: aroused and more use of antipsychotics at baseline (Table 3, study III). 


\subsection{Depression and comorbid anxiety and depression}

8.5.1 The prevalence, incidence, persistence, and remission of depression at 12-month follow-up

Depression defined as a CSDD score of $\geq 10$ was present in $23.5 \%$ of the participants (70/298) at baseline. Among those who were followed up, 22.0\% (45/205) of the participants had depression at baseline, and 27.3\% (56/205) had depression at follow-up (McNemar test, $\mathrm{p}$ $=0.161)$ (Figure 4$)$. The incidence of depression was $19.4 \%$ (31/160), persistence $55.6 \%$ (25/45), and remission rate at 12-month follow-up was 44.4\% (20/45) (Table 2, study III).

\subsubsection{The prevalence of comorbid anxiety and depression} At baseline, 52.9\% (54/102) of the participants with anxiety had comorbid depression, whereas $77.1 \%$ (54/70) of the participants with depression had comorbid anxiety (p-value between two percentages, $p=0.015$ ) (study II, Figure 2). At 12-month follow-up, $62.5 \%$ (40/64) of the participants with anxiety had comorbid depression, and $71.4 \%$ (40/56) of the participants with depression had comorbid anxiety ( $\mathrm{p}$-value between two percentages, $\mathrm{p}=$ 0.360) (Figure 4). The occurrence of comorbid anxiety and depression showed a nonsignificant increase from $17.6 \%(36 / 205)$ at baseline to $19.5 \%(40 / 205)$ at follow-up (McNemar test, $\mathrm{p}=0.644)$.

\subsubsection{Severity of symptoms in people with comorbid anxiety and depression} The participants with comorbid anxiety and depression had poorer general physical health, higher mean scores of RAID-N, CSDD, NPI-Q, and NPI-Q sub-syndromes: affective, agitation, and aroused than the participants with only anxiety (Table 3, study II). The participants with comorbid anxiety and depression had the lowest remission rate at follow-up compared with the participants with only anxiety $(16.7 \%$ vs. $57.6 \%, \mathrm{p}<0.001)$ or only depression ( $16.7 \%$ vs. 55.6\%, p = 0.024, Fisher exact test) (Table 2, study III). 

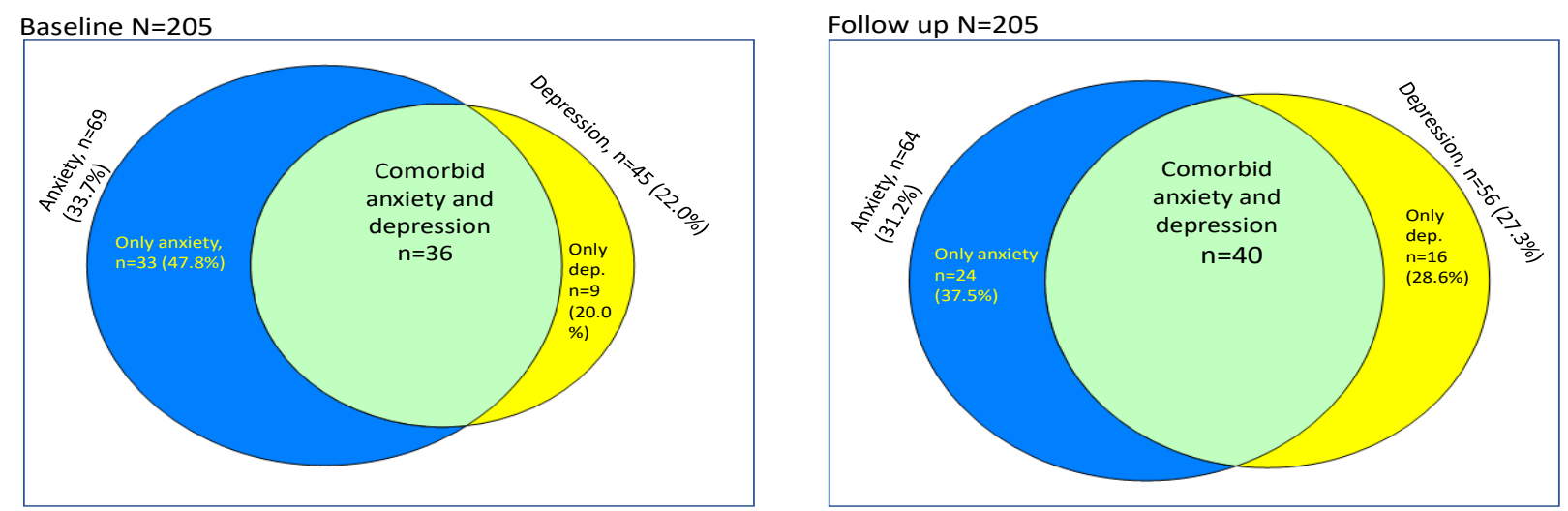

Figure 4. Relationship between anxiety, anxiety and comorbid depression, and depression from baseline to follow-up in the study sample based on data presented in study III.

\subsection{Anxiety and QoL of people with dementia}

Two distinct trajectories of QUALID scores were observed from baseline to 12-month followup. In the trajectory group 1, including 206 participants, a lower proportion of participants had anxiety (RAID-N score $\geq 12$ ) and a more stable and lower QUALID mean score (better QoL), compared to the participants of trajectory group 2 (92 participants). Anxiety, controlled for depression and other demographic and clinical factors, was associated with belonging to trajectory group 2 with poorer QoL at baseline and at 12-month follow-up (paper IV). Participants with comorbid anxiety and depression had poorer QoL than the participants without anxiety or depression, or with only anxiety or only depression (Figure 5). 


\section{Association between QoL and anxiety and/or depression}

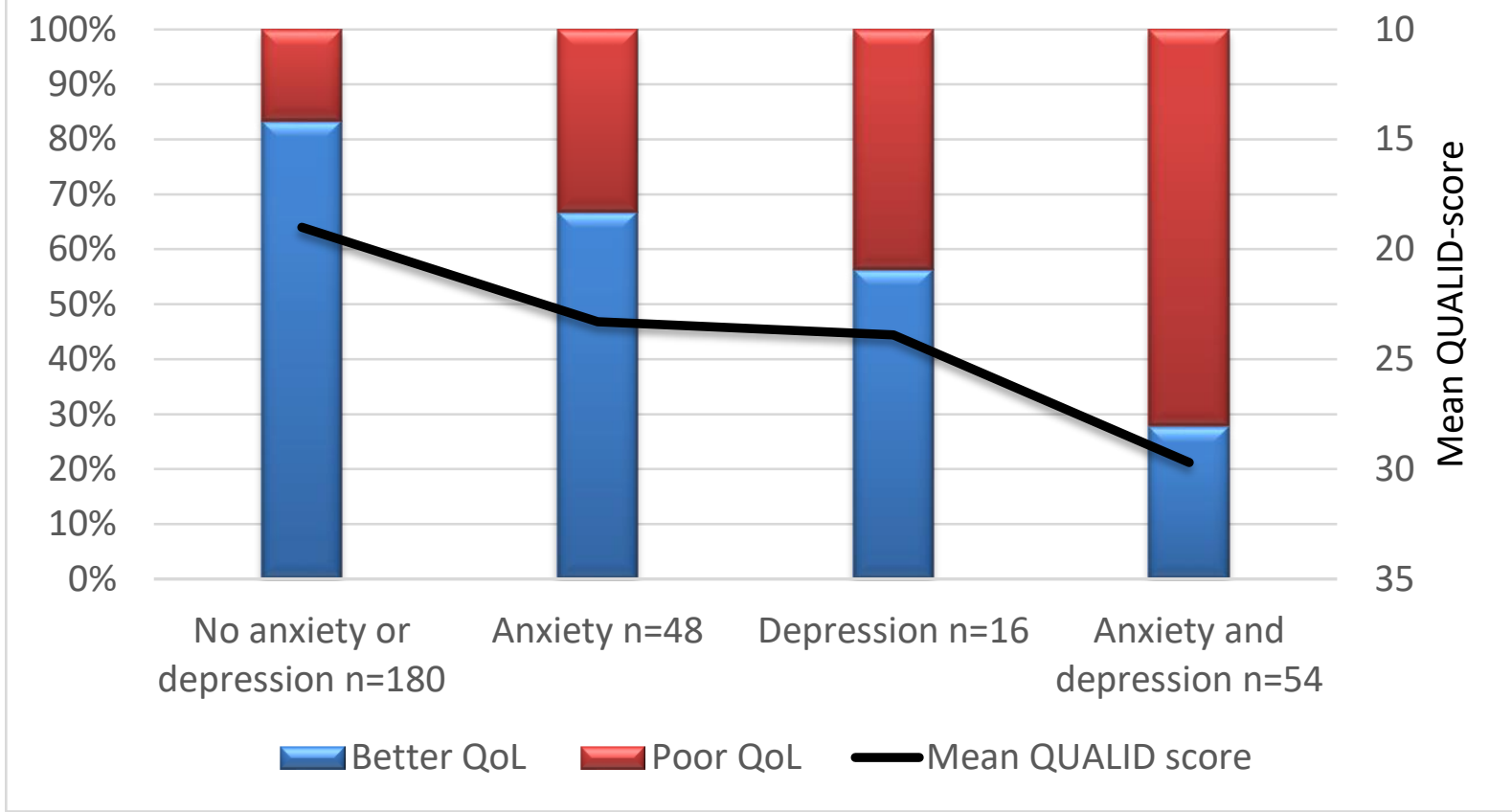

Figure 5. Illustration of different groups and their association with QoL at baseline (see Figure 2 of study II for the group distribution). The blue bars represent the trajectory group with better QoL, the red bars represent the trajectory group with poorer QoL, and the black line indicates the mean QUALID score as described in study IV. 


\subsection{Discussion}

This section is divided into two main parts. The first part is a discussion about the methodological considerations of the four studies. In the second part, the main results of the four studies are discussed.

\subsection{Discussion of methodological considerations}

The four studies of the present thesis have been conducted in nursing home residents with dementia, which presented several methodological challenges. In this section, the challenges and possible weaknesses of the studies, and how these challenges were met, will be discussed. Further, there will be a discussion of the implications this may have for the interpretations of the results.

\subsubsection{Design}

Two of the papers have a cross-sectional design, which is relevant to investigating the validity and reliability of the RAID-N and to studying the prevalence of anxiety, anxiety symptoms, and their correlates. These two papers were the basis of studying the course (longitudinal design) of anxiety in terms of changes in anxiety and anxiety symptoms (study III) and QoL of people with dementia over time (study IV). However, the study is of descriptive design and did not control for any other changes such as ongoing treatments, changes in comorbidities, or moving to other wards. The assessments were made at two time points: at baseline and at a 12-month follow-up. As the symptoms of anxiety and depression fluctuate, an assessment point between these two points might have provided better knowledge about the changes over time in anxiety, anxiety symptoms, and QoL in people with dementia in nursing homes.

\subsubsection{Sample}

The study's sample is from a selected nursing home population with dementia and may not be representative of the Norwegian nursing home population. Compared to people with dementia living at home, nursing home residents with dementia experience more behavioral disturbances, are older, and have more severe functional impairments (Wergeland et al., 2015), and the results are therefore not representative of all people with dementia. It is also reasonable to believe that living in a nursing home will have influence on anxiety and QoL.

Although the participants were from 17 nursing homes from two counties of southeastern Norway (Buskerud and Hedmark), one could argue that the study sample may be representative of the Norwegian nursing home population with dementia, as the participants 
were included from small, medium, and large nursing homes located in cities and in the countryside. Factors varying between the nursing homes were taken into account by checking the ICC and adjusting by using a multilevel model for repeated measures in studies III and IV. The sample included in the studies of the present thesis is comparable to other studies of the Norwegian nursing home population in terms of demographics and degree of dementia (Mjørud, Kirkevold, et al., 2014; Rokstad et al., 2013; Selbæk et al., 2017), and the results can possibly be generalized to the nursing homes in Norway. The two nursing homes that did not participate chose this due to lack of resources. It is possible that a lack of resources could influence the quality of care and services, which may have provided other results than the included nursing homes. It is also possible that the participating nursing homes are better and more eager in terms of professional development than the nursing homes that did not participate in this thesis. However, the small cluster effect (ICC $=4 \%$, study III) indicates that factors other than differences in the wards influence anxiety.

Some of the residents with possible dementia but without documented dementia diagnoses in their records were not asked to participate in the study, and some of the residents with documented dementia were not asked to participate due to lack of resources during inclusion time at two of the nursing homes. It is unknown whether inclusion of these participants may have affected the results of the studies of the present thesis. Previous Norwegian nursing home studies have indicated that more than $40 \%$ of the nursing home residents with dementia do not have documented dementia diagnoses in their records (Roen et al., 2017; Selbæk et al., 2007). One may speculate whether the residents without documented dementia diagnoses in their records are different in a way that they exhibit less or no NPS, and thus do not receive priority in comprehensive clinical assessments in the nursing home compared with the residents with documented dementia diagnoses, and thereby the prevalence of anxiety and other NPS of the present studies may be overestimated.

For the participants of the validity and reliability study of the RAID-N, diagnosis of dementia was made by experienced doctors based on the DSM-5 criteria of NCD. However, as many as $46 \%$ (137/298) of the participants had a P70 dementia diagnosis, and 45\% of these (61/137) had no specification of dementia etiology in their medical records. An etiological dementia diagnosis for all the participants may have added to the knowledge of prevalence of anxiety, anxiety symptoms, and their course in dementia subtypes. 


\subsubsection{Selection of the RAID scale}

There is a scarcity of anxiety assessment tools developed specifically to assess anxiety in people with dementia of severe stages. The dementia-specific anxiety scale RAID was chosen for the four studies of the present thesis, as this scale has been validated for use for people with all stages of dementia, including moderate and severe dementia (Shankar et al., 1999; Snow et al., 2012). The RAID scale assessments are made by an interview with the patient himself/herself combined with information from the caregivers' observations and the patient's medical records over the last two weeks. This increases the reliability of the assessment for people with dementia in general, and it makes it suitable to assess anxiety in people with severe dementia (Seignourel et al., 2008). A comprehensive assessment may be better than a single-method assessment among older people with multimorbidity (Balsamo et al., 2018).

The RAID scale contains six out of seven criteria of GAD in the DSM-5 (Table 1). As "impaired concentration" is a shared symptom between anxiety and dementia, the criteria of concentration is excluded from the RAID scale (Bentvelzen, Aerts, Seeher, Wesson, \& Brodaty, 2017; Shankar et al., 1999). About 25\% of the items of the RAID are worry symptoms; thereby, its sensitivity is higher in identifying GAD than other anxiety disorders, but it has a lower specificity (Bentvelzen et al., 2017; Gerolimatos et al., 2015; Shankar et al., 1999). However, the RAID scale is developed for the assessment of the severity of anxiety symptoms and is a good screening tool to identify clinically significant anxiety in people with dementia. We have used a cut-off value based on the ROC analysis using the DSM-5 criteria of GAD assessed by the doctors to identify clinically significant GAD among nursing home residents with dementia.

\subsubsection{Translation of the RAID scale to RAID-N}

The translation of the RAID scale from English to Norwegian was conducted in accordance with guidelines provided by Maneesriwongul and Dixon (2004) (see study I and section 7.3 of this thesis), and fulfills five of the six categories of the translation process suggested by the authors. In addition to testing the target version of the scale among monolingual subjects, testing the original and target versions of the scales among bilingual subjects would have been the most complete instrument translation process (Maneesriwongul \& Dixon, 2004). This would not have been easy for older Norwegian people to understand adequately, and/or it may have been difficult for them express their anxiety symptoms in English as well as in Norwegian. According to Maneesriwongul and Dixon, back-translation and testing the target 
language version among monolingual subjects is necessary to test the language clarity and appropriateness of the target version of an instrument. Besides, investigating the validity and reliability of the final version of the scale among the target population adds to the strength of the scale and is suitable for use in cross-cultural studies (Maneesriwongul \& Dixon, 2004).

\subsubsection{Administration of the RAID-N}

The caregivers must have good knowledge about the person with severe dementia when assessing the person with the RAID-N. A joint assessment of the RAID-N by two raters (who know the resident/patient well) including the self-reported assessment of the resident (when possible) may improve the reliability of anxiety assessment in people with moderate to severe dementia.

\subsubsection{Assessment methods}

Cognitive assessments made by MMSE-NR2 were analyzed only in study I. These assessments were found to be difficult for the older nursing home residents with severe auditory and visual impairments and poor general physical health, leading to missing data. Therefore, proxy information of the degree of cognition was assessed using the CDR-sob. This is also ethically reasonable for the participants in a vulnerable situation, given the nature of dementia. For example, one of the participants could not recall the name of the weekday during the MMSE-NR2 assessment. On seeing me incidentally after a few days, he approached me and mentioned the name of the current weekday.

Although the assessment scales used in the studies of this thesis have demonstrated good inter-rater reliability, the number of registered nurses (in total, 57) involved in the assessment procedure could be a drawback. There are chances of some inter-rater bias due to individual differences in the way the assessment scales were applied to the participants and interpretations of the data. However, many raters will not result in systematic error in the assessments, but may increase the risk of random error (Polit \& Beck, 2012). Besides, the nurses were experienced in using the assessment scales, and before the study began the nurses underwent a training session of 2-3 hours in administering the assessment scales.

Most of the assessment scales used in the present thesis were based on proxy-information given by the healthcare personnel of the nursing homes, and this is a limitation. The proxyinformation may be influenced by healthcare personnel's observational skills, sensibilities, 
and viewpoints. However, the nurses had knowledge about the residents, which is important in the administration of the proxy-rating scales used in the studies of the present thesis.

There may also be a possibility of bias as the same caregiver assessed the participants' NPS and QoL. Reporting an association between proxy-rated NPS and self-rated QoL, Hongisto et al. (2018) found that the self-rated QoL of people with dementia did not change significantly, despite an increase in their proxy-rated NPS. On the other hand, proxy-rated QoL of people with dementia declined significantly as their NPS increased during a 5-year follow-up (Hongisto et al., 2018). The authors suggest that self-reported QoL tools are unreliable with the progression of dementia to evaluate the effect of therapy for NPS (Hongisto et al., 2018).

QoL is mainly based on a person's subjective experience of his/her own life, but it was assessed with the QUALID scale, which is based on proxy-information. Previous studies indicate that people with mild to moderate dementia are able to provide reliable information of their own QoL (Selwood et al., 2005; Trigg et al., 2007). Thus, information on QoL reported by people with mild to moderate dementia $(\mathrm{CDR}-\mathrm{sob}<16, \mathrm{n}=230$ ) could have been collected from $77 \%$ of the participants in study IV. The proxy-assessed QUALID scale was used to keep a common QoL measurement for all the participants, which is in line with previous studies that have used the QUALID scale to assess the QoL of nursing home residents and older people in psychogeriatric units, irrespective of participants' dementia severity (Barca, Engedal, Laks, \& Selbæk, 2011; Mjørud, Kirkevold, et al., 2014; Mjørud, Røsvik, et al., 2014; Rokstad et al., 2013).

Healthcare personnel should be trained in observing positive and negative emotions in people with dementia, such as the person's facial expressions, body movement, and interaction with others, to assess anxiety, QoL, and other variables.

\subsubsection{Possible confounders}

The study cohort of this thesis is nursing home residents with dementia who also had chronic diseases and pain. Pain has not been assessed in the studies of this thesis and may have been a confounding factor. In the regression models (study IV), assessments of anxiety and QoL were adjusted for the use of psychotropic drugs, such as antipsychotics, antidepressants, anxiolytics, and participants' general medical health. Other factors such as specifications of disease, type of ward, number and qualifications of staff, and other environmental factors may have been confounding factors in the assessment of anxiety and QoL of people with dementia in nursing homes. 


\subsubsection{Strengths of the studies of the thesis}

Use of well-established assessment scales validated specifically for the nursing population with dementia, scales assessed by trained raters, a large study sample (> 200), and a homogenous or well-defined study population recruited from many nursing homes are the strengths of the studies of this thesis. Investigating the course of anxiety, anxiety symptoms, and their associations including those with QoL by a prospective longitudinal design using a dementia-specific anxiety assessment scale is another strength of the thesis. The thesis has addressed the knowledge gap by taking into account comorbid anxiety and depression in a prospective longitudinal design among people with dementia living in nursing homes.

\subsection{Discussion of the main results}

\subsubsection{Validity and reliability of the RAID-N}

The RAID-N had a high Cronbach alpha (0.81), which is in agreement with other studies of the RAID scale carried out in different countries among people with and without dementia from various settings (Creighton et al., 2018b; Shankar et al., 1999; Twelftree \& Qazi, 2006). A high Cronbach alpha indicates high internal consistency; for example, there is a high correlation between the different items of the RAID-N measuring the same construct, anxiety (Tang, Cui, \& Babenko, 2014). Using a ROC analysis, the cut-offs of $\geq 11$ and $\geq 12$ on RAID-N score both provided sensitivity $>80 \%$ and specificity $>60 \%$ as recommended by Bennett and Lincoln (2006), indicating that both cut-offs of $\geq 11$ and $\geq 12$ on the RAID-N can discriminate well between nursing home residents with and without clinically significant anxiety and GAD. However, in study I of this thesis, the accuracy was highest for the RAID$\mathrm{N}$ cut-off score of $\geq 12$, which also gave a relatively high sensitivity, suggesting that the cutoff of $\geq 12$ on the RAID-N is suitable for nursing home populations with dementia. Including inpatients (from acute and long-term care) and day center patients with mild to severe dementia, the study by Shankar et al. (1999) found the cut-off of $\geq 11$ on RAID scale to best identify clinically significant anxiety. Snow et al. (2012) included only mild and moderate dementia patients from primary and specialized clinics with scores of $\geq 4$ on the NPI-A in their study and reported the optimum cut-off of $\geq 10$ on the RAID-SI (structured interview guide) to distinguish people with clinically significant anxiety and GAD from those without an anxiety diagnosis. The small differences in the cut-offs across the studies may be owed to the differences in the study samples and cultures. 
The sensitivity of the RAID-N for the cut-off of $\geq 12$ was much higher (above $90 \%$ ) for the participants with mild to moderate dementia $(\mathrm{CDR}-\mathrm{sob}<14)$ compared to the group with severe dementia (sensitivity below 75\%). This indicates that the RAID-N is more sensitive and valid for the assessment of clinically significant anxiety of people with mild and moderate dementia. The reason may be that people with mild and moderate dementia are more able to report their anxiety symptoms than people with severe dementia, who may have communication difficulties due to severe cognitive decline. To our knowledge, no previous studies have looked into this.

The overall inter-rater agreement when assessing participants with a score of $\geq 12$ on the RAID-N was $79.2 \%(\kappa=0.58)$, which is lower than reported from other studies that investigated the reliability of the RAID (Creighton et al., 2018b; Shankar et al., 1999; Snow et al., 2012; Sung et al., 2010). Creighton et al. reported an inter-rater agreement of $\kappa=0.77$; Shankar et al. reported an overall percentage agreement between the two raters on a dichotomous scale [symptoms absent (0) or present (score 1, 2 or 3 on RAID scale)] ranging from $82 \%$ to $100 \%$; and Snow et al. reported inter-rater agreement of $\kappa=0.71$. Sung et al. translated the RAID scale into Chinese for use in a Taiwanese population with a back translation. The translated RAID was then pilot-tested for clarity on five Chinese speaking nursing staff, and they reported an inter-rater agreement of 90\% (Sung et al., 2010). The study on reliability or validity testing of the Chinese RAID is not published. However, the abovementioned studies have used small samples of inter-rater reliability assessments of the RAID scale varying from five to 33 participants (Table 2). In three of these studies, both raters were present during the same interview (Creighton et al., 2018b; Shankar et al., 1999; Snow et al., 2012), whereas for 45 of 53 of the participants of the reliability study of RAID-N, both raters interviewed the participants independently on the same day. This different design may have resulted in lower inter-rater agreement.

Using two different designs in the reliability study of CSDD, Barca et al. (2010b) reported a higher kappa value (0.91) when both raters were present during the assessment and a lower kappa value (0.57) when the raters assessed the patients independently. Landis and Koch characterized kappa values between 0.41-0.60 as moderate, which is supported by other authors (Carpentier, Combescure, Merlini, \& Perneger, 2017; Landis \& Koch, 1977). However, we assume that interviewing the participants separately provides a more correct indication of inter-rater reliability. 


\subsubsection{The prevalence and course of anxiety in people with dementia}

Anxiety disorders were reported in 32 (32\%) of the participants in the validity study sample, and 28 out of 32 of these participants $(87.5 \%)$ met the diagnostic criteria of GAD by DSM-5 (American Psychiatric Association, 2013) (study I). The finding that GAD was the most common anxiety disorder among older people with dementia in nursing homes is in line with previous studies of older people with and without dementia (Ballard et al., 2000; Calleo et al., 2011; Lindesay et al., 2012; Starkstein et al., 2007). The prevalence of clinically significant anxiety as defined by the RAID-N score $\geq 12$ was present in more than $30 \%$ of the participants at baseline and at 12-month follow-up (studies II and III), which is higher than reported in the previous Norwegian studies of nursing home residents with dementia. Selbæk et al. (2008a) and Bergh et al. (2011) reported clinically significant anxiety (NPI-anxiety score $\geq 4$ ) to be at $22 \%$ and $20 \%$, respectively. At 12 -month follow-up, both studies reported a decline in clinically significant anxiety with a prevalence of $19 \%$ and $15 \%$, respectively.

Different anxiety assessment scales may lead to different results even though the study populations are comparable, as in the studies by Selbæk et al. (2008a) Bergh et al. (2011), and the studies of the present thesis. The RAID-N has a descriptive approach of anxiety symptoms assessed from various resources including the patient, whereas anxiety is assessed with a single subscale anxiety item of NPI (Cummings et al., 1994) based on caregivers' observations. Of note, some of the GAD criteria of DSM-V such as irritability, restlessness (aberrant motor behavior), and sleep disturbances are assessed as distinct items of NPI, whereas they are operationalized as anxiety symptoms on the RAID-N. NPI is a dementiaspecific assessment scale to assess NPS among people with dementia (Cummings et al., 1994), but it is not an anxiety-specific assessment scale. Thereby, studies using anxiety variable of NPI to report anxiety among people with dementia may lead to different results compared to studies using anxiety-specific scales.

There may be many reasons for the high prevalence of anxiety among people with dementia in nursing homes. Residing in nursing home may limit autonomy, choice, and control over one's environment (Balsamo et al., 2018). The residents of the nursing homes who felt that they lacked control over their lives experienced higher levels of anxiety (Creighton et al., 2018a). For people with moderate to severe dementia, the nursing home environment with a number of external stimuli may be perceived as complex. According to the PLST model described in section 2.5 of the present thesis, older people with dementia have reduced ability to process sensory stimuli due to cognitive decline, which results in their reduced stress 
threshold level and potential risk for anxiety and related behavioral symptoms (Hall \& Buckwalter, 1987; Smith et al., 2006). Moreover, anxiety symptoms among people with dementia increase the risk of nursing home placement (Gibbons et al., 2002). Anxiety and feelings of insecurity are likely to be present among some of the people with dementia in nursing homes due to the new environment, and establishing meaningful relationships with others can be difficult due to the high turnover rates of the staff and residents. However, some residents are able to adjust better than others to the changes associated with their new stage of life due to dementia depending upon their previous personality and other physical and mental conditions (Creighton et al., 2018a; Low et al., 2002).

\subsubsection{The prevalence and course of anxiety symptoms in people with dementia} One or more anxiety symptoms as assessed by RAID-N were present in more than $90 \%$ of the participants at both assessment points (study II and III), which is high. This could be due to the broad range of anxiety symptoms assessed in the present studies and the study sample. Nursing home residents with dementia may exhibit more anxiety symptoms than people with dementia from other settings. About $65 \%$ of all dementia patients exhibited moderate to severe anxiety symptoms during a 21-month observation at a psychogeriatric day-care hospital in Sweden (Johansson \& Gustafson, 1996). In the study by Ballard et al. (2000), one or more anxiety symptoms were present in up to $71 \%$ of the patients with different kinds of dementia in a hospital sample in the United Kingdom.

Irritability, anxious and frightened, muscle tension, and restlessness were the most prevalent anxiety symptoms in the participants with clinically significant anxiety (RAID-N score $\geq 12$ ) both at baseline and at 12 months. These symptoms are the physical and emotional components of anxiety (Lindesay et al., 2012; Nordhus, 2008) (described in section 2.4.2 of the present thesis) and are among the criteria used to diagnose GAD based on the DSM-5 and ICD-10. Anxious mood and somatic muscular complaints such as body aches and body stiffness were found to be more common than other anxiety symptoms in patients with dementia (Ferretti et al., 2001; Teri et al., 1999). Teri and colleagues found that anxious feelings, fearfulness or apprehensiveness (44\%), irritability (36\%), agitation and restlessness (34\%), and subjective anxiety were the main experiences of anxiety in older adults with dementia (Teri et al., 1999). Variations in the prevalence and type of anxiety symptoms may be due to differences in study population, assessment scales, and cultural differences. 
Worry about cognitive performance was reduced significantly at follow-up compared to baseline, which is an unexpected finding. As described under sections 2.4 .8 and 2.5 of this thesis, worries about managing everyday life and worries of losing control of one's own situation due to a decline in cognitive ability is considered one of the main contributing factors of anxiety in people who begin to develop cognitive changes due to dementia. Worries are the cognitive component of anxiety (Lindesay et al., 2012; Nordhus, 2008) and one of the main criteria of GAD in the DSM-5. The caregivers may not be sensitive to symptoms of worry in their residents or patients (Gerolimatos et al., 2015), and it may be that worries are difficult to assess in people with severe stages of dementia due to difficulty in communication. A study by Calleo et al. (2011) reported that people with dementia do not express worries. One may therefore argue that anxiety is difficult to diagnose if worries are indicative of anxiety symptoms among people with severe stages of dementia (Seignourel et al., 2008), and older people with severe dementia may not experience anxiety as conceptualized by worries being the key criteria of GAD. The criteria of GAD as revised by Starkstein and colleagues (2007) may be suitable for people with mild and moderate dementia.

It may be that "worry" in mild to moderate dementia is related to a decline in cognitive abilities, whereas in severe dementia the worries may change to more physical and emotional (behavioral) symptoms of anxiety such as muscle tension, restlessness, and irritability (as described in section 2.4.2 of this thesis). At follow-up, the participants of the present thesis had significant increases in CDR-sob (Table 1, study III), indicating worsening in the severity of their dementia. With the progression of dementia and vulnerability to a reduced stress threshold (PLST model), environmental factors in the nursing home such as noise and disturbances from co-residents may increase the stress level of person with dementia, and normative behavior may be replaced by anxious and dysfunctional behavior. In the progression of dementia, anxiety is predominantly expressed behaviorally (Mohlman et al., 2012; Porter et al., 2003). Increased decline in cognition leads to disorientation of time and place, which may lead to insecurity and other behavioral symptoms.

The autonomic hypersensitivity symptoms of anxiety, such as palpitations, sweating or chills, and dry mouth, sinking feeling in the stomach were the least frequent anxiety symptoms reported in the participants with clinically significant anxiety (RAID-N score $\geq 12$ ). These findings are consistent with two studies of clinic outpatients diagnosed with AD, which 
reported that anxiety symptoms related to the heart and stomach were the least common symptoms in patients with AD (Ferretti et al., 2001). The palpitations and dry mouth, sinking feeling in the stomach are subjective symptoms that are difficult to observe unless the participant reports them him/herself. The lack of these symptoms could also be because these symptoms were not scored and confounded with other medical conditions in older people, for example, cardiovascular diseases, hyperthyroidism, and diabetes. The RAID instructions specify that symptoms should not be scored if they result from physical illness (Shankar et al., 1999). There is evidence that autonomic nervous system activity is reduced in older people (Li, Lindenberger, \& Sikstrom, 2001), meaning that the autonomic symptoms of anxiety are either reduced in older people or are difficult to identify in this age group (Bryant et al., 2013).

Unlike in younger adults with anxiety and with good communicative abilities, the subjective physiological symptoms of anxiety may not be easy to identify in older people with multimorbidity and severe dementia. During the assessments of RAID-N, it was observed that the subjective experiences of anxiety of people with dementia were almost absent in the participants' daily nursing home records. The reason may be that nursing staff seldom ask people with dementia about how they feel or if they have any worries or anxiousness, or the staff may not consider the importance of documenting patients' subjective experiences of anxiety. The assessments of anxiety symptoms with the RAID-N may contribute to nursing home staff's reflected observations and identification of subjective experiences of anxiety symptoms among people with dementia.

\subsubsection{Correlates of anxiety symptoms in people with dementia}

The participants' poor general physical health, several NPS, and use of anxiolytics were associated with increased RAID-N scores in study II (Table 4). In Table 3 of study III, the dependent variable "Change in RAID-N score" was defined as the RAID-N score at follow-up minus the RAID-N score at baseline. A positive change indicates an increase in RAID-N score at follow-up, and a negative change indicates reduction in RAID-N score at follow-up. A negative regression coefficient in Table 3 of study III indicates a smaller increment, or more reduction, in the RAID-N score at 12-month follow-up.

Few studies have investigated the correlates of anxiety symptoms over time in people with dementia (Creighton et al., 2017). In line with previous cross-sectional studies, it seems that 
poor general physical health and the presence of other NPS are strongly associated with anxiety symptoms in people with dementia living in institutions or in the community (Creighton et al., 2017; Creighton et al., 2018a; Neville \& Teri, 2011; Teri et al., 1999). A study by Teri et al. (1999) reported that higher occurrence of NPS among communitydwelling people with AD was explained mainly by the presence of anxiety. Assessing anxiety with the RAID scale, Neville and Teri (2011) reported that behavioral symptoms (higher scores on the Revised Memory and Behavior Problems Checklist) and depression were highly associated with anxiety among people with dementia living in assisted-living facilities. Symptoms of anxiety are reported to co-occur with agitation in people with dementia (Twelftree \& Qazi, 2006).

Anxiety symptoms such as irritability, fatigue, shortness of breath, and palpitations are not always easy to distinguish from poor physical health and pain among older people with dementia. Older people in nursing homes have often multimorbidity and polypharmacy (Fog et al., 2017; Gulla et al., 2016), which could lead to a vicious circle of delirium and challenging behavior such as sleep disturbances and restlessness among people with dementia. A large Norwegian nursing home study reported that residents with anxiety, depression, and agitation used more psychotropic drugs, and people with dementia were more at risk of being treated with multiple psychotropic drugs than people without dementia (Gulla et al., 2016), which is contrary to national guidelines recommending that psychotropic drugs among people with dementia should be used with caution (Helsedirektoratet, 2017; Nice guideline, 2018).

A higher NPI-Q sub-syndrome: aroused, and more use of antipsychotics at baseline was associated with increased or less reduced RAID-N scores at 12-month follow-up in study III. It is possible that participants using more antipsychotics at baseline exhibited more NPS, including sleep disturbance (one of the two NPS of NPI-Q sub-syndrome: aroused), and antipsychotics have a poor effect on anxiety symptoms among people with dementia. In a study by McCurry et al. (2004), sleep disturbance was associated with higher anxiety symptoms among people with moderate dementia living in community. The authors suggest that psychosocial interventions such as sleep hygiene practices, exposure to light, and physical activity combined with adequate management of anxiety may improve sleep and reduce anxiety symptoms among people with dementia (McCurry et al., 2004). Understanding anxiety and related NPS among people with dementia from a biological and psychosocial 
perspective is important for its appropriate management and reducing inappropriate use of antipsychotics with potentially severe side effects (Ballard et al., 2009).

Reduced or less increased RAID-N scores were associated with higher scores on the NPI-Q sub-syndrome: affective and more use of anxiolytics at baseline. The reason could be that these participants received adequate treatment with anxiolytics and other psychosocial interventions. In the study by Porter et al. (2003), very few patients with AD and anxiety were prescribed anxiolytics (3\%) and antidepressants (13\%), which could be the reason for the lack of association between anxiety and the use of anxiolytics and antidepressants in their study. The authors reports that anxiety is inadequately treated among people with dementia (Porter et al., 2003).

The strongest association of anxiety was found with depression symptoms, consistent with other studies (Bendixen et al., 2018; Creighton et al., 2017; Creighton et al., 2018a; Seignourel et al., 2008), and is discussed in the following section of comorbid anxiety and depression.

\subsubsection{Depression and comorbid anxiety and depression in people with dementia}

The prevalence, incidence, persistence, and remission rates of clinically significant depression defined as a score of $\geq 10$ on the CSDD at 12-month follow-up in study III indicate that depression is highly prevalent and persistent among nursing home residents with dementia, and the results are to some extent comparable to a previous Norwegian study (Barca et al., 2010a). Including nursing home residents with and without dementia, Barca et al. reported the prevalence of clinically significant depression (CSDD score $\geq 8$ ) to be at $21 \%$ both at baseline and at 12-month follow-up. The incidence was $15 \%$, and the persistence rate was $45 \%$ at 12 month follow-up. The difference in the study sample of Barca et al. (2010a) could be the main reason for slightly lower rates of the prevalence, incidence, and persistence of clinically significant depression compared to study III of this thesis.

Assessing clinically significant depression with a cut-off score of $>10$ on the Geriatric depression scale (GDS) (Yesavage et al., 1982), a longitudinal study of a Dutch nursing home reported the prevalence of clinically significant depression to be $41 \%$ at baseline and $30 \%$ at 6-month follow-up, with an incidence of $5 \%$ and a persistence rate of $63 \%$ at 6-month followup. The authors found that the persistence of depression symptoms was more frequent in patients with higher GDS scores (18-30) at baseline compared to those with lower GDS 
scores (Smalbrugge et al., 2006). This observation is in line with study III of this thesis, which shows a high persistence (55\%) of clinically significant depression (CSDD score $\geq 10$ ). These findings may indicate that severe depression tends to be chronic in people with dementia.

The results of studies II and III of the present thesis indicate a high occurrence of comorbid anxiety (RAID-N score $\geq 12$ ) and depression (CSDD score $\geq 10$ ) in people with dementia in nursing homes. Comorbidity of anxiety and depression symptoms was found in $54 \%$ of the community-dwelling participants with AD in the study by Teri at al. (1999). The authors reported that the participants with more severe anxiety or depression symptoms were more likely to have comorbid anxiety and depression than the participants with less severe anxiety or depression symptoms, and participants with comorbid anxiety and depression symptoms exhibited more NPS and ADL impairments than the participants with only anxiety or depression symptoms (Teri et al., 1999). In study II of this thesis, participants with comorbid anxiety and depression had poorer general physical health and an increased number of NPS than the participants with only clinically significant anxiety. However, in study II, participants with or without anxiety or comorbid anxiety and depression were not different in terms of ADL functions (PSMS score) and in study III, no association was found between ADL functions and change in RAID-N score. It is possible that the presence of anxiety and depression symptoms may have an adverse impact on ADL functions for the communitydwelling people with dementia, as indicated in the study by Teri et al. (1999), whereas impairment in ADL functions along with dementia could be some of the reasons for the admission to nursing homes (Wergeland et al., 2015) for the participants of the present thesis.

In study II of the present thesis, a higher proportion of participants with clinically significant depression had comorbidity with clinically significant anxiety at baseline than the participants with clinically significant anxiety ( $\mathrm{p}=0.015$, Figure 2 , study II), but this difference was reduced at 12-month follow-up ( $p=0.360$, Figure 4 of this thesis) in study III. A similar finding was observed in a large community-based Australian longitudinal study of older adults without dementia, which reported that $57 \%$ of participants with clinically significant depression had comorbid anxiety, while only $28 \%$ of participants with clinically significant anxiety had comorbid depression at baseline. The authors reported that participants with significant anxiety at baseline were at increased risk of developing comorbid anxiety and depression at 24-month follow-up (Almeida et al., 2012). 
Porter et al. (2003) reported that $63 \%$ of patients with AD had both anxiety and depression symptoms. The authors postulated that the presence of the condition anxious-depression in some of the patients could be the reason. Further, they found that the occurrence of comorbid anxiety and depression symptoms varied between dementia sub-types $-63 \%$ of the patients with AD had both anxiety and depression symptoms, whereas $83 \%$ of the patients with FTD and $82 \%$ of the patients with $\mathrm{VaD}$ had both anxiety and depression symptoms (Porter et al., 2003). Table 2 of study III shows that, despite the fluctuation in anxiety and depression symptoms over time, there is a tendency toward increased comorbidity of anxiety and depression symptoms over time in people with dementia (see Figure 4 of this thesis). It could be that the specific changes occurring in the brain, such as frontal atrophy and increased white matter lesions, which are associated with increased risk of depression in $\mathrm{VaD}$ and other dementia (Ballard et al., 2000; O'Brien, 2005), may lead to an increased risk of comorbid anxiety and depression symptoms with the progression of dementia.

Six of the items of the RAID-N: worries, sleep disturbances, irritability, muscle tension (verbally expressed bodily pain in the CSDD scale), restlessness, and fatigability are items found in the CSDD scale, indicating that these symptoms may represent anxiety and/or depression symptoms. Apart from these six common items, healthcare personnel should be able to distinguish symptoms of anxiety from depression in people with dementia. For instance, frightened and anxiousness is one of the most prevalent anxiety symptoms among participants with clinically significant anxiety in study III, and they are unique symptoms of anxiety.

Studies investigating the course of anxiety and its co-occurrence with depression over time among nursing home residents with dementia are lacking. The findings from communitybased studies of older people, and one nursing home study of residents with and without dementia, are consistent: anxiety and depression are distinct conditions, but coexistent at a high rate in older people; occurrence of comorbid anxiety and depression increases with the severity of the anxiety or the depression; and comorbid anxiety and depression follows a more chronic course of illness (poor remission) in older people than the presence of either condition alone (Almeida et al., 2012; Beekman et al., 2000; Lenze et al., 2005; Schoevers et al., 2003; Schoevers et al., 2005; Smalbrugge et al., 2005). These findings are in line with the findings of studies II and III of this thesis. 
The high coexistence of anxiety and depression may have many negative impacts, including poor QoL among older people with dementia in nursing homes, and both need attention. Early identification of either or both of the conditions and their adequate management is proactive for better prognosis and improved QoL in this vulnerable population.

\subsubsection{Anxiety and the QoL of people with dementia}

The follow-up assessments with the QUALID scale indicated two distinct groups with different courses of QUALID scores in study IV of this thesis. Two-thirds of the participants had a better and more stable QoL throughout the study period than the rest of the participants, who had poorer QoL that worsened slightly at 12-month follow-up. Clinically significant anxiety (RAID-N score $\geq 12$ ) was associated with belonging to the trajectory group with the poorer QoL (study IV) at baseline and its continuation at 12-month follow-up. The findings are supported by the time-dependent linear mixed model, which indicates that the associations are stable over time. Participants with comorbid anxiety and depression had poorer QoL than the participants with no anxiety or depression or with only anxiety or only depression (see Figure 5 of this thesis). To our knowledge, this is the first study investigating an association between anxiety and the trajectories of QoL and between QoL and comorbid anxiety and depression in people with dementia.

Lawton and other researchers described psychological wellbeing as an important indicator of QoL of people with dementia (Abel, 2017; Brod, Stewart, \& Sands, 1999b; Brod, Stewart, Sands, et al., 1999a; Jonker et al., 2004; Lawton, 1997). Anxiety and depression are the mood factors and overarching aspects of psychological wellbeing. The presence of clinically significant anxiety and depression could hinder other aspects of psychological wellbeing (described in section 3.1 of this thesis), such as enjoying recreational activities, smiling, enjoying meals, and interacting with other people. These aspects which are operationalized on the QUALID scale and are observable indicators of QoL of people with dementia (Weiner et al., 2000). In addition to anxiety and depression, other factors such as severe impairment in ADL functions, agitation, and use of antipsychotics were also associated with poor QoL of people with dementia (study IV).

A systematic review revealed that anxiety is associated with self-perceived low QoL among people in residential care facilities (Creighton et al., 2017). A consistent finding across the 
studies is that depression and agitation are associated with poor QoL in people with dementia (Beerens et al., 2013; Martyr et al., 2018). From the perspectives of people with dementia, a sense of belonging, wellbeing versus illness, happiness versus sadness, and mood are some of the important factors related to QoL (O'Rourke et al., 2015). It is noteworthy that about twothirds of the participants of the sample of this thesis indicated a QoL that was stable during the 12-month follow-up (study IV) despite the decline in cognitive function from baseline. Including 19 longitudinal studies in a recent meta-analysis, Martyr et al. (2018) reported that self-rated QoL at baseline was the strongest predictor of later QoL outcomes among people with dementia. Selwood et al. (2005) found that people with dementia did not perceive a decline in self-rated QoL at a one-year follow-up, and their QoL was not associated with their initial living arrangements, whether they lived alone, with family members, or in a different setting after one year.

According to Carr and Higginson, a person's QoL is individual and can be experienced as good despite decreased functional skills, a phenomenon known as the disability paradox (Carr \& Higginson, 2001). The authors reported that, although patients had significant physical health problems and difficulties in performing daily tasks, they experienced a good QoL (Carr $\&$ Higginson, 2001). This may be true for many people with dementia, too. They may tend to adapt to their new situation despite dementia and continue to have positive experiences, given that they are free from negative mood as a result of anxiety and/or depression. Mood and individual personality factors may have a greater impact than dementia itself on how a person with dementia experiences his/her own QoL. As expressed by one of the participants with severe dementia when asked if she was concerned about her memory problems, "No, I take it as it comes" (my translation).

The nursing staff has the opportunity to observe positive and negative moods of nursing home residents during assisting with ADL functions and other social activities, which is valuable in the assessment of QoL. Training the staff in dementia care and meeting the basic psychological needs of a person with dementia (such as comfort, respect, attachment, inclusion in social, physical, and recreational activities) with a person-centered approach are some of the nursing interventions that can improve the QoL of people with dementia in nursing homes (Rokstad et al., 2013; Telenius et al., 2013; Zimmerman et al., 2005). 


\subsection{Clinical implications}

In Norwegian nursing homes where the majority of residents have moderate to severe dementia, recognition of anxiety symptoms is difficult, but important. The findings of the studies of this thesis suggest that assessment of anxiety in people with dementia should be equally as important as assessing depression. Untreated or inadequately treated anxiety may increase the risk of its comorbidity with depression, delayed remission, and poor QoL.

Knowledge of anxiety and skilled observations of the nursing home residents with dementia combined with the residents' subjective expressions, structured in the form of anxiety assessment scales, become crucial in identifying anxiety in this population. The availability of a validated, dementia-specific anxiety scale may make it easier for nursing staff to identify anxiety among nursing homes residents with dementia during their busy routines, and the staff should be trained in using the scale. Early identification of both anxiety and depression by dementia-specific scales and adequate management of these conditions may prevent negative outcomes and improve the QoL of people with dementia.

Sixteen of the 18 items in the RAID-N are also present either in the DSM-5 or the ICD-10 criteria for the GAD. Worry, one of the GAD criteria of the ICD-10 and the DSM-5, is specified on the RAID-N. Worries related to false beliefs and perceptions, repeatedly calling for attention, worries about cognitive performance, and worries about physical health are based on the nature of the worries of elderly people with dementia. Specifying anxiety symptoms on the RAID-N may be helpful for the nursing staff to observe these symptoms and better evaluate the burden of clinically significant anxiety assessed by the RAID-N score in people with dementia. Repeated administration of the scale over time may indicate the utility of initiated interventions. If the RAID-N score remains high, alternative management or treatment should be considered.

Solely self-reported measures of anxiety assessment may be challenging for people with dementia when the content of the self-report may be poorly understood. Memory and language problems in older people may require proxy reports of anxiety symptoms. To overcome these assessment challenges, RAID-N includes both caregiver and patient ratings of anxiety in people with dementia. NPI and BEHAVE- AD are both based on caregiver report, whereas anxiety is a subjective state. Individuals with mild and moderate cognitive impairment may report useful information of anxiety symptoms. On interviewing the participants, most could elicit information to some points about their anxiety symptoms, 
which I found they were more than willing to share. Thus, conversation itself can be experienced as a relief.

There is an urgent need for good routines for collecting and systemizing the information to identify anxiety severity among people with dementia, which may guide appropriate interventions. Detection of clinically significant anxiety should warn comprehensive diagnostic assessment by qualified health personnel, preferably one with expertise in psychogeriatry. The RAID-N may not be a perfect anxiety assessment tool in terms of specificity and accuracy, but it is a dementia-specific anxiety scale and could be useful in the assessment of anxiety symptoms in the Norwegian population with dementia.

\subsection{Directions for future research}

More studies of anxiety in people with dementia, including nursing home residents and community-dwelling populations, with longitudinal prospective designs, less than a year between the assessments, and more than a year follow-up periods are needed to gain more knowledge and comparison of the prevalence and course of anxiety, anxiety symptoms, and their association between both settings. Further, longitudinal prospective studies of anxiety in the transition from home to nursing home may add to the knowledge about the prevalence and course of anxiety and anxiety symptoms, which may help in planning proactive interventions in dementia trajectories to combat anxiety. Using dementia-specific scales, there is a need for studying intervention techniques for anxiety and comorbid anxiety and depression in people with dementia. Development of effective non-pharmacological interventions for the management of anxiety in people with dementia should be a priority for future studies. Using RAID-N and other assessment scales of anxiety in the same population, future studies may compare different anxiety assessment scales. Future studies with large samples may provide the knowledge of anxiety, anxiety symptoms, and the pattern of comorbidity of anxiety and depression in different dementia subtypes. A future prospective longitudinal study of the association between anxiety and QoL controlled for pain among people with dementia may add to the knowledge of the role anxiety plays in QoL over time in this population.

Cross-cultural studies of anxiety with longitudinal prospective design from similar settings using similar assessment scales may provide better knowledge of the phenomenon of anxiety in people with dementia from a cross-cultural perspective. The phenomenon and existential aspects of anxiety from the perspectives of people with dementia need to be explored in future studies. 


\subsection{Conclusion}

The studies of the present thesis have addressed some issues of an existing knowledge gap mentioned in previous studies- changes occurring in anxiety, anxiety symptoms, and their correlates over time, especially their association with depression and QoL, when anxiety is assessed with a dementia-specific scale among people with dementia (Creighton et al., 2017; Creighton et al., 2018a; Seignourel et al., 2008).

The study has provided some insight into the occurrence of clinically significant anxiety among people with dementia in Norwegian nursing homes. Anxiety and anxiety symptoms are highly prevalent among people with dementia in nursing homes. Muscle tension, frightened and anxiousness, irritability, and restlessness may indicate anxiety symptoms in people with dementia and indicate a need for further assessment of anxiety. Anxiety may exist without depression, but severe anxiety is highly comorbid with depression. Comorbid anxiety and depression lead to delayed remission or may be more chronic in nature in people with dementia, which is a cause for concern. Anxiety is associated with poor QoL over time in people with dementia. The RAID-N could be a useful scale in identifying clinically significant anxiety among people with dementia who needs adequate attention and management, and plan for necessary proactive interventions among people with dementia in Norwegian nursing homes. 


\section{References}

Aalten, P., de Vugt, M. E., Lousberg, R., Korten, E., Jaspers, N., Senden, B., . . Verhey, F. R. (2003). Behavioral problems in dementia: a factor analysis of the neuropsychiatric inventory. Dementia and Geriatric Cognitive Disorders, 15(2), 99-105.

Abel, S. (2017). Revisiting three models of quality of life Lawtons model of four sectors of good life. In L. Tomey (Ed.), All about Alzheimer's. Your A-Z guide for living with Alzheimer's. Retrieved from https://www.doctorabel.us/life-in-old-age/revisiting-three-models-of-quality-of-lifelawtons-model-of-four-sectors-of-good-life.html

Agarwal, M. R., Ferran, J., Ost, K., \& Wilson, K. C. M. (1996). Ethics of 'informed consent' in dementia research - the debate continues. International Journal of Geriatric Psychiatry, 11(9), 801-806. doi:10.1002/(SICI)1099-1166(199609)11:9<801::AID-GPS379>3.0.CO;2-H

Alexopoulos, G. S., Abrams, R. C., Young, R. C., \& Shamoian, C. A. (1988). Cornell scale for depression in dementia. Biological Psychiatry, 23(3), 271-284. doi:10.1016/0006-3223(88)90038-8.

Almeida, O. P., Draper, B., Pirkis, J., Snowdon, J., Lautenschlager, N. T., Byrne, G., . . Flicker, L. (2012). Anxiety, depression, and comorbid anxiety and depression: risk factors and outcome over two years. International Psychogeriatrics, 24(10), 1622-1632.

Alzheimer's Association. (2018). Alzheimer's disease facts and figures. Alzheimer's \& Dementia, 14(3), 367-429. doi:10.1016/j.jalz.2018.02.001

American Psychiatric Association. (2013). Diagnostic and statistical manual of mental disorders: DSM5. Washington, DC: American Psychiatric Association.

Badrakalimuthu, V. R., \& Tarbuck, A. F. (2012). Anxiety: a hidden element in dementia. Advances in Psychiatric Treatment, 18(2), 119-128.

Ballard, C., Boyle, A., Bowler, C., \& Lindesay, J. (1996). Anxiety disorders in dementia sufferers. International Journal of Geriatric Psychiatry, 11(11), 987-990.

Ballard, C., Corbett, A., Orrell, M., Williams, G., Moniz-Cook, E., Romeo, R., . . Fossey, J. (2018). Impact of person-centred care training and person-centred activities on quality of life, agitation, and antipsychotic use in people with dementia living in nursing homes: a clusterrandomised controlled trial. PLoS Medicine, 15(2), e1002500. doi:10.1371/journal.pmed.1002500

Ballard, C., Hanney, M. L., Theodoulou, M., Douglas, S., McShane, R., Kossakowski, K., . . Jacoby, R. (2009). The dementia antipsychotic withdrawal trial (DART-AD): long-term follow-up of a randomised placebo-controlled trial. Lancet Neurology, 8(2), 151-157. doi:10.1016/s14744422(08)70295-3

Ballard, C., Neill, D., O'Brien, J., McKeith, I. G., Ince, P., \& Perry, R. (2000). Anxiety, depression and psychosis in vascular dementia: prevalence and associations. Journal of Affective Disorders, 59(2), 97-106.

Ballard, C. G., Margallo-Lana, M., Fossey, J., Reichelt, K., Myint, P., Potkins, D., \& O'Brien, J. (2001). A 1 -year follow-up study of behavioral and psychological symptoms in dementia among people in care environments. The Journal of Clinical Psychiatry, 62(8), 631-636.

Balsamo, M., Cataldi, F., Carlucci, L., \& Fairfield, B. (2018). Assessment of anxiety in older adults: a review of self-report measures. Clinical Interventions in Aging, 13, 573-593.

Banerjee, S., Smith, S., Lamping, D., Harwood, R., Foley, B., Smith, P., . . Mann, A. (2006). Quality of life in dementia: more than just cognition. An analysis of associations with quality of life in dementia. Journal of Neurology, Neurosurgery and Psychiatry, 77(2), 146-148.

Barca, M. L., Engedal, K., Laks, J., \& Selbæk, G. (2010a). A 12 months follow-up study of depression among nursing-home patients in Norway. Journal of Affective Disorders, 120(1), 141-148. doi:10.1016/j.jad.2009.04.028

Barca, M. L., Engedal, K., \& Selbæk, G. (2010b). A reliability and validity study of the cornell scale among elderly inpatients, using various clinical criteria. Dementia and Geriatric Cognitive Disorders, 29(5), 438-447. doi:10.1159/000313533. 
Barca, M. L., Engedal, K., Laks, J., \& Selbæk, G. (2011). Quality of Life among elderly patients with dementia in institutions. Dementia and Geriatric Cognitive Disorders, 31(6), 435-442. doi:10.1159/000328969

Barlow, D. H. (2002) The Experiences of anxiety. Shadow of intelligence or spector of death? In D. H. Barlow (Ed.), Anxiety and Its Disorders. The Nature and Treatment of Anxiety and Panic (2nd ed., pp. 1-36). New York: The Guilford Press.

Beaudreau, S. A., \& O'Hara, R. (2008). Late-life anxiety and cognitive impairment: a review. American Journal of Geriatric Psychiatry, 16(10), 790-803.

Beekman, A. T., de Beurs, E., van Balkom, A. J., Deeg, D. J., van Dyck, R., \& van Tilburg, W. (2000). Anxiety and depression in later life: co-occurrence and communality of risk factors. American Journal of Psychiatry, 157(1), 89-95.

Beerens, H. C., Zwakhalen, S. M. G., Verbeek, H., Ruwaard, D., \& Hamers, J. P. H. (2013). Factors associated with quality of life of people with dementia in long-term care facilities: a systematic review. International Journal of Nursing Studies, 50(9), 1259-1270. doi:10.1016/j.ijnurstu.2013.02.005

Bendixen, A. B., \& Engedal, K. (2015). Anxiety among older psychiatric patients: a hidden comorbidity? Aging \& Mental Health, 20(11), 1131-1138. doi:10.1080/13607863.2015.1063106

Bendixen, A. B., Engedal, K., Selbæk, G., \& Hartberg, C. B. (2018). Anxiety symptoms in older adults with depression are associated with suicidality. Dementia and Geriatric Cognitive Disorders, 45(3-4), 180-189. doi:10.1159/000488480

Bennett, H. E., \& Lincoln, N. B. (2006). Potential screening measures for depression and anxiety after stroke. International Journal of Therapy and Rehabilitation, 13(9), 401-406. doi:10.12968/ijtr.2006.13.9.21784

Bentsen, B. G. (1986). International classification of primary care. Scandinavian Journal of Primary Health Care, 4(1), 43-50.

Bentvelzen, A., Aerts, L., Seeher, K., Wesson, J., \& Brodaty, H. (2017). A Comprehensive review of the quality and feasibility of dementia assessment measures: the dementia outcomes measurement suite. Journal of the American Medical Directors Association, 18(10), 826-837. doi:https://doi.org/10.1016/j.jamda.2017.01.006

Bergh, S., Engedal, K., Røen, I., \& Selbæk, G. (2011). The course of neuropsychiatric symptoms in patients with dementia in Norwegian nursing homes. International Psychogeriatrics, 23(8), 1231-1239. doi:10.1017/S1041610211001177

Bergh, S., \& Selbæk, G. (2012). [The prevalence and the course of neuropsychiatric symptoms in patients with dementia]. Norsk Epidemiologi, 22(2), 225-232.

Bierman, E. J. M., Comijs, H. C., Jonker, C., \& Beekman, A. T. F. (2007). Symptoms of anxiety and depression in the course of cognitive decline. Dementia and Geriatric Cognitive Disorders, 24(3), 213-219.

Brod, M., Stewart, A. L., Sands, L., \& Walton, P. (1999a). Conceptualization and measurement of quality of life in dementia: the dementia quality of life instrument (DQoL). The Gerontologist, 39(1), 25-36.

Brod, M., Stewart, A. L., \& Sands, L. (1999b). Conceptualization of quality of life in dementia. Journal of Mental Health and Aging, 5(1), 7-19.

Bryant, C., Jackson, H., \& Ames, D. (2008). The prevalence of anxiety in older adults: methodological issues and a review of the literature. Journal of Affective Disorders, 109(3), 233-250. doi:10.1016/j.jad.2007.11.008

Bryant, C., Mohlman, J., Gum, A., Stanley, M., Beekman, A. T. F., Wetherell, J. L., . . Lenze, E. J. (2013). Anxiety disorders in older adults: looking to DSM5 and beyond. The American Journal of Geriatric Psychiatry : official journal of the American Association for Geriatric Psychiatry, 21(9), 872. doi:10.1016/j.jagp.2013.01.011

Byrne, G. J., \& Pachana, N. A. (2011). Development and validation of a short form of the Geriatric Anxiety Inventory--The GAI-SF. International Psychogeriatrics, 23(1), 125-131. 
Calleo, J. S., Kunik, M. E., Reid, D., Kraus-Schuman, C., Paukert, A., Regev, T., . . Stanley, M. (2011). Characteristics of generalized anxiety disorder in patients with dementia. American Journal of Alzheimer's Disease and Other Dementias, 26(6), 492-497. doi:1533317511426867

Carpentier, M., Combescure, C., Merlini, L., \& Perneger, T. V. (2017). Kappa statistic to measure agreement beyond chance in free-response assessments. BMC Medical Research Methodology, 17, 1-8. doi:10.1186/s12874-017-0340-6

Carr, A. J., \& Higginson, I. J. (2001). Are quality of life measures patient centred? British Medical Journal, 322(7298), 1357-1360.

Caselli, R. J., Reiman, E. M., Hentz, J. G., Osborne, D., \& Alexander, G. E. (2004). A Distinctive interaction between chronic anxiety and problem solving in asymptomatic APOE e4 homozygotes. The Journal of Neuropsychiatry and Clinical Neurosciences, 16(3), 320-329. doi:10.1176/jnp.16.3.320

Chen, J. C., Borson, S., \& Scanlan, J. M. (2000). Stage-specific prevalence of behavioral symptoms in Alzheimer's disease in a multi-ethnic community sample. The American Journal of Geriatric Psychiatry, 8(2), 123-133.

Cheng, S. T., Kwok, T., \& Lam, L. C. (2012). Neuropsychiatric symptom clusters of Alzheimer's disease in Hong Kong Chinese: prevalence and confirmatory factor analysis of the neuropsychiatric inventory. International Psychogeriatrics, 24(9), 1465-1473. doi:10.1017/s1041610212000609

Chenoweth, L., King, M. T., Jeon, Y.-H., Brodaty, H., Stein-Parbury, J., Norman, R., . . Luscombe, G. (2009). Caring for aged dementia care resident study (CADRES) of person-centred care, dementia-care mapping, and usual care in dementia: a cluster-randomised trial. Lancet Neurology, 8(4), 317-325. doi:10.1016/S1474-4422(09)70045-6

Chow, T. W., Liu, C. K., Fuh, J. L., Leung, V. P., Tai, C. T., Chen, L. W., .. Cummings, J. L. (2002). Neuropsychiatric symptoms of Alzheimer's disease differ in Chinese and American patients. International Journal of Geriatric Psychiatry, 17(1), 22-28.

Cicchetti, D. V. (1976). Assessing inter-rater reliability for rating scales: resolving some basic issues. The British Journal of Psychiatry, 129(5), 452-456.

Clare, L. (2003). Managing threats to self: awareness in early stage Alzheimer's disease. Social Science and Medicine, 57(6), 1017-1029.

Cohen, G. (1998). Anxiety in Alzheimer's disease: theoretical and clinical perspectives. Journal of Geriatric Psychiatry, 31, 103-116.

Cooke, M. L., Moyle, W., Shum, D. H. K., Harrison, S. D., \& Murfield, J. E. (2010). A randomized controlled trial exploring the effect of music on agitated behaviours and anxiety in older people with dementia. Aging and Mental Health, 14(8), 905-916. doi:10.1080/13607861003713190.

Creighton, A. S., Davison, T. E., \& Kissane, D. W. (2016). The prevalence of anxiety among older adults in nursing homes and other residential aged care facilities: a systematic review. International Journal of Geriatric Psychiatry, 31(6), 555-566.

Creighton, A. S., Davison, T. E., \& Kissane, D. W. (2017). The correlates of anxiety among older adults in nursing homes and other residential aged care facilities: a systematic review. International Journal of Geriatric Psychiatry, 32(2), 141-154.

Creighton, A. S., Davison, T. E., \& Kissane, D. W. (2018a). The factors associated with anxiety symptom severity in older adults living in nursing homes and other residential aged care facilities. Journal of Aging and Health, 1-24. doi:10.1177/0898264318767781

Creighton, A. S., Davison, T. E., \& Kissane, D. W. (2018b). The psychometric properties, sensitivity and specificity of the geriatric anxiety inventory, hospital anxiety and depression scale, and rating anxiety in dementia scale in aged care residents. Aginging \& Mental Health, 1-10. doi:10.1080/13607863.2018.1439882

Cummings, J. L., Mega, M., Gray, K., Rosenberg-Thompson, S., \& et al. (1994). The Neuropsychiatric inventory: comprehensive assessment of psychopathology in dementia. Neurology, 44(12), 2308-2314. 
Devier, D. J., Pelton, G. H., Tabert, M. H., Liu, X., Cuasay, K., Eisenstadt, R., . . Devanand, D. (2009). The impact of anxiety on conversion from mild cognitive impairment to Alzheimer's disease. International Journal of Geriatric Psychiatry, 24(12), 1335-1342.

Douglas, S., James, I., \& Ballard, C. (2004). Non-pharmacological interventions in dementia. Advances in Psychiatric Treatment, 10(3), 171-177.

Dröes, R.-M., Van Der Roest, H. G., Van Mierlo, L., \& Meiland, F. J. (2011). Memory problems in dementia: adaptation and coping strategies and psychosocial treatments. Expert Review of Neurotherapeutics, 11(12), 1769-1782. doi:10.1586/ern.11.167

Edvardsson, D., Winblad, B., \& Sandman, P. O. (2008). Person-centred care of people with severe Alzheimer's disease: current status and ways forward. Lancet Neurology, 7(4), 362-367. doi:10.1016/s1474-4422(08)70063-2

Edwards, M. N., Gardiner, M. M., Ritchie, M. D., Baldwin, M. K., \& Sands, M. L. (2008). Effect of exercise on negative affect in residents in special care units with moderate to severe dementia. Alzheimer Disease and Associated Disorders, 22(4), 362-368. doi:10.1097/WAD.0b013e31818ecbbc

Engedal, K., \& Haugen, P. K. (1993). The prevalence of dementia in a sample of elderly norwegians. International Journal of Geriatric Psychiatry, 8(7), 565-570. doi:doi:10.1002/gps.930080706

Engedal, K., Haugen, P. K., \& Brækhus, A. (2018). Demens : sykdommer, diagnostikk og behandling. Tønsberg, Norway: Aldring og helse.

Engel, G. L. (1977). The need for a new medical model: a challenge for biomedicine. Science, 196(4286), 129-136.

Ettema, T. P., Droes, R. M., de Lange, J., Ooms, M. E., Mellenbergh, G. J., \& Ribbe, M. W. (2005). The concept of quality of life in dementia in the different stages of the disease. International Psychogeriatrics, 17(3), 353-370.

Eugene, k., \& Joshua, T. (2010). Anxiety disorders Rosen's emergency medicine : concepts and clinical practice (Vol. 2, pp. 1445-1451). Philadelphia: Mosby/Elsevier.

Ferretti, L., McCurry, S. M., Logsdon, R., Gibbons, L., \& Teri, L. (2001). Anxiety and Alzheimer's disease. Journal of Geriatric Psychiatry and Neurology, 14(1), 52-58.

Field, A. (2013). Discovering statistics using IBM SPSS statistics : and sex and drugs and rock ' $n$ ' roll (4th ed.). Los Angeles: SAGE.

Finkel, S. I., e Silva, J. C., Cohen, G., Miller, S., \& Sartorius, N. (1997). Behavioral and psychological signs and symptoms of dementia: a consensus statement on current knowledge and implications for research and treatment. International Psychogeriatrics, 8(S3), 497-500.

Fog, A. F., Kvalvaag, G., Engedal, K., \& Straand, J. (2017). Drug-related problems and changes in drug utilization after medication reviews in nursing homes in Oslo, Norway. Scandinavian Journal of Primary Health Care, 35(4), 329-335. doi:10.1080/02813432.2017.1397246

Folstein, M. F., Folstein, S. E., \& McHugh, P. R. (1975). "Mini-mental state". A practical method for grading the cognitive state of patients for the clinician. Journal of Psychiatric Research, 12(3), 189-198. doi: 10.1016/0022-3956(75)90026-6.

Forsell, Y., \& Winblad, B. (1998). Major depression in a population of demented and nondemented older people: prevalence and correlates. Journal of the American Geriatrics Society, 46(1), 2730.

Fried, E. I. (2017). The 52 symptoms of major depression: Lack of content overlap among seven common depression scales. Journal of Affective Disorders, 208, 191-197. doi:10.1016/j.jad.2016.10.019

Gale, S. A., Acar, D., \& Daffner, K. R. (2018). Dementia. The American Journal of Medicine, 131(10), 1161-1169. doi:10.1016/j.amjmed.2018.01.022

Gallacher, J., Bayer, A., Fish, M., Pickering, J., Pedro, S., Dunstan, F., . . Ben-Shlomo, Y. (2009). Does anxiety affect risk of dementia? Findings from the Caerphilly prospective study. Psychosomatic Medicine, 71(6), 659-666.

Garden, M., \& Toft, A. (2013). Norway. In Alzheimer Europe (Ed.), Dementia in Europe: Yearbook 2013: National policies covering the care and support of people with dementia and their 
cares: including the Alzheimers Europe annual report 2012 (pp. 132-137). [Luxembourg]: Alzheimer Europe.

Gerolimatos, L. A., Ciliberti, C. M., Gregg, J. J., Nazem, S., Bamonti, P. M., Cavanagh, C. E., \& Edelstein, B. A. (2015). Development and preliminary evaluation of the anxiety in cognitive impairment and dementia (ACID) scales. International Psychogeriatrics, 27(11), 1825-1838.

Gibbons, L. E., Teri, L., Logsdon, R., McCurry, S. M., Kukull, W., Bowen, J., . . Larson, E. (2002). Anxiety symptoms as predictors of nursing home placement in patients with Alzheimer's disease. Journal of Clinical Geropsychology, 8(4), 335-342. doi:10.1023/A:1019635525375

Gjøra, L., Eek, A., \& Kirkevold, Ø. (2015). Nasjonal kartlegging av tilbudet til personer med demens. Tønsberg, Norway: Aldring og helse.

Gould, K. R., Ponsford, J. L., \& Spitz, G. (2014). Association between cognitive impairments and anxiety disorders following traumatic brain injury. Journal of Clinical and Experimental Neuropsychology, 36(1), 1-14. doi:10.1080/13803395.2013.863832

Goyal, A. R., Engedal, K., \& Eriksen, S. (2016a). Clinicians experiences of anxiety in patients with dementia. Dementia. doi:10.1177/1471301216659770

Goyal, A. R., Bergh, S., Engedal, K., Kirkevold, M., \& Kirkevold, $\varnothing$. (2016b). Norwegian version of the rating anxiety in dementia scale (RAID-N): a validity and reliability study. Aging \& Mental Health, 21(12), 1256-1261. doi:10.1080/13607863.2016.1220921

Grenier, S., Préville, M., Boyer, R., O'Connor, K., Béland, S.-G., Potvin, O., . . . the Scientific Committee of the, E. S. A. S. (2011). The impact of DSM-IV symptom and clinical significance criteria on the prevalence estimates of subthreshold and threshold anxiety in the older adult population. The American Journal of Geriatric Psychiatry, 19(4), 316-326. doi:10.1097/JGP.0b013e3181ff416c

Grossberg, G. T. (2003). Diagnosis and treatment of Alzheimer's disease. The Journal of Clinical Psychiatry, 64(9), 3-6.

Gulla, C., Selbaek, G., Flo, E., Kjome, R., Kirkevold, O., \& Husebo, B. S. (2016). Multi-psychotropic drug prescription and the association to neuropsychiatric symptoms in three Norwegian nursing home cohorts between 2004 and 2011. BMC Geriatrics, 16(1), 1-9. doi:10.1186/s12877-0160287-1

Gurian, B. S., \& Miner, J. H. (1991). Clinical presentation of anxiety in the elderly. In C. Salzman \& B. D. Lebowitz (Eds.), Anxiety in the Elderly: Treatment \& Research (pp. 31-42). New York: Springer publishing company.

Gustafson, L. (1995). Treatment of anxiety in patients with dementia. In S. I. S. Läkemedelsverket (Ed.), Treatment of Mental Conditions in Patients with Dementia (pp. 93-99): Oslo/Uppsala.

Hall, G. R., \& Buckwalter, K. C. (1987). Progressively lowered stress threshold: a conceptual model for care of adults with Alzheimer's disease. Archives of Psychiatric Nursing, 1(6), 399-406.

Halvorsen, K. H., Selbæk, G., \& Ruths, S. (2017). Trends in potentially inappropriate medication prescribing to nursing home patients: comparison of three cross-sectional studies. Pharmacoepidemiology and Drug Safety, 26(2), 192-200. doi:10.1002/pds.4142

Hancock, G. A., Woods, B., Challis, D., \& Orrell, M. (2006). The needs of older people with dementia in residential care. International Journal of Geriatric Psychiatry, 21(1), 43-49. doi:10.1002/gps.1421

Hashimoto, H., Monserratt, L., Nguyen, P., Feil, D., Harwood, D., Mandelkern, M. A., \& Sultzer, D. L. (2006). Anxiety and regional cortical glucose metabolism in patients with Alzheimer's disease. The Journal of Neuropsychiatry and Clinical Neurosciences, 18(4), 521-528.

Hellström, I., Nolan, M., Nordenfelt, L., \& Lundh, U. (2007). Ethical and methodological issues in interviewing persons with dementia. Nursing Ethics, 14(5), 608-619. doi:10.1177/0969733007080206

Helse- og omsorgsdepartementet. (2013). Forskrift for sykehjem og boform for heldøgns omsorg og pleie. Retrieved from https://lovdata.no/dokument/SF/forskrift/1988-11-14-932 
Helsedirektoratet. (2017). Nasjonal faglig retningslinje om demens. Retrieved from https://helsedirektoratet.no/retningslinjer/nasjonal-faglig-retningslinje-om-demens

Hoe, J., Hancock, G., Livingston, G., \& Orrell, M. (2006). Quality of life of people with dementia in residential care homes. The British Journal of Psychiatry, 188(5), 460-464.

Hoe, J., Hancock, G., Livingston, G., Woods, B., Challis, D., \& Orrell, M. (2009). Changes in the quality of life of people with dementia living in care homes. Alzheimer Disease and Associated Disorders, 23(3), 285-290.

Hofmans-Okkes, I., \& Lamberts, H. (1996). The international classification of primary care (ICPC): new applications in research and computer-based patient records in family practice. Family Practice, 13(3), 294-302.

Holmes, S. E., Esterlis, I., Mazure, C. M., Lim, Y. Y., Ames, D., Rainey-Smith, S., . . Maruff, P. (2018). Trajectories of depressive and anxiety symptoms in older adults: a 6-year prospective cohort study. International Journal of Geriatric Psychiatry, 33(2), 405-413. doi:10.1002/gps.4761

Hongisto, K., Hallikainen, I., Selander, T., Törmälehto, S., Väätäinen, S., Martikainen, J., . . Koivisto, A. M. (2018). Quality of life in relation to neuropsychiatric symptoms in Alzheimer's disease: 5-year prospective ALSOVA cohort study. International Journal of Geriatric Psychiatry, 33(1), 47-57. doi:10.1002/gps.4666

Hughes, C. P., Berg, L., Danziger, W. L., Coben, L. A., \& Martin, R. L. (1982). A new clinical scale for the staging of dementia. British Journal of Psychiatry, 140, 566-572. doi: 10.1192/bjp.140.6.566

Hynninen, M. J., Breitve, M. H., Rongve, A., Aarsland, D., \& Nordhus, I. H. (2012). The frequency and correlates of anxiety in patients with first-time diagnosed mild dementia. International Psychogeriatrics, 24(11), 1771-1778.

Hynninen, M. J., Breitve, M. H., Wiborg, A. B., Pallesen, S., \& Nordhus, I. H. (2005). Psychological characteristics of patients with chronic obstructive pulmonary disease: a review. Journal of Psychosomatic Research, 59(6), 429-443. doi:10.1016/j.jpsychores.2005.04.007

Jeste, D. V., Blazer, D. G., \& First, M. (2005). Aging-related diagnostic variations: need for diagnostic criteria appropriate for elderly psychiatric patients. Biological Psychiatry, 58(4), 265-271.

Johannessen, A., Helvik, A.-S., Engedal, K., \& Sørlie, V. M. (2016). Older peoples' narratives of use and misuse of alcohol and psychotropic drugs. Scandinavian Journal of Caring Sciences, 30(3), 586-593. doi:doi:10.1111/scs.12282

Johansson, A., \& Gustafson, L. (1996). Psychiatric symptoms in patients with dementia treated in a psychogeriatric day hospital. International Psychogeriatrics, 8(4), 645-658. doi:10.1017/S1041610296002955

John, A., Patel, U., Rusted, J., Richards, M., \& Gaysina, D. (2018). Affective problems and decline in cognitive state in older adults: a systematic review and meta-analysis. Psychological medicine, 1-13. doi:10.1017/\$0033291718001137

Jonker, C., Gerritsen, D. L., Bosboom, P. R., \& Van der Steen, J. T. (2004). A Model for quality of life measures in patients with dementia: Lawton's next step. Dementia and Geriatric Cognitive Disorders, 18(2), 159-164. doi:10.1159/000079196

Kaufer, D. I., Cummings, J. L., Ketchel, P., Smith, V., MacMillan, A., Shelley, T., ... DeKosky, S. T. (2000). Validation of the NPI-Q, a brief clinical form of the neuropsychiatric inventory. The Journal of Neuropsychiatry and Clinical Neurosciences, 12(2), 233-239.

Kirkevold, M., \& Gonzalez, M. T. (2012). Betydningen av sansehage og terapeutisk hagebruk for personer med demens. Sykepleien Forskning, 7(1), 52-64. doi:10.4220/sykepleienf.2012.0029

Kirkevold, $\varnothing$., Eek, A., \& Engedal, K. (2012). Development of residential care services facilitated for persons with dementia in Norway. Aging Clinical and Experimental Research, 24(1), 1-5.

Kitwood, T. (1990). The dialectics of dementia: with particular reference to Alzheimer's disease. Ageing and Society, 10(2), 177-196. doi:10.1017/S0144686X00008060

Kitwood, T. M. (1997). Dementia reconsidered : the person comes first. Berkshire, UK: Open University Press. 
Kueper, J. K., Speechley, M., Lingum, N. R., \& Montero-Odasso, M. (2017). Motor function and incident dementia: a systematic review and meta-analysis. Age and Ageing, 46(5), 729-738. doi:10.1093/ageing/afx084

Kvaal, K., \& Laake, K. (2003). Anxiety and well-being in older people after discharge from hospital. Journal of Advanced Nursing, 44(3), 271-277.

Kvaal, K., Macijauskiene, J., Engedal, K., \& Laake, K. (2001). High prevalence of anxiety symptoms in hospitalized geriatric patients. International Journal of Geriatric Psychiatry, 16(7), 690-693.

Lai, C. K. Y. (2014). The merits and problems of neuropsychiatric inventory as an assessment tool in people with dementia and other neurological disorders. Clinical Interventions in Aging, 9, 1051-1061. doi:10.2147/CIA.S63504

Landis, J. R., \& Koch, G. G. (1977). The measurement of observer agreement for categorical data. Biometrics, 33(1), 159-174.

Lawton, M. P. (1994). Quality of life in Alzheimer disease. Alzheimer Disease and Associated Disorders, 8(Suppl 3), 138-150.

Lawton, M. P. (1997). Assessing quality of life in Alzheimer disease research. Alzheimer Disease and Associated Disorders, 11 (Suppl 6), 91-99.

Lawton, M. P., \& Brody, E. M. (1969). Assessment of older people: self-maintaining and instrumental activities of daily living. Gerontologist, 9(3), 179-186.

Le Roux, H., Gatz, M., \& Wetherell, J. L. (2005). Age at onset of generalized anxiety disorder in older adults. American Journal of Geriatric Psychiatry, 13(1), 23-30.

Lenze, E. J., Mulsant, B. H., Mohlman, J., Shear, M. K., Dew, M. A., Schulz, R., . . Reynolds, C. F. (2005). Generalized anxiety disorder in late life: lifetime course and comorbidity with major depressive disorder. American Journal of Geriatric Psychiatry, 13(1), 77-80.

Li, S. C., Lindenberger, U., \& Sikstrom, S. (2001). Aging cognition: from neuromodulation to representation. Trends in Cognitive Sciences, 5(11), 479-486.

$\mathrm{Li}, \mathrm{X}$. X., \& Li, Z. (2018). The impact of anxiety on the progression of mild cognitive impairment to dementia in Chinese and English data bases: a systematic review and meta-analysis. International Journal of Geriatric Psychiatry, 33(1), 131-140. doi:10.1002/gps.4694

Lichtwarck, B., Selbæk, G., Kirkevold, O., Rokstad, A. M. M., Benth, J. S., Lindstrom, J. C., \& Bergh, S. (2018). Targeted interdisciplinary model for evaluation and treatment of neuropsychiatric symptoms: a cluster randomized controlled trial. American Journal of Geriatric Psychiatry, 26(1), 25-38. doi:10.1016/j.jagp.2017.05.015

Lindesay, J., Baillon, S., Brugha, T., Dennis, M., Stewart, R., Araya, R., \& Meltzer, H. (2006). Worry content across the lifespan: an analysis of 16-to 74-year-old participants in the British national survey of psychiatric morbidity 2000. Psychological Medicine, 36(11), 1625-1633.

Lindesay, J., Stewart, R., \& Bisla, J. (2012). Anxiety disorders in older people. Reviews in Clinical Gerontology, 22(3), 204-217. doi:10.1017/S0959259812000019

Liston, H. E. (1979). Clinical findings in presenile dementia a report of 50 cases. The Journal of Nervous and Mental Disease, 167(6), 337-342. doi:10.1097/00005053-197906000-00002

Livingston, G., Sommerlad, A., Orgeta, V., Costafreda, S. G., Huntley, J., Ames, D., . . Mukadam, N. (2017). Dementia prevention, intervention, and care. Lancet, 390(10113), 2673-2734. doi:10.1016/S0140-6736(17)31363-6

Low, L. F., Brodaty, H., \& Draper, B. (2002). A study of premorbid personality and behavioural and psychological symptoms of dementia in nursing home residents. International Journal of Geriatric Psychiatry, 17(8), 779-783. doi:10.1002/gps.697

Lyketsos, C. G., Galik, E., Steele, C., Steinberg, M., Rosenblatt, A., Warren, A., . . Brandt, J. (1999). The general medical health rating: a bedside global rating of medical comorbidity in patients with dementia. Journal of the American Geriatrics Society, 47(4), 487-491.

Lyketsos, C. G., Sheppard, J. M. E., Steinberg, M., Tschanz, J. A. T., Norton, M. C., Steffens, D. C., \& Breitner, J. (2001). Neuropsychiatric disturbance in Alzheimer's disease clusters into three groups: the Cache County study. International Journal of Geriatric Psychiatry, 16(11), 10431053. 
Mak, E., Su, L., Williams, G. B., \& O’Brien, J. T. (2014). Neuroimaging characteristics of dementia with Lewy bodies. Alzheimer's Research \& Therapy, 6(2), 18-18. doi:10.1186/alzrt248

Maneesriwongul, W., \& Dixon, J. K. (2004). Instrument translation process: a methods review. Journal of Advanced Nursing, 48(2), 175-186. doi:10.1111/j.1365-2648.2004.03185.x

Martin-Cook, K., Hynan, L. S., Rice-Koch, K., Svetlik, D. A., \& Weiner, M. F. (2005). Responsiveness of the quality of life in late-stage dementia scale to psychotropic drug treatment in late-stage dementia. Dementia and Geriatric Cognitive Disorders, 19(2-3), 82-85. doi:10.1159/000082353

Martyr, A., Nelis, S. M., Quinn, C., Wu, Y. T., Lamont, R. A., Henderson, C., . . Clare, L. (2018). Living well with dementia: a systematic review and correlational meta-analysis of factors associated with quality of life, well-being and life satisfaction in people with dementia. Psychological Medicine, 48(13), 2130-2139. doi:10.1017/s0033291718000405

McClive-Reed, K. P., \& Gellis, Z. D. (2011). Anxiety and related symptoms in older persons with dementia: directions for practice. Journal of Gerontological Social Work, 54(1), 6-28. doi:10.1080/01634372.2010.524284

McCurry, S. M., Gibbons, L. E., Logsdon, R. G., \& Teri, L. (2004). Anxiety and nighttime behavioral disturbances: awakenings in patients with Alzheimer's disease. Journal of Gerontological Nursing, 30(1), 12-20.

McKeith, I. (2007). Dementia with Lewy bodies: handbook of clinical neurology: Vol. 84 (3rd series, pp. 531-548). Switzerland: Elsevier.

McKhann, G. M., Albert, M. S., Grossman, M., Miller, B., Dickson, D., \& Trojanowski, J. Q. (2001). Clinical and pathological diagnosis of frontotemporal dementia: report of the work group on frontotemporal dementia and pick's disease. Archives of Neurology, 58(11), 1803-1809. doi:10.1001/archneur.58.11.1803

Mega, M. S., Cummings, J. L., Fiorello, T., \& Gornbein, J. (1996). The spectrum of behavioral changes in Alzheimer's disease. Neurology, 46(1), 130-135.

Miesen, B., \& Jones, G. M. M. (2006). Care-giving in dementia : research and applications. London: Routledge.

Ministry of Health and Care Services. (2007). Public health. Retrieved from https://www.regjeringen.no/en/dep/hod/About-the-Ministry/id426/

Ministry of health and Care Services. (2008). Act on medical and health research. Retrieved from https://www.regjeringen.no/globalassets/upload/hod/hra/helseforskning/helseforskningslov en---engelsk-endelig-29-06-09.pdf?id=2287768

Ministry of Health and Care Services. (2011). Lov om kommunale helse- og omsorgstjenester m.m. (helse- og omsorgstjenesteloven). Retrieved from https://lovdata.no/dokument/NL/lov/2011-06-24-30

Ministry of Health and Care Services. (2015). Dementia Plan 2020. (I-1170 E). Retrieved from https://www.regjeringen.no/contentassets/3bbec72c19a04af88fa78ffb02a203da/dementia -plan_2020_long.pdf

Missotten, P., Dupuis, G., \& Adam, S. (2016). Dementia-specific quality of life instruments: a conceptual analysis. International Psychogeriatrics, 28(8), 1245-1262. doi:10.1017/s1041610216000417

Mjørud, M., Kirkevold, M., Røsvik, J., Selbæk, G., \& Engedal, K. (2014). Variables associated to quality of life among nursing home patients with dementia. Aging \& Mental Health, 18(8), 10131021.

Mjørud, M., Røsvik, J., Rokstad, A. M. M., Kirkevold, M., \& Engedal, K. (2014). Variables associated with change in quality of life among persons with dementia in nursing homes: a 10 months follow-up study. PloS One, 9(12), 1-17. doi:10.1371/journal.pone.0115248

Mohlman, J., Bryant, C., Lenze, E. J., Stanley, M. A., Gum, A., Flint, A., . . Craske, M. G. (2012). Improving recognition of late life anxiety disorders in diagnostic and statistical manual of mental disorders, fifth edition: observations and recommendations of the advisory 
committee to the lifespan disorders work group. International Journal of Geriatric Psychiatry, 27(6), 549-556. doi:10.1002/gps.2752

Mozley, C. G., Huxley, P., Sutcliffe, C., Bagley, H., Burns, A., Challis, D., \& Cordingley, L. (1999). 'Not knowing where I am doesn't mean I don't know what I like': cognitive impairment and quality of life responses in elderly people. International Journal of Geriatric Psychiatry, 14(9), 776783.

Neville, C., \& Teri, L. (2011). Anxiety, anxiety symptoms, and associations among older people with dementia in assisted-living facilities. International Journal of Mental Health Nursing, 20(3), 195-201. doi: 10.1111/j.1447-0349.2010.00724.x

Nice guideline, N. I. f. H. a. C. E. (2018). Dementia: assessment, mangement and support for people living with dementia and their carers. Retrieved from https://www.nice.org.uk/guidance/ng97. .

Nordhus, I. H. (2008). Manifestations of depression and anxiety in older adults. In B. Woods \& L. Clare (Eds.), Handbook of the clinical psychology of ageing (2nd ed., pp. 95-110). West Sussex, England: John Wiley \& Sons Ltd.

Nordhus, I. H., Skjerve, S., \& Aasen, H. S. (2006). Demens, samtykkekompetanse og rett til selvbestemmelse; utfordringer ved behandling og forskning. Nordisk Tidsskrift for Menneskerettigheter, 24 (4), 362-371.

O'Brien, J. (2005). Dementia associated with psychiatric disorders. International Psychogeriatrics, 17 (Suppl 1), 207-221.

O'Rourke, H., Duggleby, W., Fraser, K., \& Jerke, L. (2015). Factors that affect quality of life from the perspective of people with dementia: a metasynthesis. Journal of the American Geriatrics Society, 63(1), 24-28. doi:10.1111/jgs.13178

O’Bryant, S. E., Waring, S. C., Cullum, C. M., Hall, J., Lacritz, L., Massman, P. J., . . . Doody, R. (2008). Staging dementia using clinical dementia rating scale sum of boxes scores: a Texas Alzheimer's research consortium study. Archives of Neurology, 65(8), 1091-1095. doi:10.1001/archneur.65.8.1091

Orgeta, V., Qazi, A., Spector, A., \& Orrell, M. (2015). Psychological treatments for depression and anxiety in dementia and mild cognitive impairment: systematic review and meta-analysis. The British Journal of Psychiatry, 207(4), 293-298.

Orrell, M., \& Bebbington, P. (1996). Psychosocial stress and anxiety in senile dementia. Journal of Affective Disorders, 39(3), 165-173. doi:10.1016/0165-0327(95)00094-1

Ownby, R. L., Harwood, D. G., Barker, W. W., \& Duara, R. (2000). Predictors of anxiety in patients with Alzheimer's disease. Depression and Anxiety, 11(1), 38-42. doi:10.1002/(SICI)15206394(2000)11:1<38::AID-DA6>3.0.CO;2-E

Pachana, N. A., Byrne, G. J., Siddle, H., Koloski, N., Harley, E., \& Arnold, E. (2007). Development and validation of the geriatric anxiety inventory. International Psychogeriatrics, 19(1), 103-114. doi:10.1017/S1041610206003504

Payne, J. L., Sheppard, J. M., Steinberg, M., Warren, A., Baker, A., Steele, C., . . Lyketsos, C. G. (2002). Incidence, prevalence, and outcomes of depression in residents of a long-term care facility with dementia. International Journal of Geriatric Psychiatry, 17(3), 247-253.

Polit, D. F., \& Beck, C. T. (2012). Nursing research: generating and assessing evidence for nursing practice (9th ed.). Philadelphia, Pennsylvania: Wolters Kluwer Health.

Porta, M. (2014). A Dictionary of epidemiology (6th ed.). Oxford: Oxford University Press.

Porter, V. R., Buxton, W. G., Fairbanks, L. A., Strickland, T., O'Connor, S. M., Rosenberg-Thompson, S., \& Cummings, J. L. (2003). Frequency and characteristics of anxiety among patients with Alzheimer's disease and related dementias. The Journal of Neuropsychiatry and Clinical Neurosciences, 15(2), 180-186.

Prince, M., Bryce, R., Albanese, E., Wimo, A., Ribeiro, W., \& Ferri, C. P. (2013). The global prevalence of dementia: a systematic review and metaanalysis. Alzheimer's \& Dementia, 9(1), 63-75. doi:10.1016/j.jalz.2012.11.007 
Qazi, A., Spector, A., \& Orrell, M. (2010). User, carer and staff perspectives on anxiety in dementia: a qualitative study. Journal of Affective Disorders, 125(1-3), 295-300.

Rabins, P. V., \& Kasper, J. D. (1997). Measuring quality of life in dementia: conceptual and practical issues. Alzheimer Disease and Associated Disorders, 11(Supp/ 6), 100-104.

Rabins, P. V., Kasper, J. D., Kleinman, L., Black, B. S., \& Patrick, D. L. (1999). Concepts and methods in the development of the ADRQL: an instrument for assessing health-related quality of life in persons with Alzheimer's disease. Journal of Mental Health \& Aging, 5(1), 33-48.

Reisberg, B. (1996a). Behavioral intervention approaches to the treatment and management of Alzheimer's disease: a research agenda. International Psychogeriatrics, 8 Suppl 1, 38.

Reisberg, B., Auer, S. R., \& Monteiro, I. M. (1996b). Behavioral pathology in Alzheimer's disease (BEHAVE-AD) rating scale. International Psychogeriatrics, 8 (Supp/ 3), 301-308.

Roen, I., Selbaek, G., Kirkevold, O., Engedal, K., Testad, I., \& Bergh, S. (2017). Resourse use and disease course in dementia - nursing home (REDIC-NH), a longitudinal cohort study; design and patient characteristics at admission to Norwegian nursing homes. BMC Health Services Research, 17, 1-15. doi:10.1186/s12913-017-2289-x

Rokstad, A. M. M., Røsvik, J., Kirkevold, Ø., Selbaek, G., Saltyte Benth, J., \& Engedal, K. (2013). The effect of person-centred dementia care to prevent agitation and other neuropsychiatric symptoms and enhance quality of life in nursing home patients: a 10-month randomized controlled trial. Dementia and Geriatric Cognitive Disorders, 36(5-6), 340-353.

Román, G. C. (2003). Vascular dementia: distinguishing characteristics, treatment, and prevention. Journal of the American Geriatrics Society, 51(5s2), 296-304. doi:doi:10.1046/j.15325415.5155.x

Rosvik, J., Kirkevold, M., Engedal, K., Brooker, D., \& Kirkevold, O. (2011). A model for using the VIPS framework for person-centred care for persons with dementia in nursing homes: a qualitative evaluative study. International Journal of Older People Nursing, 6(3), 227-236. doi:10.1111/j.1748-3743.2011.00290.x

Røen, I., Selbæk, G., Kirkevold, Ø., Engedal, K., Lerdal, A., \& Bergh, S. (2015). The reliability and validity of the Norwegian version of the quality of life in late-stage dementia scale. Dementia and Geriatric Cognitive Disorders, 40(3-4), 233-242.

Sadavoy, J. (1991). Psychodynamic perspectives on Alzheimer's disease and related dementias. American Journal of Alzheimer's Care and Related Disorders \& Research, 6(3), 12-20. doi:10.1177/153331759100600304

Salzman, C., \& Lebowitz, B. D. (Eds.). (1991). Anxiety in the elderly: Treatment \& Research. New York: Springer.

Schoevers, R. A., Beekman, A., Deeg, D., Jonker, C., \& Tilburg, W. v. (2003). Comorbidity and risk-patterns of depression, generalised anxiety disorder and mixed anxiety-depression in later life: results from the AMSTEL study. International Journal of Geriatric Psychiatry, 18(11), 994-1001.

Schoevers, R. A., Deeg, D., Van Tilburg, W., \& Beekman, A. (2005). Depression and generalized anxiety disorder: co-occurrence and longitudinal patterns in elderly patients. The American Journal of Geriatric Psychiatry, 13(1), 31-39.

Seignourel, P. J., Kunik, M. E., Snow, L., Wilson, N., \& Stanley, M. (2008). Anxiety in dementia: a critical review. Clinical Psychology Review, 28(7), 1071-1082. doi: 10.1016/j.cpr.2008.02.008

Selbæk, G., Kirkevold, $\varnothing$., \& Engedal, K. (2007). The prevalence of psychiatric symptoms and behavioural disturbances and the use of psychotropic drugs in Norwegian nursing homes. International Journal of Geriatric Psychiatry, 22(9), 843-849.

Selbæk, G., Kirkevold, $\varnothing$., \& Engedal, K. (2008a). The course of psychiatric and behavioral symptoms and the use of psychotropic medication in patients with dementia in Norwegian nursing homes-a 12-month follow-up study. The American Journal of Geriatric Psychiatry, 16(7), 528-536. 
Selbæk, G., Kirkevold, Ø., Sommer, O. H., \& Engedal, K. (2008b). The reliability and validity of the Norwegian version of the neuropsychiatric inventory, nursing home version (NPI-NH). International Psychogeriatrics, 20(2), 375-382. doi:10.1017/S1041610207005601

Selbæk, G., \& Engedal, K. (2012). Stability of the factor structure of the neuropsychiatric inventory in a 31-month follow-up study of a large sample of nursing-home patients with dementia. International Psychogeriatrics, 24(01), 62-73.

Selbæk, G., Engedal, K., Benth, J. Š., \& Bergh, S. (2013a). The course of neuropsychiatric symptoms in nursing-home patients with dementia over a 53-month follow-up period. International Psychogeriatrics, 26(01), 81-91.

Selbæk, G., Engedal, K., \& Bergh, S. (2013b). The prevalence and course of neuropsychiatric symptoms in nursing home patients with dementia: a systematic review. Journal of the American Medical Directors Association, 14(3), 161-169. doi:10.1016/j.jamda.2012.09.027

Selbæk, G., Janus, S. I. M., Bergh, S., Engedal, K., Ruths, S., Helvik, A. S., . . Zuidema, S. U. (2017). Change in psychotropic drug use in Norwegian nursing homes between 2004 and 2011. International Psychogeriatrics, 30(3), 385-394. doi:10.1017/S1041610217001788

Selwood, A., Thorgrimsen, L., \& Orrell, M. (2005). Quality of life in dementia-a one-year follow-up study. International Journal of Geriatric Psychiatry, 20(3), 232-237.

Shankar, K., Walker, M., Frost, D., \& Orrell, M. (1999). The development of a valid and reliable scale for rating anxiety in dementia (RAID). Aging \& Mental Health, 3(1), 39-49. doi: $10.1080 / 13607869956424$

Shankar, K. K., \& Orrell, W. M. (2000). Detecting and managing depression and anxiety in people with dementia. Current Opinion in Psychiatry, 13(1), 55-59. doi:10.1097/00001504-20000100000010

Shin, L. M., \& Liberzon, I. (2010). The neurocircuitry of fear, stress, and anxiety disorders. Neuropsychopharmacology, 35(1), 169-191.

Shorter, E. (1991). Historical changes in the subjective experience of Alzheimer's disease: the role of anxiety. American Journal of Alzheimer's Care and Related Disorders \& Research, 6(3), 35-39. doi:10.1177/153331759100600307

Skovdahl, K., Sörlie, V., \& Kihlgren, M. (2007). Tactile stimulation associated with nursing care to individuals with dementia showing aggressive or restless tendencies: an intervention study in dementia care. International Journal of Older People Nursing, 2(3), 162-170. doi:10.1111/j.1748-3743.2007.00056.x

Slaughter, S., Cole, D., Jennings, E., \& Reimer, M. A. (2007). Consent and assent to participate in research from people with dementia. Nursing Ethics, 14(1), 27-40. doi:10.1177/0969733007071355

Smalbrugge, M., Jongenelis, L., Pot, A. M., Beekman, A. T., \& Eefsting, J. A. (2005). Comorbidity of depression and anxiety in nursing home patients. International Journal of Geriatric Psychiatry, 20(3), 218-226.

Smalbrugge, M., Jongenelis, L., Pot, A. M., Eefsting, J. A., Ribbe, M. W., \& Beekman, A. T. (2006). Incidence and outcome of depressive symptoms in nursing home patients in the Netherlands. American Journal of Geriatric Psychiatry, 14(12), 1069-1076. doi:10.1097/01.jgp.0000224605.37317.88

Smith, M., Gerdner, L. A., Hall, G. R., \& Buckwalter, K. C. (2004). History, development, and future of the progressively lowered stress threshold: a conceptual model for dementia care. Journal of the American Geriatrics Society, 52(10), 1755-1760. doi:10.1111/j.1532-5415.2004.52473.x

Smith, M., Hall, G. R., Gerdner, L., \& Buckwalter, K. C. (2006). Application of the progressively lowered stress threshold model across the continuum of care. The Nursing Clinics of North America, 41(1), 57-81. doi:10.1016/j.cnur.2005.09.006

Snow, A. L., Huddleston, C., Robinson, C., Kunik, M. E., Bush, A. L., Wilson, N., . . Stanley, M. A. (2012). Psychometric properties of a structured interview guide for the rating for anxiety in dementia. Aging \& Mental Health, 16(5), 592-602. doi:10.1080/13607863.2011.644518 
Spector, A., \& Orrell, M. (2010). Using a biopsychosocial model of dementia as a tool to guide clinical practice. International Psychogeriatrics, 22(6), 957-965. doi:10.1017/s1041610210000840

Starkstein, S. E., Jorge, R., Petracca, G., \& Robinson, R. G. (2007). The construct of generalized anxiety disorder in Alzheimer disease. American Journal of Geriatric Psychiatry, 15(1), 42-49. doi:10.1097/01.JGP.0000229664.11306.b9

Statistics Norway. (2017). Helse-og omsorgsinstitusjonar, plassar og rom etter type og eigarforhold. Retrieved from https://www.ssb.no/helse/statistikker/pleie

Statistics Norway. (2018). Population projections. Retrieved from https://www.ssb.no/en/befolkning/statistikker/folkfram

Stedman, T. L. (2012). Stedman's medical dictionary for the health professions and nursing (7th ed.). Philadelphia: Wolters Kluwer/Lippincott Williams \& Wilkins.

Stern, D. N. (1985). The interpersonal world of the infant : a view from psychoanalysis and developmental psychology. New York: Basic Books.

Strobel, C., \& Engedal, K. (2014). Norsk revidert mini mental status evaluering (MMSE-NR2). Tønberg, Norway: Nasjonal kompetansetjenste for aldring og helse.

Sung, H. C., Chang, A. M., \& Lee, W. L. (2010). A preferred music listening intervention to reduce anxiety in older adults with dementia in nursing homes. Journal of Clinical Nursing, 19(7-8), 1056-1064. doi:10.1111/j.1365-2702.2009.03016.x

Sung, H. C., Lee, W. L., Li, T. L., \& Watson, R. (2012). A group music intervention using percussion instruments with familiar music to reduce anxiety and agitation of institutionalized older adults with dementia. International Journal of Geriatric Psychiatry, 27(6), 621-627. doi:10.1002/gps. 2761

Tagai, K., Nagata, T., Shinagawa, S., Nemoto, K., Inamura, K., Tsuno, N., \& Nakayama, K. (2014). Correlation between both morphologic and functional changes and anxiety in Alzheimer's disease. Dementia and Geriatric Cognitive Disorders, 38(3-4), 153-160.

Tang, W., Cui, Y., \& Babenko, O. (2014). Internal consistency: do we really know what it is and how to assess It? Journal of Psychology and Behavioral Science, 2(2), 205-220.

Telenius, E., Engedal, K., \& Bergland, A. (2013). Physical performance and quality of life of nursinghome residents with mild and moderate dementia. International Journal of Environmental Research and Public Health, 10(12), 6672-6686. doi:10.3390/ijerph10126672

Teri, L., Ferretti, L. E., Gibbons, L. E., Logsdon, R. G., McCurry, S. M., Kukull, W. A., . . Larson, E. B. (1999). Anxiety in Alzheimer's disease: prevalence, and comorbidity. Journal of Gerontology, Series A , 54(7), 348-352. doi:10.1093/gerona/54.7.M348

Trigg, R., Jones, R. W., \& Skevington, S. M. (2007). Can people with mild to moderate dementia provide reliable answers about their quality of life? Age and Ageing, 36(6), 663-669. doi:10.1093/ageing/afm077

Twelftree, H., \& Qazi, A. (2006). Relationship between anxiety and agitation in dementia. Aging and Mental Health, 10(4), 362-367. doi:10.1080/13607860600638511

Van Der Linde, R. M., Dening, T., Matthews, F. E., \& Brayne, C. (2014). Grouping of behavioural and psychological symptoms of dementia. International Journal of Geriatric Psychiatry, 29(6), 562-568. doi:10.1002/gps.4037

Van Der Linde, R. M., Dening, T., Stephan, B. C., Prina, A. M., Evans, E., \& Brayne, C. (2016). Longitudinal course of behavioural and psychological symptoms of dementia: systematic review. The British Journal of Psychiatry, 209(5), 366-377.

Weiner, M. F., Martin-Cook, K., Svetlik, D. A., Saine, K., Foster, B., \& Fontaine, C. (2000). The quality of life in late-stage dementia (QUALID) scale. Journal of the American Medical Directors Association, 1(3), 114-116.

Wergeland, J. N., Selbæk, G., Bergh, S., Soederhamn, U., \& Kirkevold, Ø. (2015). Predictors for nursing home admission and death among community-dwelling people 70 years and older who receive domiciliary care. Dementia and Geriatric Cognitive Disorders Extra, 5(3), 320-329. 
Westbury, J. L., Gee, P., Ling, T., Brown, D. T., Franks, K. H., Bindoff, I., . . Peterson, G. M. (2018). RedUSe: reducing antipsychotic and benzodiazepine prescribing in residential aged care facilities. The Medical journal of Australia, 208(9), 398-403. doi:10.5694/mja17.00857

Westhuis, D., \& Thyer, B. (1989). Development and validation of the clinical anxiety scale: a rapid assessment instrument for empirical practice. Educational and Psychological Measurement, 49(1), 153-163. doi:10.1177/0013164489491016

Wetzels, R., Zuidema, S., Jansen, I., Verhey, F., \& Koopmans, R. (2010). Course of neuropsychiatric symptoms in residents with dementia in long-term care institutions: a systematic review. International Psychogeriatrics, 22(7), 1040-1053.

WHO. (1995). The world health organization quality of life assessment (WHOQOL): position paper from the world health organization. Social Science and Medicine, 41(10), 1403-1409.

WHO. (2001). International classification of functioning, disability and health: ICF. Geneva: World Health Organization.

WHO. (2011). WHO ICD-10 : psykiske lidelser og adfærdsmæssige forstyrrelser : klassifikation og diagnostiske kriterier. København: Munksgaard.

WHO, \& Helsedirektoratet. (2011). ICD-10 : den internasjonale statistiske klassifikasjon av sykdommer og beslektede helseproblemer (10. revisjon, norsk utg. ed.). Oslo: Helsedirektoratet.

WHO Collaborating Centre for Drug Statistics Methodology, \& Norwegian Institute of Public Health. (2017). ATC/DDD index. Retrieved from https://www.whocc.no/atc_ddd_index/

WHO. (2018). ICD-11 for Mortality and Morbidity Statistics [online]. Retrieved from https://icd.who.int/browse11/l$\mathrm{m} /$ en\#/http\%3a\%2f\%2fid.who.int\%2ficd\%2fentity\%2f795022044

WHOQOL Group. (1998). Development of the world health organization WHOQOL-BREF quality of life assessment. Psychological Medicine, 28(3), 551-558.

Wolitzky-Taylor, K. B., Castriotta, N., Lenze, E. J., Stanley, M. A., \& Craske, M. G. (2010). Anxiety disorders in older adults: a comprehensive review. Depression and Anxiety, 27, 190-211.

Woods, B., O'Philbin, L., Farrell, E. M., Spector, A. E., \& Orrell, M. (2018). Reminiscence therapy for dementia. The Cochrane database of systematic reviews, 3(3), CD001120. doi:10.1002/14651858.CD001120.pub3

World Medical Association. (2013). WMA declaration of Helsinki - ethical principles for medical research involving human subjects. Retrieved from https://www.wma.net/what-wedo/medical-ethics/declaration-of-helsinki/

Yesavage, J. A., Brink, T. L., Rose, T. L., Lum, O., Huang, V., Adey, M., \& Leirer, V. O. (1982). Development and validation of a geriatric depression screening scale: a preliminary report. Journal of Psychiatric Research, 17(1), 37-49.

Yesavage, J. A., \& Taylor, B. (1991). Anxiety and Dementia. In C. Salzman \& B. D. Lebowitz (Eds.), Anxiety in the elderly: treatment \& research (pp. 79-84). New York: Springer publishing company.

Zbozinek, T. D., Rose, R. D., Wolitzky-Taylor, K. B., Sherbourne, C., Sullivan, G., Stein, M. B., .. Craske, M. G. (2012). Diagnostic overlap of generalized anxiety disorder and major depressive disorder in a primary care sample. Depression and Anxiety, 29(12), 1065-1071. doi:10.1002/da.22026

Zigmond, A. S., \& Snaith, R. P. (1983). The Hospital anxiety and depression scale. Acta Psychiatrica Scandinavica, 67(6), 361-370. doi:10.1111/j.1600-0447.1983.tb09716.x

Zimmerman, S., Williams, C. S., Reed, P. S., Boustani, M., Preisser, J. S., Heck, E., \& Sloane, P. D. (2005). Attitudes, stress, and satisfaction of staff who care for residents with dementia. Gerontologist, 45(1), 96-105.

Zingmark, K., Norberg, A., \& Sandman, P.-O. (1993). Experience of at-homeness and homesickness in patients with Alzheimer's disease. American Journal of Alzheimer's Care and Related Disorders \& Research, 8(3), 10-16. 
Zweig, M. H., \& Campbell, G. (1993). Receiver-operating characteristic (ROC) plots: a fundamental evaluation tool in clinical medicine. Clinical Chemistry, 39(4), 561-577.

\section{Original studies}


I 



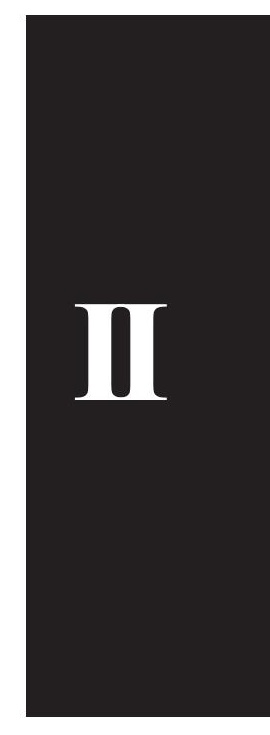





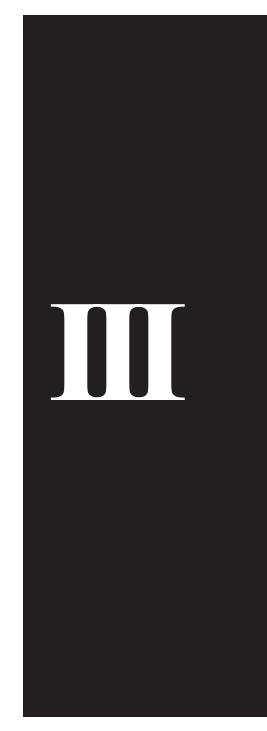



$\mathbf{I V}$ 



\section{PLOS $\left.\right|_{\text {ONE }}$}

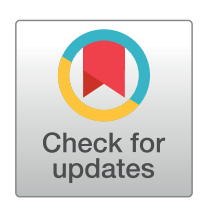

\section{Gopenaccess}

Citation: Goyal AR, Bergh S, Engedal K, Kirkevold M, Kirkevold $\varnothing$ (2018) Trajectories of quality of life and their association with anxiety in people with dementia in nursing homes: A 12-month follow-up study. PLoS ONE 13(9): e0203773. https://doi.org/ 10.1371/journal.pone.0203773

Editor: Peter Van Bogaert, University of Antwerp, BELGIUM

Received: April 17, 2018

Accepted: August 27, 2018

Published: September 11, 2018

Copyright: @ 2018 Goyal et al. This is an open access article distributed under the terms of the Creative Commons Attribution License, which permits unrestricted use, distribution, and reproduction in any medium, provided the original author and source are credited.

Data Availability Statement: As per our participants' consent form, access to data material shall only be provided after the approval from the Regional Committee for Medical and Health Research Ethics (REK) in each single case (e-mail: post@etikkom.no), (https://www.etikkom.no/en/). Due to ethical and legal restrictions, data sets are not allowed for open data sharing, but are available upon request from: The Research Centre for Age Related Functional Decline and Diseases, Innlandet Hospital Trust, pb. 68, 2312 0ttestad, Norway.
RESEARCH ARTICLE

\section{Trajectories of quality of life and their association with anxiety in people with dementia in nursing homes: A 12-month follow-up study}

\author{
Alka R. Goyal ${ }^{1,2,3 *}$, Sverre Bergh ${ }^{1,2}$, Knut Engedal $^{2}$, Marit Kirkevold ${ }^{3}, \varnothing$ yvind Kirkevold ${ }^{1,2,4}$ \\ 1 The Research Centre for Age Related Functional Decline and Diseases, Innlandet Hospital Trust, Ottestad, \\ Norway, 2 Norwegian National Advisory Unit on Aging and Health, Vestfold Hospital Trust, Tønsberg, \\ Norway, 3 Department of Nursing Science, Institute of Health and Society, University of Oslo, Oslo, Norway, \\ 4 Norwegian University of Science and Technology (NTNU) in Gjøvik, Faculty of Health, Care and Nursing, \\ Gjøvik, Norway \\ * alkgoy@sykehuset-innlandet.no
}

\section{Abstract}

\section{Objectives}

This study aimed to identify possible groups of people with dementia (PWD) in nursing homes with different trajectories of proxy-rated quality of life (QoL), and to explore how anxiety (along with other characteristics) was associated with these trajectories of QoL of PWD in nursing homes at a 12-month follow-up.

\section{Methods}

We included 298 PWD aged 65 years and older from 17 Norwegian nursing homes. The Norwegian version of the Rating Anxiety in Dementia scale (RAID-N) was used to assess anxiety, defined as RAID-N score $\geq 12$; proxy-rated QoL was assessed by Quality of Life in Late-Stage Dementia (QUALID). The assessments were made at baseline and after a mean follow-up period of 350 days (SD 12.3). A growth mixture model identified two distinct trajectories of QUALID scores. Association between the QUALID score trajectories and demographic and clinical characteristics were analyzed with logistic regression models.

\section{Results}

Trajectory group 1 (206 participants) had a lower proportion of participants with anxiety, and a more stable and better QoL, compared to trajectory group 2 (92 participants) at a 12month follow-up. In a multivariate logistic regression analysis, more severe impairment in activities of daily living, along with presence of anxiety, depression, agitation, and use of antipsychotics at baseline, were associated with belonging to the trajectory group with proxy-rated poor QoL. 
Funding: This study was supported by The Research Centre for Age Related Functional Decline and Diseases, Innlandet Hospital Trust, Ottestad Norway under grant number 150279 to ØK; and the Norwegian National Advisory Unit on Ageing and Health under grant number 150279 to ARG. The funders had no role in study design, data collection and analysis, decision to publish, or preparation of the manuscript.

Competing interests: Alka R. Goyal is currently receiving $\mathrm{PhD}$ grant from Innlandet Hospital Trust and the Norwegian National Advisory Unit on Ageing and Health. The remaining authors have declared that no competing interests exist.

\section{Significances}

This study reveals that anxiety is associated with proxy-rated poor QoL of PWD at a 12month follow-up. Efforts should be made to identify anxiety among nursing home residents with dementia to initiate treatment.

\section{Introduction}

Dementia disorders are usually progressive; irreversible; and characterized by impaired cognition, impaired functions in activities of daily living, and behavioral changes that are often disruptive for the person him/herself and for his/her family. So far, there is no cure for the various brain disorders causing dementia. As the person's daily life function is affected, the person gradually becomes dependent on others. Dementia along with higher age, behavioral disturbances such as delusions and hallucinations, and increased functional impairment are some of the main factors leading to nursing home admission $[1,2]$. In Norway, about $40 \%$ of people affected with dementia live in institutions, mainly in nursing homes [3]. This transition, and the inevitable changes in a person's life due to dementia, may provoke negative reactions and apprehensions in the person with dementia, which may affect the person's quality of life (QoL). Many cross-sectional studies have investigated factors associated with QoL in people with dementia (PWD) in long-term care facilities [4], but few longitudinal studies have investigated characteristics that could possibly affect the course of QoL of PWD in nursing homes [5-8].

A person's QoL has multidimensional aspects; according to a definition by the World Health Organization, quality of life is usually based on the person's subjective experience of own life, objective criteria in the context of culture, and the values of the society in which the person lives [9]. People with mild to moderate dementia can provide reliable perceptions of their own QoL $[7,10]$, whereas assessment of one's own QoL can be difficult for people with severe dementia $[5,7,11]$. In nursing homes, most PWD have moderate to severe stages of dementia [12, 13]. Various dementia-specific QoL assessment scales are available that are rated by the PWD and/ or by the health care personnel/family caregivers $[11,14]$. There is evidence indicating discrepancies between self and proxy-rated QoL of PWD. Proxy-rated QoL may be influenced by caregivers' or family members' own perspectives of QoL $[15,16]$. However, in the nursing homes, most of the residents with dementia have more frequent and direct contacts with the nursing care staff during a day than their own family members. Thus, proxy-based instruments based on nursing care staff s direct observations of a person's behavior, emotions, and daily needs-such as the Quality of Life in Late-Stage Dementia (QUALID) - are considered appropriate to assess QoL in persons with moderate and severe stages of dementia living in nursing homes [17]. The knowledge that nursing homes' health care personnel have about their residents with dementia should be used in assessing the QoL of PWD [15].

It is well known that anxiety and depression are highly prevalent among nursing home residents with dementia, and that these affect their self-rated QoL [4, 18-20], but the association between anxiety and depression and proxy-rated QoL of PWD has been ambiguous [4]. A systematic review indicates that dementia-specific depression scales, such as the Cornell Scale of Depression in Dementia (CSDD) [21], have been used in research studies on QoL of PWD [4, 7]. Only three studies have reported an association between anxiety and QoL in PWD using a dementiaspecific anxiety scale, such as the Rating Anxiety in Dementia (RAID) scale [22] [5, 7, 23].

Hoe et al. [23] reported that both self-and proxy-rated high QoL of care home residents with dementia was correlated with low levels of anxiety symptoms. At a 20-week follow-up, 
the study by Hoe et al. [5] reported that self-rated increased QoL was associated with fewer baseline anxiety symptoms, whereas fewer baseline depressive symptoms were associated with proxy-rated increase in QoL. In a study by Selwood et al. [7], self-rated poor QoL was associated with more anxiety symptoms at one-year follow-up among PWD.

Knowledge is sparse about the role of anxiety and associated risk factors in proxy-rated QoL of PWD over time, especially when anxiety is assessed with a dementia-specific anxiety scale. More longitudinal studies of anxiety and related risk factors for proxy-rated QoL of PWD may add to the knowledge of factors that are important for QoL. This, in turn, can help health care personnel in nursing homes develop appropriate, proactive care interventions and management to enhance the QoL of PWD in nursing homes.

The main aim of this study was to identify possible groups of nursing home residents with dementia with different trajectories of QoL, and to explore how anxiety, along with other demographic and clinical characteristics, was associated with these trajectories of proxy-rated QoL of PWD in nursing homes at a 12-month follow-up.

\section{Methods}

\section{Participants}

A set of 21 nursing homes from two counties in south-eastern Norway were approached to recruit participants for the study. In total, 298 women and men with dementia aged 65 years or older from 17 nursing homes participated in the study. The dementia diagnoses were based on the research criteria of either the Diagnostic and Statistical Manual of Mental Disorders, Fifth Edition (DSM-V) ( $\mathrm{n}=101$, the validation study group) [24, 25], the International Statistical Classification of Diseases and Related Health Problems, Tenth Revision (ICD-10) $(n=60)$ [26], or the International Classification of Primary Care-2 (ICPC-2) P70 ( $\mathrm{n}=137)$ [27], as documented in the medical records. Residents who were terminally ill, had schizophrenia or did not understand Norwegian well were excluded from the study. Participants were ethnic Norwegians or Scandinavians, except for one who had lived in Norway for many years. The recruitment process is described in detail elsewhere [18].

The participants were assessed at two points: a baseline assessment $(\mathrm{N}=298)$ between August 2014 and November 2015, and a follow- up assessment $(\mathrm{N}=205)$ between September 2015 and September 2016, with a mean interval of 350 days (SD 12.3). The attrition of 93 participants from baseline to follow-up (31.2\%) was due to death. The participants who moved to other wards within the same nursing homes $(n=17)$ or to other nursing homes $(n=8)$ were also assessed at follow-up. The reasons for participants' shifting to other wards or nursing homes included deterioration in physical condition $(\mathrm{n}=10)$, deterioration of neuropsychiatric symptoms (NPS) $(n=9)$, and organizational changes in the nursing home $(n=6)$.

\section{Assessment scales}

Anxiety was assessed by the Norwegian version of Rating Anxiety in Dementia scale (RAID-N). Shankar et al. [22] developed the RAID scale to assess anxiety symptoms in patients with all stages of dementia. It includes 20 items, of which 18 can be scored from zero (absent) to three (severe) or U (symptoms unable to measure); total scores range between zero and 54, and higher scores indicate more severe anxiety. Two items (phobias and panic attacks) are not included in the total score. RAID-N was validated for the PWD living in Norwegian nursing homes, and a cut-off score of $\geq 12$ indicates a clinically significant generalized anxiety disorder (GAD) in patients with dementia [25]. The RAID-N score was based on clinical observations, information from the patient's medical records, and a short interview with the patient him/ 
herself about symptoms over the past two weeks. In the present study, anxiety as clinically significant was defined as RAID-N score $\geq 12$.

QUALID is a proxy-based instrument assessing QoL in people with late stages of dementia. The scale is translated into Norwegian and has acceptable psychometric properties in assessing the QoL of PWD living in Norwegian nursing homes [28]. QUALID has 11 items that assess both positive and negative dimensions of behaviors considered to be indicative of QoL. Each item is rated from 1 to 5 : the minimum score 11 indicates the best QoL, and the maximum score 55 indicates the poorest QoL. QUALID is administered as a structured interview of the caregiver, based on his or her direct observations of the person over the previous seven days [17]. QUALID is sensitive to assessing changes in QoL over a period of time, hence valid as a longitudinal measure of proxy-rated QoL $[6,29]$.

The participants' dementia severity was assessed by the Clinical Dementia Rating scale, using sum of boxes (CDR-sob) [30]. Clinical Dementia Rating is a valid and reliable scale to categorize different stages of dementia [31]. CDR-sob correlates highly with the categorical score of Clinical Dementia Rating scale [30]. The CDR-sob rates six items individually, from zero to three (total CDR-sob scores zero to 18). Scores in the 4.5-9.0 range denote mild dementia, 9.5-15.5 moderate dementia, and 16.0-18.0 severe dementia [30].

Depressive symptoms were assessed by the Norwegian version of the CSDD [21,32]. The CSDD is scored by using a short interview with the participant and a report from the primary caregiver based on direct observations. It has 19 items assessing depressive symptoms over the past week. The total score ranges between zero and 38, where a score $\geq 10$ indicates clinically significant depression for nursing home patients [32]. In the present study, depression was defined as a score $\geq 10$ on the CSDD.

Neuropsychiatric symptoms (NPS) were assessed by the Neuropsychiatric Inventory brief Questionnaire (NPI-Q) [33]. The ratings were based on the caregivers' observations over the previous month. The questionnaire has 12 items assessing NPS severity, and the score ranges between zero and 36, with a higher score representing more severe NPS [33]. The 12 items of NPI-Q were grouped into four distinct sub-syndromes based on a factor analysis derived from the baseline study sample: psychosis (delusions and hallucinations), affective (dysphoria, anxiety, apathy, and appetite), agitation (agitation, irritability, disinhibition, and aberrant motor) and aroused (euphoria and nighttime disturbances) [18].

The participants' activities of daily living (ADL) functions were assessed by the Physical Self-Maintenance scale (PSMS) [34], based on caregivers' observations over the past week. The total score ranges between six and 30, with a higher score indicating more severe functional impairment. The participants' general physical health was assessed by the General Medical Health Rating (GMHR) [35] based on participant's present physical health status and regular medication use, and it included four categories: excellent, good, fair, and poor.

Assessment procedure. The assessment scales were administered by the participants' primary nurses (in total, 57 nurses) or by the first author (ARG). In Norwegian nursing homes, the nursing care of the residents is organized under a primary nurse and a primary caregiver system. A primary nurse is a registered nurse (RN), who has the responsibility of a complete care plan of a resident under his/her care. A primary caregiver usually an auxiliary nurse, along with the primary nurse, has the responsibility to follow-up the care plan and other practical tasks of the resident. Before data collection, the primary and auxiliary nurses received 2-3 hours training from the first author in administering the assessment scales. The same nurse assessed the participant both at baseline and at follow-up. The same assessment scales were used at both assessment points. The primary nurses administered the assessment scales based on their direct observations of the resident, and a short interview with the resident when required. The first author interviewed the participants' primary caregiver, and interviewed the 
participants when required. The first author was available for consultation during the data collection.

Information retrieved from the participants records. Demographic and clinical dataincluding age, gender, marital status, education, length of stay in nursing homes, dementia and other diagnoses, and participants' regular use of medication-were collected by the participants' primary nurses or by the first author.

Participants' regular use of psychotropic medication were grouped into anxiolytics, antidepressants, antipsychotics, hypnotics and sedatives, and cognitive enhancers according to the Anatomical Therapeutic Chemical (ATC) index [36].

\section{Statistical analysis}

Anxiety (RAID-N score $\geq 12$ ) and depression (CSDD score $\geq 10$ ) were dichotomized into present or absent. The GMHR scale was dichotomized into excellent/good and fair/poor. A growth mixture model was estimated to identify potential (unobserved) groups of participants following distinct trajectories of QUALID scores throughout the study period. Baseline differences in demographic and clinical variables between the trajectory groups were analyzed with $t$-test for continuous, and $\chi^{2}$ test for categorical, scales. To determine the participants' characteristics and related risk factors pertaining to QUALID scores trajectories, a bivariate and a multivariate logistic regression was carried out with QoL group as dependent variable $(0=$ better QoL, 1 = poor QoL). Association between the participants' characteristics measured at baseline and follow-up and a trend in QUALID scores was assessed by estimating a linear mixed model with random effects for residents. We included fixed effects for time, coded as before or after the characteristics. The same independent variables were used in the linear mixed model as in the logistic regression.

Due to high multicollinearity between RAID-N and CSDD scores (baseline $r=0.72$; followup $r=0.74$ ), these variables were not used in the regression models. At baseline, the overlap of dichotomized values of RAID-N and CSDD were 54 out of 118 participants ( 48 with only anxiety and 16 with only depression); therefore, we chose to use dichotomized variables of RAID-N and CSDD scores in the models. The variable NPI-Q affective was not included in the models, due to multicollinearity with both RAID-N dich. and CSDD-dich. Correlation between baseline CDR-sob and PSMS sum was $r=0.63$. $P$-values $<0.05$ were considered statistically significant. IBM SPSS Statistics, Version 23.0 (Armonk, NY, USA) was used for the descriptive statistics, for analyses of the differences within and between the groups, and for the logistic regression. MLwiN, Version 3.01 (Bristol, UK) was used for the linear mixed model.

\section{Ethical issues}

The study was approved by the Regional Committee for Medical and Health Research Ethics (REK) in south-eastern Norway (ref. 2012/1958). Written informed consent was collected from the participants $(n=106)$ or from the next of kin if the participants did not have the capacity to give consent $(\mathrm{n}=192)$.

\section{Results}

At baseline, the participants' ( $\mathrm{N}=298)$ mean age was 85.5 years (SD 6.8), and $73.2 \%$ were female. Participants who died during the follow-up $(n=93)$ were older [mean age 87.0 years (SD 5.5) vs. 84.9 years (SD 7.2), $p=0.005$ ], had more impaired cognition [mean CDR-sob score 13.6 (SD 3.5) vs. 12.5 (SD 3.4), $p=0.012$ ], and had more impaired ADL functions [mean PSMS- sum 17.4 (SD 4.4) vs.15.6 (SD 4.6), $p=0.001$ ], but were not different in terms of severity of anxiety [mean RAID-N-sum 10.3 (SD 6.8) vs. 9.5 (SD 7.4), $p=0.367$ ] or QoL [mean 
QUALID-sum 22.7 (SD 7.2) vs. 21.5 (SD 7.2), $p=0.174$ ] than the participants who participated in the follow-up $(\mathrm{n}=205)$.

The growth mixture model, based on QUALID scores, revealed two distinct trajectories of QUALID scores. Trajectory group 1 consisted of 206 participants and had a lower and more stable QUALID sum score (better QoL) compared to trajectory group 2. Trajectory group 2 consisted of 92 participants who had a higher and a non-significant increase in QUALID sum score (poorer QoL) during the study period (Fig 1). The average group probabilities were larger than 0.7 , and $95 \%$ confidence intervals (CI) for the two trajectories did not overlap (Fig 1 and Table 1). Baseline characteristics of the two trajectory groups are presented in Table 2. Participants in trajectory group 2 (with poorer QoL) were more impaired in terms of cognition (higher CDR-sob score) and ADL functions (higher PSMS score), had poorer general physical health, had more anxiety and depression, had more severe NPS (higher NPI-Q score), and used more anxiolytics, antidepressants, and antipsychotics than the participants in trajectory group 1, see Table 2 .

The adjusted multivariate logistic regression analysis revealed that a higher PSMS score (more severe ADL impairment), presence of significant anxiety and depression, higher score on the NPI-Q sub-syndrome agitation, and use of antipsychotics at baseline were significantly

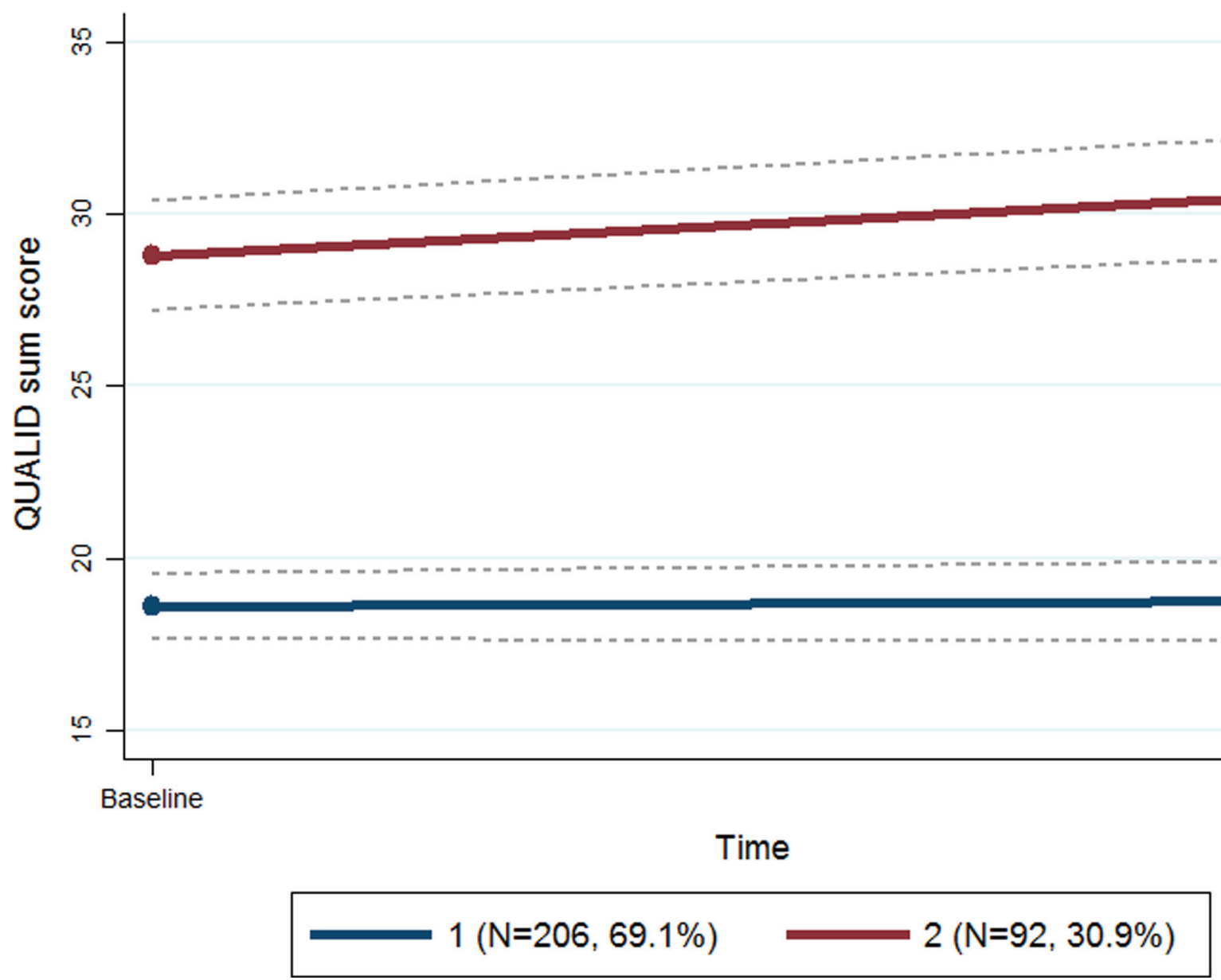

Fig 1. Trajectories analysis of quality of life by the quality of life in Late-Stage Dementia (QUALID).

https://doi.org/10.1371/journal.pone.0203773.g001 
Table 1. Trajectories analysis of quality of life by the quality of life in Late-Stage Dementia (QUALID).

\begin{tabular}{|c|c|c|c|c|}
\hline Variables & Trajectory group $1(n=206)$ & & Trajectory group $2(n=92)$ & \\
\hline & Regre. coeff. (SE) & $p$-value & Regre. coeff. (SE) & $p$-value \\
\hline Intercept & $18.59(0.49)$ & $<0.001$ & $28.80(0.81)$ & $<0.001$ \\
\hline Time & $0.16(0.66)$ & 0.804 & $1.80(1.04)$ & 0.083 \\
\hline Average probability & 0.92 & & 0.86 & \\
\hline
\end{tabular}

https://doi.org/10.1371/journal.pone.0203773.t001

associated with belonging to trajectory group 2 . Table 3 shows odds ratios of the various characteristics of the bivariate and multivariate analyses. The strongest association with belonging to trajectory group 2 was the use of antipsychotics, with an odds ratio of 4.53 , followed by

Table 2. Baseline differences between the trajectory groups. Trajectory group 1 with better quality of life QoL, and trajectory group 2 with poorer QoL.

\begin{tabular}{|c|c|c|c|}
\hline Characteristics & $\begin{array}{l}\text { Trajectory group } 1 \\
\quad(n=206)\end{array}$ & $\begin{array}{c}\text { Trajectory } \\
\text { group } 2 \\
(\mathbf{n}=92)\end{array}$ & $p$-value \\
\hline Age in years, mean (SD) & $86.0(6.5)$ & $84.6(7.3)$ & $0.102^{1}$ \\
\hline Female gender, n (\%) & $150(72.8)$ & $68(73.9)$ & $0.843^{2}$ \\
\hline Married, n (\%) & $49(23.8)$ & $16(17.4)$ & $0.217^{2}$ \\
\hline Education in years, mean (SD) & $8.6(2.3)^{3}$ & $9.1(2.8)^{4}$ & $0.157^{1}$ \\
\hline CDR-sob, mean (SD) & $12.4(3.4)$ & $13.9(3.3)$ & $<0.001^{1}$ \\
\hline PSMS-sum, mean (SD) & $15.4(4.5)$ & $17.8(4.5)$ & $<0.001^{1}$ \\
\hline GMHR-dich. (excellent/good), n (\%) & $96(46.6)$ & $26(28.3)$ & $0.003^{2}$ \\
\hline QUALID-sum mean (SD) & $18.5(4.6)$ & $29.6(5.9)$ & $<0.001^{1}$ \\
\hline RAID-N-sum, mean (SD) & $8.0(6.3)$ & $13.9(7.4)$ & $<0.001^{1}$ \\
\hline RAID-N dich., n (\%) & $47(22.8)$ & $55(59.8)$ & $<0.001^{2}$ \\
\hline CSDD-sum, mean (SD) & $5.0(4.3)$ & $10.0(4.9)$ & $<0.001^{1}$ \\
\hline CSDD-dich, n (\%) & $24(11.7)$ & $46(50)$ & $<0.001^{2}$ \\
\hline NPI-Q-sum, mean (SD) & $4.9(4.2)$ & $10.6(5.8)$ & $<0.001^{1}$ \\
\hline NPI-Q-psychosis-sum, mean (SD) & $0.8(1.3)$ & $1.2(1.6)$ & $0.045^{1}$ \\
\hline NPI-Q-affective-sum, mean (SD) & $1.4(1.7)$ & $4.1(2.8)$ & $<0.001^{1}$ \\
\hline NPI-Q-agitation-sum, mean (SD) & $2.1(2.4)$ & $4.1(3.3)$ & $<0.001^{1}$ \\
\hline NPI-Q-aroused-sum, mean (SD) & $0.6(0.9)$ & $1.2(1.3)$ & $<0.001^{1}$ \\
\hline Anxiolytics, n (\%) & $21(10.2)$ & $24(26.1)$ & $<0.001^{2}$ \\
\hline Antidepressants, n (\%) & $86(41.7)$ & $50(54.3)$ & $0.044^{2}$ \\
\hline Antipsychotics, n (\%) & $22(10.7)$ & $30(32.6)$ & $<0.001^{2}$ \\
\hline Hypnotics and sedatives, n (\%) & $49(23.8)$ & $29(31.5)$ & $0.161^{2}$ \\
\hline Cognitive enhancers, $\mathrm{n}(\%)$ & $65(31.6)$ & $27(29.3)$ & $0.703^{2}$ \\
\hline
\end{tabular}

${ }^{1}$ t- test;

${ }^{2} \chi^{2}$ test;

${ }^{3} \mathrm{n}=204$;

${ }^{4} \mathrm{n}=90$

CDR-sob, Clinical Dementia Rating Scale-sum of boxes; PSMS, Physical Self-Maintenance scale; GMHR-dich., General Medical Health Rating- fair /poor = 0, excellent/ good = 1; QUALID, Quality of Life in Late-Stage Dementia; RAID-N, Rating Anxiety in Dementia-Norwegian version; RAID-N dich., RAID-N score $<12=0$, $\geq 12=1$; CSDD, Cornell Scale for Depression in Dementia; CSDD-dich., CSDD score $<10=0, \geq 10=1$; NPI-Q, Neuropsychiatric Inventory-Questionnaire; NPI-Q-psychosis (Delusions and Hallucinations); NPI-Q affective (Dysphoria, Anxiety, Apathy and Appetite); NPI-Q agitation (Agitation, Irritability, Disinhibition and Aberrant Motor); NPI-Q aroused (Euphoria and Nighttime Disturbances).

https://doi.org/10.1371/journal.pone.0203773.t002 
Table 3. Logistic regression models predicting associating factors belonging to the trajectory group with poorer quality of Life $(\mathrm{QoL})(\mathrm{n}=92)$. Trajectory group with better QoL $(n=206)$ as reference.

\begin{tabular}{|c|c|c|c|c|}
\hline Variables & $\begin{array}{c}\text { Bivariate models } \\
\text { OR }(95 \% \mathrm{CI})\end{array}$ & $p$-value & $\begin{array}{c}\text { Multivariate model } \\
\text { OR }(95 \% \mathrm{CI})\end{array}$ & $p$-value \\
\hline Age & $0.97(0.94 ; 1.01)$ & 0.103 & $0.98(0.94 ; 1.03)$ & 0.472 \\
\hline Gender & $0.95(0.54 ; 1.65)$ & 0.843 & $0.86(0.40 ; 1.82)$ & 0.685 \\
\hline Married & $0.68(0.36 ; 1.26)$ & 0.219 & $0.67(0.29 ; 1.53)$ & 0.344 \\
\hline CDR-sob & $1.15(1.06 ; 1.25)$ & $<0.001$ & $1.05(0.93 ; 1.20)$ & 0.436 \\
\hline PSMS-sum & $1.13(1.07 ; 1.20)$ & $<0.001$ & $1.11(1.01 ; 1.21)$ & 0.029 \\
\hline RAID-N dich & $5.03(2.96 ; 8.53)$ & $<0.001$ & $2.19(1.10 ; 4.37)$ & 0.026 \\
\hline CSDD-dich & $7.58(4.20 ; 13.68)$ & $<0.001$ & $3.28(1.50 ; 7.18)$ & 0.003 \\
\hline NPI-Q-psychosis & $1.20(1.01 ; 1.42)$ & 0.031 & $0.93(0.75 ; 1.17)$ & 0.554 \\
\hline NPI-Q-agitation & $1.28(1.17 ; 1.41)$ & $<0.001$ & $1.15(1.02 ; 1.30)$ & 0.027 \\
\hline NPI-Q-aroused & $1.63(1.29 ; 2.04)$ & $<0.001$ & $1.17(0.87 ; 1.57)$ & 0.306 \\
\hline Anxiolytics (no/yes) & $3.11(1.63 ; 5.95)$ & 0.001 & $1.38(0.61 ; 3.10)$ & 0.438 \\
\hline Antipsychotics (no/yes) & $4.05(2.18 ; 7.53)$ & $<0.001$ & 4.53 (2.08; 9.87) & $<0.001$ \\
\hline
\end{tabular}

Trajectory groups, 0 = better QoL, 1 = poor QoL; Gender, 0 = female, 1 = male; Married, $0=$ unmarried/others, $1=$ married; CDR-sob, Clinical Dementia Rating Scalesum of boxes; PSMS, Physical Self-Maintenance scale; GMHR-dich., General Medical Health Rating- 0 = fair /poor, $1=$ excellent/good; RAID-N dich., Norwegian version of Rating Anxiety in Dementia score, $0=<12,1=\geq 12$; CSDD-dich., Cornell Scale for Depression in Dementia score, $0=<10,1=\geq 10$; NPI-Q-psychosis, Neuropsychiatric Inventory-Questionnaire (Delusions and Hallucinations); NPI-Q agitation (Agitation, Irritability, Disinhibition and Aberrant Motor); NPI-Q aroused (Euphoria and Nighttime Disturbances).

$0=$ no, 1 = yes.

depression and anxiety, with odds ratios of 3.28 and 2.19, respectively. Between $29.7 \%$ (Cox and Snell $\mathrm{R}^{2}$ ) and $41.8 \%$ (Nagelkerke $\mathrm{R}^{2}$ ) of the variability was explained by the models.

The adjusted multivariate linear mixed model showed that higher PSMS score $(\beta=0.40, p$ $<0.001)$; presence of significant anxiety $(\beta=2.23, p<0.001)$ and depression $(\beta=5.28, p$ $<0.001)$; and higher scores on the NPI-Q sub-syndrome agitation $(\beta=0.46, p<0.001)$ were associated with increased QUALID score, representing a poorer QoL. On the other hand, presence of excellent/good general physical health was associated with a lower QUALID score, representing better QoL ( $\beta=-1.60, p=0.003)$. An association between use of antipsychotics and increase in QUALID score did not reach a significant level $(\beta=1.33, p=0.06)$ in the adjusted linear mixed model.

\section{Discussion}

\section{Main findings}

The present study revealed two distinct groups of PWD, with different trajectories of QoL: trajectory group 1 with better QoL, and trajectory group 2 with poorer QoL. In trajectory group 1 (which included approximately two-thirds of the participants), a lower proportion of participants had a RAID-N score of 12 and above (significant anxiety), and had more stable and better QoL compared with the participants in trajectory group 2. A RAID-N score of 12 and above was also associated with belonging to trajectory group 2 in the adjusted logistic regression analysis. The main findings associated with the trajectories of QoL will structure this discussion section.

Participants who died between the assessments were older and more impaired in terms of cognition and ADL functions than the participants who were alive at follow up; this is an 
expected finding. However, they did not differ in terms of anxiety or QoL from the rest of the participants. In line with previous findings, these results indicate that anxiety and QoL are not directly associated with mortality among PWD living in nursing homes [7, 37]. The QoL groups were different concerning several clinical variables, but in an adjusted logistic regression analysis, belonging to the trajectory group with the poorest QoL was associated with severity of impairment in ADL functions, presence of clinically significant anxiety and depression, high NPI-Q sub-syndrome agitation score, and use of antipsychotics at baseline.

In the present study, QoL in PWD was not independently affected by the severity of dementia itself, but we suggest that there is an indirect association between the factors-such as impaired ADL and severity of NPS, which are found to be related to the QoL of PWD [6-8]. The relationship between QoL, the severity of dementia and ADL functions is complex. A clear association exists between deterioration in cognitive impairment and ADL functions [38, 39]. However, in the present study, the correlation coefficient for the severity of dementia and ADL functions was $<0.70$, indicating that they can be treated as independent variables [40]. Furthermore, severity of dementia and impairment in ADL functions were both significantly associated with belonging to trajectory group 2 (with poor QoL) in the bivariate model; however, when controlling for each other, only ADL severity functions remained significantly correlated with belonging to trajectory group 2 . Therefore, the consequence of dementia as expressed by impairment in ADL was a stronger factor associated with poor QoL than the severity of dementia itself.

A poor general physical health may also lead to decline in ADL function and to poor QoL in old PWD. Results of the linear mixed model of the present study indicate that participants' excellent/good general physical health was associated with better QoL, a finding supported by previous studies $[6,12]$. However, in our adjusted logistic regression analysis, poor general physical health was not significantly associated with belonging to the poor QoL trajectory group. The reason for the two analyses producing different results could be due to groupings. In the linear mixed model, we compared the participants' general physical health with QoL both at baseline and follow-up; whereas, in the logistic regression model, the participants are dichotomized into two different trajectory groups, and the participants' baseline GMHR scores are analyzed for association with belonging to one of the two trajectory groups. Different analytic strategies lead to different results, which indicate that the association between general physical health and QoL may be weak in PWD living in nursing homes.

Previous studies have reported that depression is highly associated with poor QoL in PWD [4]. Anxiety and depression often coexist in PWD, as in old people in general [18, 19, 41]. In the present study, anxiety controlled for depression was associated with belonging to the trajectory group with poor QoL, a result indicating that anxiety is an independent risk factor for poor QoL. This is an important finding of the study, due to two main reasons: scarcity of longitudinal studies on anxiety and QoL in PWD, and inconsistent findings of the association of anxiety with proxy-rated QoL. The results of the present study may contribute to reducing the ambiguity of the role anxiety plays in proxy-rated QoL of PWD over time [4], and may draw health care personnel's attention to early detection and management of anxiety.

In the present study, all the NPI-Q sub-syndromes scores (psychosis, affective, agitation, and aroused) were significantly higher at baseline in the trajectory group with poorer QoL compared to the trajectory group with better QoL. The adjusted analysis indicated that participants with higher scores of NPI-Q sub-syndrome agitation are more likely to end up in the trajectory group with poorer QoL, compared to participants with lower NPI-Q sub-syndrome agitation scores. Many studies have reported that severe NPS, as assessed by caregivers, are associated with proxy-rated poor QoL in PWD $[4,6,12]$. NPS are prevalent in people in all stages of dementia [42]. A higher prevalence of NPS, especially agitation, imposes a challenge 
for PWD and a burden to the caregivers, thus reducing the QoL of PWD. Previous studies have also reported that more agitation is related to proxy-rated poor QoL [43-45]. A comprehensive assessment and management of agitation, anxiety and other NPS should be an important task for nursing home staff.

All else being equal, the use of antipsychotics inflicts the highest risk of ending up in trajectory group 2 (with poorer QoL), compared to participants not using antipsychotics. This is an another important finding of the present study, as only few studies have taken this factor into account concerning QoL of PWD, and previous findings were inconclusive [4]. A comparable study reported that the use of antipsychotics was related to proxy-rated poor QoL at baseline and increased mortality at a 10-month follow-up among PWD living in nursing homes [6]. Other studies have reported an association between the use of antipsychotics and increased mortality among PWD [46, 47]. NPS such as delusion, hallucination, and agitation among PWD are often treated with antipsychotics, even though the evidence for a positive effect is uncertain or limited $[48,49]$, with severe side-effects. To enhance the QoL of PWD, adequate management of agitation and other NPS by non-pharmacological interventions-such as TIME (Targeted Interdisciplinary Model for Evaluation and Treatment of NPS) and PCC (Person-centered care) based interventions may-play an important role [50-52]. It must be noted that the association between the use of antipsychotics and poorer QoL was not significant in the adjusted linear mixed model in the present study. However, the $p$-value of 0.06 shows a clear tendency of a relationship between the use of antipsychotics and QoL of PWD. This association needs further investigations, with utmost priority.

\section{Limitations and strengths}

The QUALID scale is constructed to assess the QoL of people in late stage of dementia. To have a common QoL measure for all the participants of the present study, we chose the QUALID scale to assess QoL including people with mild to severe stages of dementia in the nursing home. This is in line with previous studies using QUALID scale for the assessment of QoL of PWD in the nursing homes and in geriatric psychiatric units $[6,51,53]$. Since QUALID is a proxy-rated scale, we may have lost valuable information on QoL perceived by people with mild to moderate dementia. The study was an observational study; it did not control for ongoing interventions or any other changes in the participants, such as comorbidities or shifting to other wards/nursing homes, which may have affected the results. Attrition can be a source of bias of main outcomes in follow-up studies (31.2\% in present study), but here the attrition sample was not significantly different in terms of anxiety or QoL. The attrition sample was more impaired in ADL functions than the remaining participants, and this factor was taken into account by both regression models. The logistic regression included baseline variables of all the participants, whereas the linear mixed model included assessments at both time points.

The study population was nursing home residents with dementia, and the results cannot be generalized to other populations with dementia. A clear etiological dementia diagnosis, especially among the participants with unspecified dementia, may have added to the knowledge of QoL and anxiety in different dementia disorders. Many assessors involved in the assessment scales may have biased the results, although the assessors were trained in the administration of the scales and knew the participants well. With only two assessment points, the present study provides limited knowledge about the course of QoL of PWD in nursing homes. The strength of the study is its use of well-known, structured, and validated assessment scales; homogeneity of the study sample; and its prospective design. 


\section{Conclusions}

To our knowledge, this is the first study investigating association of anxiety with trajectories of QoL of PWD. Anxiety was found to be independently associated both with belonging to the trajectory group with poor QoL, as well as with proxy-rated poor QoL from baseline to 12-month follow-up. It is therefore important among nursing home personnel to increase awareness of and skills in identifying anxiety by validated dementia-specific anxiety instruments.

\section{Acknowledgments}

We would like to thank Jūratė Šaltytė Benth for assistance in the analysis and interpretation of the results. This study was supported by The Research Centre for Age Related Functional Decline and Diseases, Innlandet Hospital Trust, Ottestad, Norway under grant number 150279 to $Ø \mathrm{~K}$, and the Norwegian National Advisory Unit on Ageing and Health, Vestfold Hospital Trust, under grant number 150279 to ARG. The funders had no role in study design, data collection and analysis, decision to publish, or preparation of the manuscript.

\section{Author Contributions}

Conceptualization: Sverre Bergh, Knut Engedal, Øyvind Kirkevold.

Data curation: Alka R. Goyal.

Formal analysis: Alka R. Goyal, Øyvind Kirkevold.

Funding acquisition: Alka R. Goyal.

Methodology: Alka R. Goyal, Sverre Bergh, Knut Engedal, Marit Kirkevold, Øyvind Kirkevold.

Project administration: Alka R. Goyal, Øyvind Kirkevold.

Resources: Alka R. Goyal.

Supervision: Alka R. Goyal, Øyvind Kirkevold.

Writing - original draft: Alka R. Goyal.

Writing - review \& editing: Sverre Bergh, Knut Engedal, Marit Kirkevold, Øyvind Kirkevold.

\section{References}

1. Wang S-Y, Shamliyan TA, Talley KMC, Ramakrishnan R, Kane RL. Not just specific diseases: systematic review of the association of geriatric syndromes with hospitalization or nursing home admission. Arch Gerontol Geriatr. 2013; 57(1):16. https://doi.org/10.1016/j.archger.2013.03.007 PMID: 23578847

2. Wergeland JN, Selbæk G, Bergh S, Soederhamn U, Kirkevold $\varnothing$. Predictors for nursing home admission and death among community-dwelling people 70 years and older who receive domiciliary care. Dement Geriatr Cogn Dis Extra. 2015; 5(3):320-9. https://doi.org/10.1159/000437382 PMID: 26483831

3. Engedal K, Haugen PK. Demens: fakta og utfordringer: en lærebok. 5. ed. Tønsberg: Aldring og helse; 2009. 424 p. Norwegian.

4. Beerens HC, Zwakhalen SMG, Verbeek H, Ruwaard D, Hamers JPH. Factors associated with quality of life of people with dementia in long-term care facilities: a systematic review. Int J Nurs Stud. 2013; 50 (9):1259-70. https://doi.org/10.1016/j.jpurstu.2013.02.005 PMID: 23465959

5. Hoe J, Hancock G, Livingston G, Woods B, Challis D, Orrell M. Changes in the quality of life of people with dementia living in care homes. Alzheimer Dis Assoc Disord. 2009; 23(3):285-90. https://doi.org/10. 1097/WAD.0b013e318194fc1e PMID: 19812472 
6. Mjørud M, Røsvik J, Rokstad AMM, Kirkevold M, Engedal K. Variables associated with change in quality of life among persons with dementia in nursing homes: a 10 months follow-up study. PLoS One. 2014; 9 (12):e115248. https://doi.org/10.1371/journal.pone.0115248 PMID: 25521336

7. Selwood A, Thorgrimsen L, Orrell M. Quality of life in dementia-a one-year follow-up study. Int J Geriatr Psychiatry. 2005; 20(3):232-7. https://doi.org/10.1002/gps.1271 PMID: 15717339

8. Lyketsos CG, Gonzales-Salvador T, Chin JJ, Baker A, Black B, Rabins P. A follow-up study of change in quality of life among persons with dementia residing in a long-term care facility. Int J Geriatr Psychiatry. 2003; 18(4):275-81. https://doi.org/10.1002/gps.796 PMID: 12673600

9. WHO. The World Health Organization quality of life assessment (WHOQOL): position paper from the World Health Organization. Soc Sci Med. 1995; 41(10):1403-9. PMID: 8560308

10. Trigg R, Jones RW, Skevington SM. Can people with mild to moderate dementia provide reliable answers about their quality of life? Age Ageing. 2007; 36(6):663-9. Epub 2007/06/26. https://doi.org/10. 1093/ageing/afm077 PMID: 17586556.

11. Ettema TP, Droes RM, de Lange J, Ooms ME, Mellenbergh GJ, Ribbe MW. The concept of quality of life in dementia in the different stages of the disease. Int Psychogeriatr. 2005; 17(3):353-70. Epub 2005/10/28. PMID: 16252370.

12. Mjørud M, Kirkevold M, Røsvik J, Selbæk G, Engedal K. Variables associated to quality of life among nursing home patients with dementia. Aging Ment Health. 2014; 18(8):1013-21. https://doi.org/10. 1080/13607863.2014.903468 PMID: 24911813

13. Selbæk G, Kirkevold $\varnothing$, Engedal K. The prevalence of psychiatric symptoms and behavioural disturbances and the use of psychotropic drugs in Norwegian nursing homes. Int J Geriatr Psychiatry. 2007; 22(9):843-9. https://doi.org/10.1002/gps.1749 PMID: 17193341

14. Bowling A, Rowe G, Adams S, Sands P, Samsi K, Crane M, et al. Quality of life in dementia: a systematically conducted narrative review of dementia-specific measurement scales. Aging Ment Health. 2015; 19(1):13-31. Epub 2014/06/03. https://doi.org/10.1080/13607863.2014.915923 PMID: 24881888.

15. Hongisto K, Hallikainen I, Selander T, Törmälehto S, Väätäinen S, Martikainen J, et al. Quality of life in relation to neuropsychiatric symptoms in Alzheimer's disease: 5-year prospective ALSOVA cohort study. Int J Geriatr Psychiatry. 2018; 33(1):47-57. https://doi.org/10.1002/gps.4666 PMID: 28067961

16. Spector A, Orrell M. Quality of life (QoL) in dementia: a comparison of the perceptions of people with dementia and care staff in residential homes. Alzheimer Dis Assoc Disord. 2006; 20(3):160-5. Epub 2006/08/19. PMID: 16917186.

17. Weiner MF, Martin-Cook K, Svetlik DA, Saine K, Foster B, Fontaine C. The quality of life in late-stage dementia (QUALID) scale. J Am Med Dir Assoc. 2000; 1(3):114-16. PMID: 12818023

18. Goyal AR, Bergh S, Engedal K, Kirkevold M, Kirkevold Ø. Anxiety, anxiety Symptoms, and their correlates in persons with dementia in Norwegian nursing homes: a cause for concern. Dement Geriatr Cogn Disord. 2017; 43(5-6):294-305. https://doi.org/10.1159/000471796 PMID: 28463828

19. Seignourel PJ, Kunik ME, Snow L, Wilson N, Stanley M. Anxiety in dementia: a critical review. Clin Psychol Rev. 2008; 28(7):1071-82. https://doi.org/10.1016/j.cpr.2008.02.008 PMID: 18555569.

20. Barca ML, Engedal K, Laks J, Selbaek G. A 12 months follow-up study of depression among nursinghome patients in Norway. J Affect Disord. 2010; 120(1):141-8. https://doi.org/10.1016/j.jad.2009.04. 028 PMID: 19467560

21. Alexopoulos GS, Abrams RC, Young RC, Shamoian CA. Cornell scale for depression in dementia. Biol Psychiatry. 1988; 23(3):271-84. https://doi.org/10.1016/0006-3223(88)90038-8 PMID: 3337862.

22. Shankar $K$, Walker $M$, Frost $D$, Orrell $M$. The development of a valid and reliable scale for rating anxiety in dementia (RAID). Aging Ment Health. 1999; 3(1):39-49. https://doi.org/10.1080/13607869956424 PMID: 1999-05135-004.

23. Hoe J, Hancock G, Livingston G, Orrell M. Quality of life of people with dementia in residential care homes. B J Psych. 2006; 188(5):460-4.

24. American Psychiatric Association. Diagnostic and statistical manual of mental disorders: DSM-5. Washington, D.C.: American Psychiatric Association; 2013. XLIV, 947 p.

25. Goyal AR, Bergh S, Engedal K, Kirkevold M, Kirkevold $\varnothing$. Norwegian version of the rating anxiety in dementia scale (RAID-N): a validity and reliability study. Aging Ment Health. 2016:1-6. https://doi.org/ 10.1080/13607863.2016.1220921 PMID: 27584559

26. ICD-10 W. WHO ICD-10: Psykiske lidelser og adfærdsmæssige forstyrrelser: klassifikation og diagnostiske kriterier. København: Munksgaard; 2011. 254 p. Norwegian.

27. Hofmans-Okkes I, Lamberts $\mathrm{H}$. The international classification of primary care (ICPC): new applications in research and computer-based patient records in family practice. Fam Pract. 1996; 13(3):294-302. PMID: 8671139 
28. Røen I, Selbæk G, Kirkevold Ø, Engedal K, Lerdal A, Bergh S. The reliability and validity of the Norwegian version of the quality of life in late-stage dementia scale. Dement Geriatr Cogn Disord. 2015; 40(34):233-42. https://doi.org/10.1159/000437093 PMID: 26227299

29. Martin-Cook K, Hynan LS, Rice-Koch K, Svetlik DA, Weiner MF. Responsiveness of the quality of life in late-stage dementia scale to psychotropic drug treatment in late-stage dementia. Dement Geriatr Cogn Disord. 2005; 19(2-3):82-5. https://doi.org/10.1159/000082353 PMID: 15572876

30. O'Bryant SE, Waring SC, Cullum CM, Hall J, Lacritz L, Massman PJ, et al. Staging dementia using clinical dementia rating scale sum of boxes scores: a Texas Alzheimer's research consortium study. Arch Neurol. 2008; 65(8):1091-5. https://doi.org/10.1001/archneur.65.8.1091 PMID: 18695059

31. Hughes CP, Berg L, Danziger WL, Coben LA, Martin RL. A new clinical scale for the staging of dementia. B J Psych. 1982; 140:566-72. Epub 1982/06/01. https://doi.org/10.1192/bjp.140.6.566 PMID: 7104545

32. Barca ML, Engedal K, Selbæk G. A reliability and validity study of the cornell scale among elderly inpatients, using various clinical criteria. Dement Geriatr Cogn Disord. 2010; 29(5):438-47. https://doi.org/ 10.1159/000313533 PMID: 20502018

33. Kaufer DI, Cummings JL, Ketchel P, Smith V, MacMillan A, Shelley T, et al. Validation of the NPI-Q, a brief clinical form of the neuropsychiatric inventory. J Neuropsychiatry Clin Neurosci. 2000; 12(2):2339. https://doi.org/10.1176/jnp.12.2.233 PMID: 11001602

34. Lawton MP, Brody EM. Assessment of older people: self-maintaining and instrumental activities of daily living. Gerontologist. 1969; 9:179-86. PMID: 5349366

35. Lyketsos CG, Galik E, Steele C, Steinberg M, Rosenblatt A, Warren A, et al. The general medical health rating: a bedside global rating of medical comorbidity in patients with dementia. J Am Geriatr Soci. 1999; 47(4):487-91

36. WHO. Collaborating centre for drug statistics methodology. International language for drug utilization research ATC/DDD.: Norwegian institute of public health. 2017 [updated 20.12.201701.06.2018]. Available from: https://www.whocc.no/atc_ddd_index/.

37. Sami MB, Nilforooshan R. The natural course of anxiety disorders in the elderly: a systematic review of longitudinal trials. Int Psychogeriatr. 2015; 27(7):1061-9. https://doi.org/10.1017/S1041610214001847 PMID: 25192470

38. Helvik A-S, Høgseth LD, Bergh S, Šaltytė-Benth J, Kirkevold Ø, Selbæk G. A 36-month follow-up of decline in activities of daily living in individuals receiving domiciliary care. BMC Geriatrics. 2015. https:// doi.org/10.1186/s12877-015-0047-7 PMID: 25888187

39. Stuck AE, Walthert JM, Nikolaus T, Büla CJ, Hohmann C, Beck JC. Risk factors for functional status decline in community-living elderly people: a systematic literature review. Soc Sci Med. 1999; 48 (4):445-69. https://doi.org/10.1016/S0277-9536(98)00370-0 PMID: 10075171

40. Altman DG. Practical statistics for medical research. London: Chapman and Hall; 1991.

41. Schoevers RA, Deeg D, Van Tilburg W, Beekman A. Depression and generalized anxiety disorder: cooccurrence and longitudinal patterns in elderly patients. Am J Geriatr Psychiatry. 2005; 13(1):31-9. https://doi.org/10.1176/appi.ajgp.13.1.31 PMID: 15653938

42. Bergh S, Selbæk $\mathrm{G}$. The prevalence and the course of neuropsychiatric symptoms in patients with dementia. Nor Epidemiolo. 2012; 22(2):225-32.

43. Nakanishi $\mathrm{K}$, Hanihara $\mathrm{T}$, Mutai $\mathrm{H}$, Nakaaki S. Evaluating the quality of life of people with dementia in residential care facilities. Dement Geriatr Cogn Disord. 2011; 32(1):39-44. https://doi.org/10.1159/ 000329443 PMID: 21846987

44. Samus QM, Rosenblatt A, Steele C, Baker A, Harper M, Brandt J, et al. The association of neuropsychiatric symptoms and environment with quality of life in assisted living residents with dementia. Gerontologist. 2005;45(suppl_1):19-26.

45. Wetzels R, Zuidema SU, de Jonghe JF, Verhey F, Koopmans R. Determinants of quality of life in nursing home residents with dementia. Dement Geriatr Cogn Disord. 2010; 29(3):189-97. https://doi.org/ 10.1159/000280437 PMID: 20215750

46. Ballard C, Hanney ML, Theodoulou M, Douglas S, McShane R, Kossakowski K, et al. The dementia antipsychotic withdrawal trial (DART-AD): long-term follow-up of a randomised placebo-controlled trial. Lancet Neurol. 2009; 8(2):151-7. Epub 2009/01/14. https://doi.org/10.1016/S1474-4422(08)70295-3 PMID: 19138567.

47. Schneider LS, Dagerman KS, Insel P. Risk of death with atypical antipsychotic drug treatment for dementia: meta-analysis of randomized placebo-controlled trials. JAMA. 2005; 294(15):1934-43. Epub 2005/10/20. https://doi.org/10.1001/jama.294.15.1934 PMID: 16234500.

48. Ballard CG, Thomas A, Fossey J, Lee L, Jacoby R, Lana MM, et al. A 3-month, randomized, placebocontrolled, neuroleptic discontinuation study in 100 people with dementia: the neuropsychiatric 
inventory median cutoff is a predictor of clinical outcome. J Clin Psychiatry. 2004; 65(1):114-9. PMID: 14744180

49. Bergh S, Engedal K. The withdrawal of antipsychotics and antidepressants from patients with dementia and BPSD living in nursing homes-an open pilot study. Int J Geriatr Psychiatry. 2008; 23(8):877-9. https://doi.org/10.1002/gps.2008 PMID: 18655022

50. Lichtwarck B, Selbaek G, Kirkevold O, Rokstad AMM, Benth JS, Lindstrom JC, et al. Targeted interdisciplinary model for evaluation and treatment of neuropsychiatric symptoms: a cluster randomized controlled trial. Am J Geriatr Psychiatry. 2018; 26(1):25-38. Epub 2017/07/04. https://doi.org/10.1016/j. jagp.2017.05.015 PMID: 28669575.

51. Rokstad AMM, Røsvik J, Kirkevold Ø, Selbaek G, Saltyte Benth J, Engedal K. The effect of person-centred dementia care to prevent agitation and other neuropsychiatric symptoms and enhance quality of life in nursing home patients: a 10-month randomized controlled trial. Dement Geriatr Cogn Disord. 2013; 36(5-6):340-53. https://doi.org/10.1159/000354366 PMID: 24022375

52. Fossey J, Ballard C, Juszczak E, James I, Alder N, Jacoby R, et al. Effect of enhanced psychosocial care on antipsychotic use in nursing home residents with severe dementia: cluster randomised trial. BMJ. 2006; 332(7544):756-61. https://doi.org/10.1136/bmj.38782.575868.7C PMID: 16543297

53. Barca ML, Engedal K, Laks J, Selbæk G. Quality of life among elderly patients with dementia in institutions. Dement Geriatr Cogn Disord. 2011; 31(6):435-42. https://doi.org/10.1159/000328969 PMID: 21757909 


\section{RAID-N - Rating Anxiety In Dementia}

\section{Dato for kartlegging}

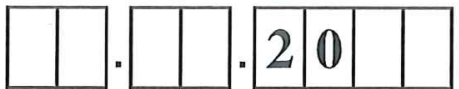

Senter nr

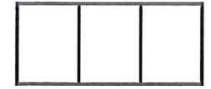

Pasient nr

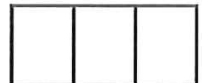

Pasient initialer

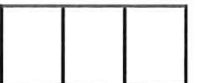

Scoring baseres på symptomer og tegn som har vart til stede de to siste ukene før unders $\emptyset$ kelsen.

Det skal ikke gis poeng hvis symptomene skyldes kroppsig funksjonshemning

\section{Bekymring}

1. Bekymring om kroppslig helse

2. Bekymring om kognitiv fungering (sviktende hukommelse, rote seg bort/ikke finne veien utendørs, ikke være i stand til å følge med i en samtale)

3. Bekymring for egen $\emptyset$ konomi eller penger, for familieproblemer, for slekningers kroppslige helse

4. Bekymring i tilknytning til feiltolking og/ eller feiloppfattelse

5. Bekymring for bagateller (stadig rette oppmerksomhet mot uvesentlige ting)

\section{Engstelse og vaktsomhet}

6. Lettskremt og engstelig (anspent og nervøs)

7. Følsomhet overfor lyder (overdreven forskrekkelses-reaksjon)

8. Søvnproblem (vansker med innsovning eller med sammenhengende $s \varnothing \mathrm{vn})$

9. Irritabilitet (blir lettere irritert enn til vanlig, ha "kort lunte" eller sinneutbrudd)

\section{Motorisk anspendthet}

10. Skjelving

11. Muskulære spenningstilstander (klage over hodepine, annen form for kroppslig ømhet og smerte)

12. Rastløshet (vimser omkring, kan ikke sitte stille, går fram og tilbake, vrir hendene, plukker på klærne)

13. Økt trettbarhet, trøtthet

\section{Autonom hypersensitivitet}

14. Palpitasjoner (klage over rask puls eller hjertebank)

15. Munntørrhet (ikke som medikamentell bivirkning), det knyter seg i magen

16. Hyperventilering (raske og dype åndedrag), kortpustet (uten relasjon til anstrengelse)

17. Svimmelhet eller $\varnothing$ rhet (klage på at man holder på å besvime)

18. Svetting, rødming eller kuldegysninger, kribling eller nummenhet i fingre og tær

\begin{tabular}{|l|c|c|}
$\begin{array}{l}\text { Lar seg } \\
\text { ikke } \\
\text { evaluere }\end{array}$ & $\begin{array}{l}\text { Ikke til } \\
\text { stede }\end{array}$ & $\begin{array}{c}\text { p } \\
\text { sted }\end{array}$
\end{tabular}

\begin{tabular}{|l|c|c}
$\begin{array}{l}\text { Mild eller bare } \\
\text { periodevis til } \\
\text { stede }\end{array}$ & Moderat & Alvorlig \\
& 2 & 3
\end{tabular}

\begin{tabular}{|c|c|c|c|c} 
& 0 & 1 & 2 & 3 \\
$\square$ & $\square$ & $\square$ & $\square$ & $\square$ \\
$\square$ & $\square$ & $\square$ & $\square$ & $\square$ \\
$\square$ & $\square$ & $\square$ & $\square$ & $\square$ \\
$\square$ & $\square$ & $\square$ & $\square$ & $\square$ \\
$\square$ & $\square$ & $\square$ & $\square$ & $\square$
\end{tabular}




\section{Forespørsel om delltalkelse if forskmingsprosjelktet" Angst vedl demems"}

Dette er et spørsmål til deg om å delta i en forskningsstudie som undersøker angst ved demens hos eldre personer. Alderspsykiatrisk forskningssenter, Sykehuset Innlandet HF er ansvarlig for prosjektet.

\section{Bakgrumin og hemsilkt}

Angst som sykdom er hyppig forekommende ved demens og er en betydelig belastning for den syke og deres omsorgspersoner. Det er vanskelig å fange opp angst hos personer med demens på grunn av likhet med andre symptomer ved demens og depresjon. Det er få kartleggingsverktøy som er utviklet for å kartlegge angst hos personer med demens. Ingen av disse kartleggingsverktøyene har tidligere blitt utprøvd i Norge. Hensikten med denne studien er å evaluere og forbedre et kartleggingsverktøy som fanger opp angst, og evaluere hvordan angsten påvirker personer som har en demensdiagnose i tillegg. Dette vil gi mer kunnskap om angst hos personer med demens og bedre behandlingsmuligheter.

\section{Hva immebaerer deltagelse is studien?}

Eldre fra 65 år og over, hjemmeboende, sykehjemsbeboere og fra alderspsykiatrisk avdeling som har en demenssykdom med eller uten angst problematikk, vil bli spurt om å delta i studien. Du vil bli stilt noen spørsmål om din nåværende helsetilstand, funksjonsevne, hukommelsesevne og om symptomer på angst ut fra spørreskjemaer. Din nærmeste pårørende eller helsepersonell kan også bli bedt om å gi supplerende opplysninger ut fra samme spørreskjemaer. Vi ber også om å få innhente opplysninger om diagnose og bruk av medisiner fra din journal hos fastlege, hjemmesykepleie, sykehjem eller alderspsykiatrisk avdeling. Spørsmålene om din helsetilstand, funksjonsevne, hukommelse og angstsymptomer vil bli gjentatt etter ett år.

\section{Mulige fordeler og ullemper}

Du vil få en mer omfattende helseundersøkelse enn vanlig. Det vil ikke være noen spesielle bivirkninger eller ulemper ved å delta i studien.

\section{Hiva slkjer med informasjomen om dleg?}

Informasjonen som registreres om deg skal kun brukes slik som beskrevet i hensikten med studien. Alle opplysningene som er samlet inn vil bli behandlet uten navn og fødselsnummer eller andre direkte gjenkjennende opplysninger. En kode knytter deg til dine opplysninger gjennom en navneliste. Navnelisten vil være innelåst i en safe ved forskningssenterets arkiv. Det er kun autorisert personell knyttet til prosjektet som har adgang til navnelisten og som kan finne tilbake til deg. Navnelisten vil bli slettet innen utgangen av 2021, og etter det vil ingen opplysninger kunne knyttes til din person. Det vil ikke være mulig å identifisere deg i resultatene av studien når disse publiseres. Hvis du sier ja til å delta i studien, har du rett til å få innsyn i hvilke opplysninger som registreres om deg. Du har videre rett til å få korrigert eventuelle feil i opplysningene vi har registrert. Dersom du trekker deg, kan du kreve å få 
slettet innsamlede opplysninger, med mindre opplysningene allerede er inngått $\mathrm{i}$ analyser eller brukt i vitenskapelige publikasjoner.

Frivillig deltagellse

Det er frivillig å delta i studien. Om du nå sier ja til å delta, kan du senere trekke tilbake ditt samtykke uten å oppgi noen grunn uten at det påvirker din øvrige behandling eller ditt kommunale hjelpetilbud. Dersom du senere ønsker å trekke deg eller har spørsmål om studien, kan du kontakte prosjektmedarbeider Alka R. Goyal tlf. 48122963 eller prosjektleder Øyvind Kirkevold tlf. 91594775 . Dersom du ønsker å delta, undertegner du samtykkeerklæringen på siste side.

Studien er godkjent av Regional komité for medisinsk og helsefaglig forskningsetikk REK, Sør- Øst.

Ytterligere informasjon om personverm, ølkomomi og forsilkring fimmes i lkapittel $\mathbb{B}$. Samtylklkeerklaering følger etter kapittel $\mathbb{B}$.

\section{Kapittel $\mathbf{A}$ - utdypende forlklaring av hwa studliem immelbaerer}

\section{- Kriterier for dleltakelse}

Eldre fra 65 år og over, hjemmeboende, sykehjemsbeboere, og fra alderspsykiatrisk avdeling som har en demensdiagnose med eller uten angst vil bli forespurt om å delta $\mathrm{i}$ studien. Deres pårørende eller helsepersonell som har minst ukentlig kontakt med disse personene, vil bli forespurt om å gi utfyllende opplysninger om pasientens helsetilstand.

- Balkgrummsimformasjon om studlien

Vi har lite kunnskap om angst ved demens. Det er få kartleggingsverktøy som er spesielt utviklet for å kartlegge angst hos personer med demens. Ingen av disse verktøyene har tidligere blitt utprøvd på en norsk befolkning. Hensikten med denne studien er å kunne gi bedre behandlingsmuligheter ved å evaluere og forbedre kartleggingsverktøyet som fanger opp angst ved demens, og å øke kunnskap om hvordan angst påvirkninger andre tilstander hos denne pasient gruppen.

- Altermativ behandling dersom du velger å ilkke della i studiem Dersom du velger å ikke delta i studien, vil ikke dette påvirke dine hjemmebaserte tjenester, sykehjemsplass eller annen behandling som du får per i dag.

- Undersølkelser og ammet du må gjenmom Spørreskjemaene som blir brukt undersøker din psykiske helse, mental fungering, generelt helsetilstand, dagliglivets funksjoner, livskvalitet og medikamentbruk.

- Tidlsskjema - lhva slkjer og når skjjer det? Undersøkelser og samtale med deg og din pårørende vil skje én gang i løpet av 2014 eller 2015 på et tidspunkt og sted som måtte passe deg og din pårørende. Samme undersøkelser og samtale med deg og din nærmeste vil bli gjentatt etter ett år.

- Mulige fordeler, bivirlkninger eller ulbehag/ullemper 
Undersøkelsene om din psykiske helse, generelt helsetilstand, dagliglivets funksjoner, livskvalitet og medikamentbruk er mer omfattende enn det som er vanlig når man bor hjemme, på sykehjem eller innlagt på alderspsykiatrisk avdeling. Det er sannsynlig at denne studien vil gjøre personale i kommunehelsetjenesten og spesialisthelsetjenesten bedre i stand til å fange opp angst og dermed bedre behandlingstilbudet hos personer med demens. Det er ingen direkte ulemper eller bivirkninger i forbindelse med deltakelse i studien, men noen kan oppleve det slitsomt å fylle ut spørreskjemaer.

- Som deltager i studien vil du bli orientert så rask som mulig dersom ny informasjon blir tilgjengelig som kan påvirke din villighet til å delta i studien.

- Som deltager i studien vil du bli orientert om mulige beslutninger/situasjoner som gjør at din deltagelse i studien kan bli avsluttet tidligere enn planlagt.

\section{Kapittell $\mathbb{B}-$ Personverm, ølkomomi og forsilkning}

\section{- Personverm}

Opplysningene som registreres om deg er om psykisk helse, generelt helsetilstand, dagliglivets funksjoner, livskvalitet og medikamentbruk. Vi vil be om å kunne innhente opplysninger om diagnose og bruk av medisiner fra din journal hos din fastlege og fra hjemmesykepleie, evt. fra din journal på sykehjemmet eller på alderspsykiatrisk avdeling. Formålet med å innhente disse opplysningene er å kontrollere om studieopplysningene stemmer overens med tilsvarende opplysninger i din journal. Alle som får innsyn har taushetsplikt.

Sykehuset Innlandet HF ved administrerende direktør har det overordnede rettslige ansvaret for studien.

\section{- Utlleverimg av materialle og opplysminger till andlre}

Tilgang til datamateriale skal bare gis videre i anonymisert form og bare til noen som skal bruke det i et av sine fra REK godkjente forskningsprosjekter.

- Rett till imnsyn og sletting av opplysninger om deg

Hvis du sier ja til å delta i studien, har du rett til å få innsyn i hvilke opplysninger som er registrert om deg. Du har videre rett til å få korrigert eventuelle feil i de opplysningene vi har registrert. Dersom du trekker deg fra studien, kan du kreve å få slettet innsamlede opplysninger, med mindre opplysningene allerede er inngått i analyser eller brukt i vitenskapelige publikasjoner.

- Olkomomi/Sylkelhuset Immlandets rolle Studien utgår fra alderspsykiatrisk forskningssenter (AFS) ved Sykehuset Innlandet HF som også er økonomisk ansvarlig for studien. 
- Forsilkring

I og med at studien ikke innebærer noen form for behandling eller undersøkelser utover det som er vanlig klinisk praksis og at risikoen for bivirkninger er minimal, er det ikke etablert noen egen forsikringsordning for studien.

- Informasjom om utfallet av studliem

Som deltager har du rett til å få informasjon om utfallet/resultatet av studien.

\section{Samntylklke till deltagellse i studliem}

Jeg er villig til å delta i studien

(Signert av prosjektdeltaker, dato)

Jeg bekrefter å ha gitt informasjon om studien

(Signert, rolle i studien, dato) 


\section{Sammtylklke ved påreøremdle på vegme av pasientem.}

\section{Forrespørisell om delltalkelse i forsknningsprosjektet "Angst ved dlemems"}

Dette er et spørsmål til deg som pårørende til en pasient som selv ikke kan samtykke til å delta $\mathrm{i}$ en forskningsstudie som undersøker angst ved demens hos eldre personer.

Alderspsykiatrisk forskningssenter, Sykehuset Innlandet HF er ansvarlig for prosjektet.

\section{Balkgrumn og hemsilkt}

Angst som sykdom er hyppig forekommende ved demens og er en betydelig belastning for den syke og deres omsorgspersoner. Det er vanskelig å fange opp angst hos personer med demens på grunn av likhet med andre symptomer ved demens og depresjon. Det er få kartleggingsverktøy som er utviklet for å kartlegge angst hos personer med demens. Ingen av disse kartleggingsverktøyene har tidligere blitt utprøvd i Norge. Hensikten med denne studien er å evaluere og forbedre et kartleggingsverktøy som fanger opp angst, og evaluere hvordan angsten påvirker personer som har en demensdiagnose. Dette vil gi mer kunnskap om angst hos personer med demens og bedre behandlingsmuligheter.

\section{Hva inmelbarer delltagelse i studiem?}

Eldre fra 65 år og over, hjemmeboende, sykehjemsbeboere og fra alderspsykiatriske avdelinger som har en demenssykdom med eller uten angst problematikk, vil bli spurt om å delta i studien. Vi ønsker å samle inn informasjon om pasientens helsetilstand, funksjonsevne, hukommelsesevne og om symptomer på angst ut fra spørreskjemaer. Du som pasientens nærmeste pårørende eller helsepersonell kan også bli bedt om å gi supplerende opplysninger ut fra de spørreskjemaene. Vi ber også om å få innhente opplysninger om diagnose og bruk av medisiner fra pasientens journal hos fastlege, hjemmesykepleie, sykehjem eller alderspsykiatrisk avdeling. Spørsmålene om pasientens helsetilstand, funksjonsevne, hukommelse og om angstsymptomer vil bli gjentatt etter ett år.

\section{Mullige fordeler og ullemper}

Pasienten vil få en mer omfattende helseundersøkelse enn vanlig. Det vil ikke være noen spesielle bivirkninger eller ulemper ved å delta i studien.

\section{Hva slkjer med informasjonen om pasienten?}

Informasjonen som registreres om pasienten skal kun brukes slik som beskrevet $\mathrm{i}$ hensikten med studien. Alle opplysningene som er samlet inn vil bli behandlet uten navn og fødselsnummer eller andre direkte gjenkjennende opplysninger. En kode knytter pasienten til opplysninger gjennom en navneliste. Navnelisten vil være innelåst $i$ en safe ved forskningssenterets arkiv. Det er kun autorisert personell knyttet til prosjektet som har adgang til navnelisten og som kan finne tilbake til pasienten. Navnelisten vil bli slettet innen utgangen av 2021, og etter det vil ingen opplysninger kunne knyttes til pasienten. Det vil ikke være mulig å identifisere pasienten i resultatene av studien når disse publiseres. Du har rett til å få innsyn i hvilke opplysninger som registres om pasienten. Du har videre rett til å få korrigert eventuelle feil i de registrerte opplysningene. Dersom pasienten trekkes fra studien, 
kan du kreve å få slettet innsamlede opplysninger, med mindre opplysningene allerede er inngått $\mathrm{i}$ analyser eller brukt i vitenskapelige publikasjoner.

\section{Frivillig deltagelse}

Det er frivillig å delta i studien. Dersom du ikke ønsker at pasienten skal delta, trenger du ikke å oppgi noen grunn, og det får ingen konsekvenser for den videre behandlingen av pasienten eller kommunale hjelpetilbud. Dersom du ikke har imot at pasienten deltar, undertegner du samtykkeerklæringen på siste side. Dersom du senere ikke ønsker at pasienten skal delta eller har spørsmål om studien, kan du kontakte prosjektmedarbeider Alka R. Goyal tlf. 48122963 eller prosjektleder Øyvind Kirkevold tlf. 91594775.

Studien er godkjent av Regional komité for medisinsk og helsefaglig forskningsetikk REK Sør Øst.

Ytterligere informasjon om personverm, ølkomomi og forsilkring finmes illkapittell $\mathbb{B}$. Samilyklkeerlklaering følger etter lkapittel $\mathbb{B}$.

\section{Kapittel $\mathbf{A}$ - utdypende forkllaring av hwa studlien inmelbaerer}

\section{- Kriterier for dellakellse}

Eldre fra 65 år og over, hjemmeboende, sykehjemsbeboere og fra alderspsykiatriske avdelinger som har en demensdiagnose med eller uten angst vil bli forespurt om å delta $\mathrm{i}$ studien. Deres pårørende eller helsepersonell som har minst ukentlig kontakt med disse personene, vil bli forespurt om å gi utfyllende opplysninger om pasientens helsetilstand.

- Balkgrunnsimformasjon om studien

Vi har lite kunnskap om angst ved demens. Det er få kartleggingsverktøy som er spesielt utviklet for å kartlegge angst hos personer med demens. Ingen av disse verktøyene har tidligere blitt utprøvd på en norsk befolkning. Hensikten med denne studien er å kunne gi bedre behandlingsmuligheter ved å evaluere og forbedre kartleggingsverktøyet som fanger opp angst ved demens, og å øke kunnskap om hvordan angst påvirker andre tilstander hos denne pasient gruppen.

- Altermativ behandling dersom pasienten ilklke deltar i studiem Dersom du ikke ønsker at pasienten skal delta i studien, vil ikke dette påvirke pasientens hjemmebaserte tjenester, sykehjemsplass eller annen behandling som pasienten får per i dag.

- Undersølkellser og annet pasienten må gjemmom Spørreskjemaene som blir brukt undersøker pasientens psykiske helse, mental fungering, generelt helsetilstand, dagliglivets funksjoner, livskvalitet og medikamentbruk. 
- Tidlsskjema - hva skjer og mår skjjer dlet?

Undersøkelser og samtale med pasienten og deg som pårørende vil skje én gang i løpet av 2014 eller 2015 på et tidspunkt og sted som måtte passe pasienten og deg. Samme undersøkelser og samtale med pasienten og deg vil bli gjentatt etter ett år.

- Mullige fordeller, bivirkminger eller ulbehag/ullemper

Undersøkelsene om pasientens psykiske helse, generelt helsetilstand, dagliglivets funksjoner, livskvalitet og medikamentbruk er mer omfattende enn det som er vanlig når man bor hjemme, på sykehjem eller innlagt på alderspsykiatrisk avdeling. Det er sannsynlig at denne studien vil gjøre personale i kommunehelsetjenesten og spesialisthelsetjenesten bedre i stand til å fange opp angst og dermed bedre behandlingstilbudet hos personer med demens. Det er ingen direkte ulemper eller bivirkninger i forbindelse med deltakelse $\mathbf{i}$ studien, men noen kan oppleve det slitsomt å fylle ut spørreskjemaer.

- Som deltager vill pasienten bli orientert så rask som mulig dersom ny informasjon blir tilgjengelig som kan påvirke om pasienten skal delta i studien.

- Som pårørende till en deltager i studien vil du bli orientert om mulige beslutninger/situasjoner som gjør at pasientens deltagelse i studien kan bli avsluttet tidligere enn planlagt.

\section{Kapittell $\mathbb{B}$ - Personverm, ølkomomi og forsilkring}

\section{- Persomverm}

Opplysningene som registreres om pasienten er om psykisk helse, generelt helsetilstand, dagliglivets funksjoner, livskvalitet og medikamentbruk. Vi vil be om å få innhente opplysninger om diagnose og bruk av medisiner fra pasientens fastlege og hjemmesykepleie, evt. fra pasientens journal på sykehjemmet eller på alderspsykiatrisk avdeling. Formålet med å innhente disse opplysningene er å kontrollere om studieopplysningene stemmer overens med tilsvarende opplysninger i pasientens journal. Alle som făr innsyn har taushetsplikt.

Sykehuset Innlandet HF ved administrerende direktør har det overordnede rettslige ansvaret for studien.

- Utleveriing av materiale og opplysninger till andre

Tilgang til datamateriale skal bare gis videre i anonymisert form og bare til noen som skal bruke det $i$ et av sine fra REK godkjente forskningsprosjekter.

\section{- Rett til innsyn og sletting av opplysminger om pasienten}

Hvis du ønsker at pasienten deltar i studien, har du rett til å få innsyn i hvilke opplysninger som er registrert om pasienten. Du har videre rett til å få korrigert eventuelle feil i de registrerte opplysningene. Dersom du ikke ønsker at pasienten skal delta i studien, kan du kreve å få slettet innsamlede opplysninger, med mindre opplysningene allerede er inngått $\mathrm{i}$ analyser eller brukt $\mathrm{i}$ vitenskapelige publikasjoner. 
- Olkomomi/Sylkelouset Immlandets rolle

Studien utgår fra alderspsykiatrisk forskningssenter (AFS) ved Sykehuset Innlandet HF som også er økonomisk ansvarlig for studien.

- $\quad$ Forsilkning

I og med at studien ikke innebærer noen form for behandling eller undersøkelser utover det som er vanlig klinisk praksis og at risikoen for bivirkninger er minimal, er det ikke etablert noen egen forsikringsordning for studien.

- Imformasjon om utifallet av studien

Som pårørende til en deltager har du rett til å få informasjon om utfallet/resultatet av studien.

\section{Samtylkke till delltagellse i studliem}

Jeg er ikke i mot at

(pasientens navn) deltar i studien.

(Signert av prosjektdeltakers pårørende, dato)

Jeg bekrefter å ha gitt informasjon om studien:

(Signert, rolle i studien, dato) 